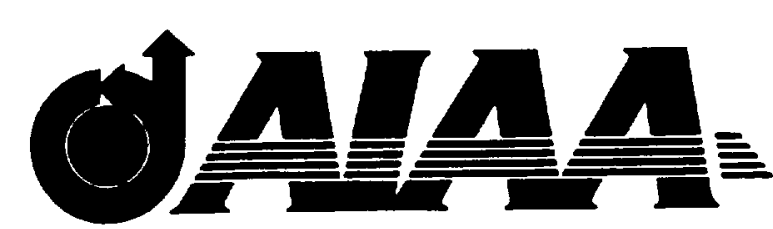

AIAA 95-0101

\title{
THREE DIMENSIONAL SOLUTION OF PNEUMATIC ACTIVE CONTROL OF FOREBODY VORTEX ASYMMETRY
}

Osama A. Kandil and Hazem H. Sharaf El-Din Old Dominion University, Norfolk, VA 23529

C. H. Liu

NASA Langley Research Center, Hampton, VA 23681

\section{3rd Aerospace Sciences Meeting and Exhibit January 9-12, 1995 / Reno, NV}

For permission to copy or republish, contact the American Instltuto of Aoronautics and Astronautics 370 L'Enfant Promonade, S.W., Washington, D.C. 20024 



\title{
THREE DIMENSIONAL SOLUTION OF PNEUMATIC ACTIVE CONTROL OF FOREBODY VORTEX ASYMMETRY
}

\author{
Osama A. Kandil* and Hazem H. Sharaff El-Din** \\ Aerospace Engineering Department \\ Old Dominion University, Norfolk, VA 23529 \\ and C. H. Liu *** \\ Aerodynamics and Acoustics Methods Branch \\ NASA Langley Research Center, Hampton, VA 23681
}

\begin{abstract}
Pneumatic active control of asymmetric vortical flows around slender pointed forebody is investigated using the three-dimensional solution of the compressible thin-layer Navier-Stokes equations. The computational applications cover the normal and tangential injection control of asymmetric flows around a $5^{\circ}$-semi-apex angle cone at $40^{\circ}$ angle of attack, 1.4 freestream Mach number and $6 \times 10^{6}$ freestream Reynolds number (based on the cone length). The effective tangential-angle range of $67.5^{\circ} \rightarrow-67.5^{\circ}$ is used for both normal and tangential ports of injection. The effective axial length of injection is varied from 0.1 to 0.26 and the maximum mass-flow rate is varied from 0.03 to 0.05 . The computational solver uses the implicit, upwind, flux-difference splitting finite-volume scheme and the grid consists of $161 \times 55 \times 65$ points in the wrap-around, normal and axial directions, respectively. The results show that tangential injection is more effective than normal injection
\end{abstract}

\section{INTRODUCTION}

The problem of asymmetric flow around slender bodies and wings in the high angle-of-attack range is of vital importance to the dynamic stability and controllability of missiles and fighter aircraft. The onset of flow asymmetry occurs when the relative incidence (ratio of the angle of attack to nose semi-apex angle) of pointed forebodies exceeds certain critical values. In addition to the relative incidence as one of the influential parameters for the onset of flow asymmetry, the freestream Mach number, Reynolds number and the shape of the body cross sectional area are also influential parameters. The flow asymmetry develops due to absolute or convected disturbances. Passive control of flow asymmetry can be achieved by using vertical fins along the leeward plane of geometric symmetry ${ }^{1.2}$, side-strakes near the body nose ${ }^{3-6}$, rotatable forebody tips which have variable cross sections ${ }^{7}$ and boundary-layer trips on the windward side of the forebody surface. ${ }^{8}$ However, passive-control methods have limited effectiveness at very high angles of attack and are incapable of providing adaptive control capability.

\footnotetext{
-Professor. Eminent Scholar and Department Chaiman. Associate Fellow AIAA

*Ph.D. Graduate Student. Member AlAA.

- -Senior Scientist. Associate Fellow AlAA

Copyrighto 1995 by Professor Osama A. Kandil - Published by the American

Institute of Aeronautics and Astronsutics, Inc. with Permission
}

Various active-control methods have been used either to eliminate forebody vortex asymmetry and the corresponding side force and yawing moment, or to provide additional controlled forces and moments to rapidly maneuver modern fighter aircraft. The focus of the present paper is on active-control methods that eliminate or alleviate forebody vortex asymmetry and the corresponding adverse aerodynamic loads. Active-Control methods include blowing and suction, spinning and rotatory oscillation and surface heating; among others. The effectiveness of normal blowing was investigated by Peake et. al9. 10, Almosnino and Rom ${ }^{11}$ and Kandil et al ${ }^{12}$. The effectiveness of tangential blowing was investigated by Wood et al $^{13.14}$ and Kandil et al ${ }^{12}$. Active control of asymmetric flows around slender pointed bodies using spinning and rotatory oscillations of the body, body nose tip or a band of the body has been investigated by Kruse ${ }^{15}$. Fidler ${ }^{16}$, Contanceau and Menard ${ }^{17}$, Taneda ${ }^{18}$ and Kandil et al ${ }^{19}$.

Research work on using normal and tangential blowing to produce side forces and yawing moments to rapidly maneuver modern fighter aircraft was recently conducted by Tavella and Schiff ${ }^{20}$, Murman et al ${ }^{21}$. Kramer et a ${ }^{22}$ and Celik ${ }^{23}$. An extensive review of the literature of active control methods can be found in the Ph.D. dissertation of Sharaf El-Din ${ }^{24}$.

In the present paper, Computational research work is focussed on the injection active control of threedimensional asymmetric flow around a pointed-nose cone representing a forebody. By using the effective tangential angle range of injection of $67.5^{\circ} \rightarrow-67.5^{\circ}$ of Ref. 19, by the present authors, the effective axial length of injection (measured from the body nose) and the maximum mass-flow rate of injection are considered. Both normal and tangential injection are investigated.

\section{FORMULATION AND COMPUTATIONAL SCHEME}

\section{Thin-layer Navier-Stokes Equations}

The conservative form of the dimensionless, unsteady, compressible, thin-layer Navier-Stokes equations in terms of time-independent, body-conformed coordinates $\xi^{1}, \xi^{2}$, and $\xi^{3}$ is given by

$$
\frac{\partial \bar{Q}}{\partial t}+\frac{\partial \bar{E}_{m}}{\partial \xi^{m}}-\frac{\partial\left(\bar{E}_{v}\right)_{2}}{\partial \xi^{2}}=0 ; m=1-3
$$


where

$$
\begin{gathered}
\xi^{m}=\xi^{m}\left(x_{1}, x_{2}, x_{3}\right) \\
\bar{Q}=\frac{\hat{q}}{J}=\frac{1}{J}\left[\rho, \rho u_{1}, \rho u_{2}, \rho u_{3}, \rho e\right]^{t}
\end{gathered}
$$

$$
\begin{aligned}
\bar{E}_{m} & \equiv \text { inviscid flux } \\
& =\frac{1}{J}\left[\partial_{k} \xi^{m} \dot{E}_{k}\right]^{t} \\
& =\frac{1}{J}\left[\rho U_{m}, \rho u_{1} U_{m}+\partial_{1} \xi^{m} p, \rho u_{2} U_{m}\right. \\
& \left.+\partial_{2} \xi^{m} p, \rho u_{3} U_{m}+\partial_{3} \xi^{m} p,(\rho e+p) U_{m}\right]^{t}
\end{aligned}
$$

$\left(\bar{E}_{v}\right)_{2} \equiv$ viscous and heat-conduction flux in $\xi^{2}$ direction

$$
\begin{gathered}
=\frac{1}{J}\left[0, \partial_{k} \xi^{2} \tau_{k 1}, \partial_{k} \xi^{2} \tau_{k 2}, \partial_{k} \xi^{2} \tau_{k 3}, \partial_{k} \xi^{2}\left(u_{n} \tau_{k n}-q_{k}\right)\right]^{t}(5) \\
U_{m}=\partial_{k} \xi^{m} u_{k}
\end{gathered}
$$

The first element of the three momentum elements of Eq. (5) is given by

$$
\partial_{k} \xi^{2} \tau_{k]}=\frac{M_{\infty} \mu}{\operatorname{Re}}\left(\psi \partial_{1} \xi^{2}+\frac{\partial u_{1}}{\partial \xi^{2}}\right)
$$

where

$$
\phi=\partial_{k} \xi^{2} \partial_{k} \xi^{2}, \quad \psi=\frac{1}{3} \partial_{k} \xi^{2} \frac{\partial u_{k}}{\partial \xi^{2}}
$$

The second and third elements of the momentum elements are obtained by replacing the subscript 1 , everywhere in Eq. (7), with 2 and 3, respectively. The last element of Eq. (5) is given by

$$
\begin{aligned}
& \partial_{k} \xi^{2}\left(u_{n} \tau_{k n}-q_{k}\right) \equiv \frac{M_{\infty} \mu}{\operatorname{Re}}\{\psi W \\
&\left.+\phi\left[\frac{1}{2} \frac{\partial}{\xi^{2}} u_{s} u_{s}+\frac{1}{(\gamma-1) \operatorname{Pr}} \frac{\partial\left(a^{2}\right)}{\partial \xi^{2}}\right]\right\}
\end{aligned}
$$

where

$$
W=\partial_{n} \xi^{2} u_{n}
$$

The reference parameters for the dimensionless form of the equations are $L, a_{\infty}, L / a_{\infty}, \rho_{\infty}$ and $\mu_{\infty}$ for the length, velocity, time, density and molecular viscosity, respectively. The Reynolds number is defined as Re $=\rho_{\infty} V_{\infty} L / \mu_{\infty}$, and the pressure, $p$, is related to the total energy per unit mass, $e$, and density, $\rho$, by the gas equation

$$
p=(\gamma-1) \rho\left(e-\frac{1}{2} u_{n} u_{n}\right)
$$

The viscosity, $\mu$, is calculated from the Sutherland law

$$
\mu=T^{3 / 2}\left(\frac{1+C}{T+C}\right), \quad C=0.4317,
$$

and the Prandtl number $\operatorname{Pr}=0.72$.
In equations (1)-(11), the indicial notation is used for convenience. The subscripts $k$ and $n$ are summation indices, the superscript or subscript $s$ is a summation index and the superscript or subscript $m$ is a free index. The range of $k, n, s$ and $m$ is $1-3$, and $\partial_{k} \equiv \partial / \partial x_{k}$. In equations (1)-(12), $u_{n}$ is the Cartesian velocity component, $U_{m}$ the contravariant velocity component, $\tau_{m}$ the Cartesian component of the shear stress tensor, $q_{k}$ the Cartesian component of heat fiux vector, $a$ the local speed of sound and $M_{\infty}$ the freestream Mach number.

\section{Boundary and Initial Conditions}

The boundary conditions are explicitly satisfied. in general, they include inflow-outflow conditions and solitboundary conditions. For problems of flow asymmetry, where the flow is solved throughout the whole computational domain, periodic boundary conditions are used at the plane of geometric symmetry of the body.

For the asymmetric flow problems around slender bodies and for supersonic inflow-outflow boundary, the Riemann-invariant boundary conditions are used. They require that the inflow variables be at the freestream conditions, and the conical shock enclosing the body be captured as part of the solution. For supersonic outflow boundary, the Riemann-invariant boundary conditions $\mathrm{r}$ quire that all flow variables be extrapolated from the interior cells. On the solid boundary, without injection, the no-slip and no-penetration conditions are enforced. Moreover, the zero normal-pressure gradient and adiubatic boundary condition are enforced. For the present active control problems, the mass-flow rate is specified at the body surface for the normal injection control. For the tangential injection control, the mass-fiow rate and tangential velocity are specified.

The initial conditions correspond to the uniform flow conditions with $u_{1}=u_{2}=u_{3}=0$ on the solid boundary. These conditions are used to obtain the asymmetric fiow solution. Next, the flow control conditions are enforced and the previously obtained asymmetric solution is used for the initial conditions of the active control problem.

\section{Computational Scheme}

The implicit, upwind, flux-difference splitting, finitevolume scheme is used to solve the unsteady, compres;ible, thin-layer Navier-Stokes equations. The scheme uses the flux-difference splitting scheme of Roe which is based on the solution of the approximate Riemann problem. In the Roe scheme, the inviscid flux difference at the ir terface of computational cells is split into two parts; left and right flux differences. The splitting is accomplished according to the signs of the eigenvalues of the Roe averaged-Jacobian matrix of the inviscid fluxes at the cell interface. The min-mod flux limiter is used to eliminate oscillations at locations of large flow gradients. The viscous terms are differenced using a second-order accurate central differencing. The resulting difference equation is approximately factored and is solved in three sweeps in 
the $\xi^{1}, \xi^{2}$, and $\xi^{3}$ directions. The computational scheme is coded in the computer program "FTNS3D" which is a modified version of the "CFL3D" Code.

\section{COMPUTATIONAL STUDY AND DISCUSSION}

\section{Flow Conditions and Grid:}

For all the computational studies in this paper, a $5^{\circ}$ semi-apex angle circular cone, representing the forebody, at 1.4 freestream Mach number and $6 \times 10^{6}$ freestream Reynolds number (based on body length) is considered. The grid consists $161 \times 55 \times 65$ points in the wrap-around, normal and axial directions, respectively. The grid is generated with a modified Joukowskj transformation in the cross-flow planes with a minimum grid size of $10^{-4}$ in the normal direction at the body surface. A geometric series is used for grid clustering in the normal direction and another geometric series is used for grid clustering in the axial direction in the nose region. Figure 1 shows a typical grid.

\section{Asymmetric Flow Solution (No Control):}

While the numerical disturbances (Machine round-off error) were sufficient to simulate wind tunnel or real flight disturbances in producing the asymmetry in the flowfield for conical flow solutions ${ }^{4}$, such disturbances are insufficient for the three-dimensional solution of thin-layer Navier-Stokes equations since the three-dimensional solution never reached to machine zero during the iterative solution. The disturbance in the present case is applied physically, such as a transient short-time side-slip disturbance. For the case under consideration, a side-slip disturbance of $10^{\circ}$ is applied for 300 iteration steps. Next, the disturbance is removed and the asymmetry was persistent.

In Fig. 2, the surface-pressure coefficient is shown at several different axial stations along the cone length, and Fig. 3 shows the total-pressure-loss contours at the same axial stations. From these figures as well as Fig. 4, which is a three-dimensional view of stagnation-pressure contours at different axial stations, one can observe that the flowfield is highly asymmetric. Also, it is observed that the vortex asymmetric structure is changing sides with the axial direction, and hence the corresponding side forces are changing directions along the cone axis. Examining the figures at different axial stations, one concludes that the asymmetry grows spatially in the axial direction. This is in agreement with both experimental and computational results which relate the onset of asymmetry with small disturbances starting at the body nose and growing in the downstream direction. Since the solution is steady, the vortex shedding is a spatial one.

The fact that the flow asymmetry is not one-side biased restricts the choice of the active control method. Uniform mass injection would be of limited effectiveness since either it will be applied in a symmetric or antisymmetric way and either of the two methods will not be effective along the cone length. Hence, a variable injection mass-flow rate per unit area approach, similar to the one used in the conical flow applications ${ }^{19}$, is chosen. The variable injection idea is based on sensing the pressure difference between the corresponding points on the right and left sides of the cone and applying a mass-fiow rate that is proportional to this difference. The maximum mass-flow rate, $\dot{m}_{\max }$, corresponds to the maximum of all pressure differences between the corresponding points on the right and left sides.

\section{Normal Injection:}

The reference case solution is used as initial condition for the normal injection control under consideration, in which $l_{\text {ess }}$, is chosen to be 0.1 . The effective angle of the injection; $\theta_{\text {eff }}$ extends from $-67.5^{\circ}$ to $67.5^{\circ}$, where $\theta_{\text {efs }}$ is measured from the leeward side of the geometric plane of symmetry. The maximum mass-flow rate is 0.05 .

Figures 5-7 show the surface-pressure coefficient at different axial stations, the total-pressure-loss contours at different axial stations and the stagnation-pressure contours at different axial stations, respectively. Comparing these figures with the corresponding figures of the reference case, it is observed that the asymmetry has been eliminated on about $70 \%$ of the cone length, and significantly reduced on the remaining $30 \%$ of the cone length. It is also observed that both the surface-pressure coefficient and the total-pressure loss-contours show small regions of asymmetry that grow along the cone length. These observations show that the level or area of injection used is insufficient to eliminate the asymmetry over the entire cone length.

Next, the effective length of injection is increased to $l_{e f f}=0.15$ while $\dot{m}_{\max }$ is kept at 0.05 . The results (not shown) indicated that the flowfield became symmetric up to $80 \%$ of the cone length only. Slight asymmetry was observed on the remaining $20 \%$ of the cone length.

Increasing the effective length of injection to $l_{\text {eff }}=$ 0.26 eliminates the flow asymmetry over the entire cone length. The results of this case are shown in Figs. 8-10. No asymmetry in the flowfield or the surface pressure can be observed. To study the effect of the mass flow rate, the previous case is repeated with $\dot{m}_{\max }=0.03$ keeping $l_{\text {eff }}=0.26$. The results of this case were identical to the previous case.

\section{Tangential Injection:}

The direction of the injection in this case is tangent to the body surface towards the leeward plane of geometric symmetry. The initial conditions for this case is the solution of the reference case of Figs. 2-4. The effective angle of injection is chosen to extend from $-67.5^{\circ}$ to $67.5^{\circ}$, and the maximum mass-flow rate per unit area is taken to be 0.05 , while the effective length of injection 
is 0.1. The results of this case are shown in Figs. 11-13. The results show that the flow has recovered its symmetry and there is no sign of any significant asymmetry. Comparing these results with the corresponding results for the normal-injection case; Figs. 5-7, we conclude that tangential injection control is more effective than normalinjection control in eliminating the flow asymmetry and the corresponding side force for the same flow conditions.

\section{CONCLUDING REMARKS}

The compressible thin-layer Navier-Stokes equations have been solved to investigate the effectiveness of the active control using flow injection on a slender pointed cone. First, flow asymmetry has been obtained around the cone by inducing a short-time side-slip of $10^{\circ}$ as a transient flow disturbance. The disturbance is induced for 300 iteration steps and then removed. Flow asymmetry was persistent in the form of vortex asymmetric structure which changed sides along the cone length and showed spatial vortex shedding. Flow asymmetry was not possible using disturbances in the form of machine round-off error (as in the case of conical flows) since the residual error never reached machine zero during the iterative solution. Once the asymmetric flow is obtained, the injection control is applied using normal or tangential flow injection. The effective injection angle, length and maximum mass-flow rate are specified and the boundary conditions are modified according to the type of injection control; normal or tangential. The maximum mass-flow rate is used for the maximum pressure difference between the right and left sides of the cone. For the pressure difference between other corresponding points on the right and left, a mass-flow rate which is proportional to this difference is used. It has been shown that the tangential injection control is more effective than the normal injection control for the same flow conditions. In the present study, the cone angle of attack is kept fixed at $40^{\circ}$ and no additional flow cases have been investigated due to the limitation on the computational resources.

\section{ACKNOWLEDGMENTS}

For the first two authors this research work is supported by the NASA Langley Research Center under Grant No. NAG-1-994. The authors acknowledge the computational time on the CRAY C-90 provided by the NAS Program at NASA Ames Research Center and the Computation time on the CRAY YMP provided by the NASA Langley Research Center.

\section{REFERENCES}

1. Stahl, W., "Suppression of Asymmetry of The Vorex Flow Behind a Circular Cone at High Incidence:," AlAA Paper No. 89-3373-CP, AlAA Atmosphe;ic Flight Mechanics Conference, 1989, pp. 231-236.

2. Degani, D.. "Effect of Splitter Plate on Unsteady Flows around a Body of Revolution at Incidence," Physics of Fluids A, vol. 3, September 1991, F.p. 2122-2131.

3. Kandil, O. A., Wong, T.-C., Kandil, H. A., and Liu,. . H.. "Computation and Control of Asymmetric Vortex Flow Around Circular Cones Using Navier-Stokes Equations," in ICAS Paper No. 3.5.3, vol. 2, 1990. pp. 883-893.

4. Kandil, O. A., Wong, T.-C., and Liu, C. H., "Prediction of Steady and Unsteady Asymmetric Vortical Flow Around Cones," AIAA Journal, vol. 29, December 1991, pp. 2169-2178.

5. Kandil, O. A., Wong, T.-C., and Liu, C. H., "Asyrnmetric Supersonic Flow Around Cones with Noncircular Sections," in AGARD CP 493, Missile Aerodynamics, Paper No. 16, 1990.

6. Ng, T. T., "Effect of a Single Strake on the Forebody Vortex Asymmetry," Journal of Aircraft, vol. 27, September 1990, pp. 844-846.

7. Moskovitz, C., Hall, R. and DeJarnette, "Experimental Investigation of a New Device to Control the Asymmetric Flowfield on Forebodies at Large Angles of Attack," AIAA 90-0069, 1990.

8. Rao, D. M., "Side-Force Alleviation on Slender, Pointed Forebodies at High Angles of Attack," Journal of Aircraft, vol. 16, November 1979, po. 763-768.

9. Peake, D. J. and Owen, F. K., "Control of Forebocy Three-Dimensional Flow Separation," in AGARD Cp-262, Aerodynamic Characterstics of Controls, P:aper No. 15, 1979.

10. Peake, D. J., Owen, F. K., and Johnson, D. A., "Control of Forbody Vortex Orientation to Alleviate Side Forces," AIAA Paper No. 80-0183, 18th Aerospace Sciences Meeting, January 1980.

11. Aimosnino, D. and Rom, J., "Laterial Forces on a Slender Body and Therir Alleviation at High Incidence," Journal of Spacecraft, vol. 18, SeptemberOctober 1981, pp. 393-400.

12. Kandil, O. A., Sharaf El-Din, H. H., and Liu, C. H., "Recent Advances in Computational Active Control of Asymmetric Flows around Conical Forebodies." in Fourth Internation Conference of Fluid Mechanics, Alexandria, Egypt, April 1992, pp. 237-249. 
13. Wood, N. J. and Roberts, L., "Control of Vortical Lift on Delta Wings by Tangential Leading-Edge Blowing," Journal of Aircraft, vol. 25, March 1988, pp. 236-243.

14. Wood, N. J., Roberts, L., and Celik, Z. Z., "The Control of Asymmetric Vortical Flows Over Delta Wings at High Angles of Attack," AIAA Paper No. 1989-3347-CP, 1989.

15. Kruse, R. L., "Influence of Spin Rate on Side Force of an Axisymmetric Body," AIAA Journal, Vol. 16, No. 4, April 1974, pp. 415-416.

16. Fidler, J. E., "Active Control of Asymmetric Vortex Effects," J. of Aircraft, Vol. 18. No. 4, April 1981, pp. 267-272.

17. Coutanceau, M. and Ménard, C., "Influence of Rotation on the Near-Wake Development behind an Impulsively Started Circular Cylinder," Journal of Fluid Mechanics, Vol. 158, 1985, pp. 399-446.

18. Taneda, S., "Visual Observations of the Flow Past a Circular Cylinder Performing Rotatory Oscillation," Journal of Physical Society of Japan, Vol. 45, 1978, pp. 1038-1043.

19. Kandil, O. A., Sharaf El-Din, H. H. and Liu, C. H., "Active Control of Asymmetric Conical Flow Using Spinning and Rotatory Oscillation," AlAA 93-2958,
AIAA 24th Fluid Dynamics Conference, Orlando, FL, June 6-9, 1993.

20. Tavella, D. A. and Schiff, L. B., "Pneumatic Vortical Flow control at High Angles of Attack," AlAA Paper No. 90-0098, 28th Aerospace Sciences Meeting, January 1990.

21. Murman, S. M., Rizk, Y. M., Cummings, R. M., and Schiff, L. B., "Computational Investigation of Slot Blowing for Fuselage Forebody Flow Control," AIAA Paper No. 92-0020, 30th Aerospace Sciences Meeting and Exhibit, January 1992.

22. Kramer, B. R., Suarez, C. J., Malcolm, G., and James, K. D., "Forebody Vortex Control with Jet and Slot Blowing on an F/A-18," AIAA Paper No. 93-3449-CP, 1993.

23. Celik, Z. Z., "Dynamic Roll and Taw Control by Tangential Forebody Blowing," AlAA Paper No. 94-1853-CP, 12th AIAA Applied Aerodynamics Conference Colorado Springs, CO, June 1994.

24. Sharaf El-Din, H. H., "Simulation of Active Control of Asymmetric Flows Around Slender Pointed Forebodies," Ph.D. Dissertation, Aerospace Engineering Department, Old Dominion University, Norfolk, VA, December 1994. 


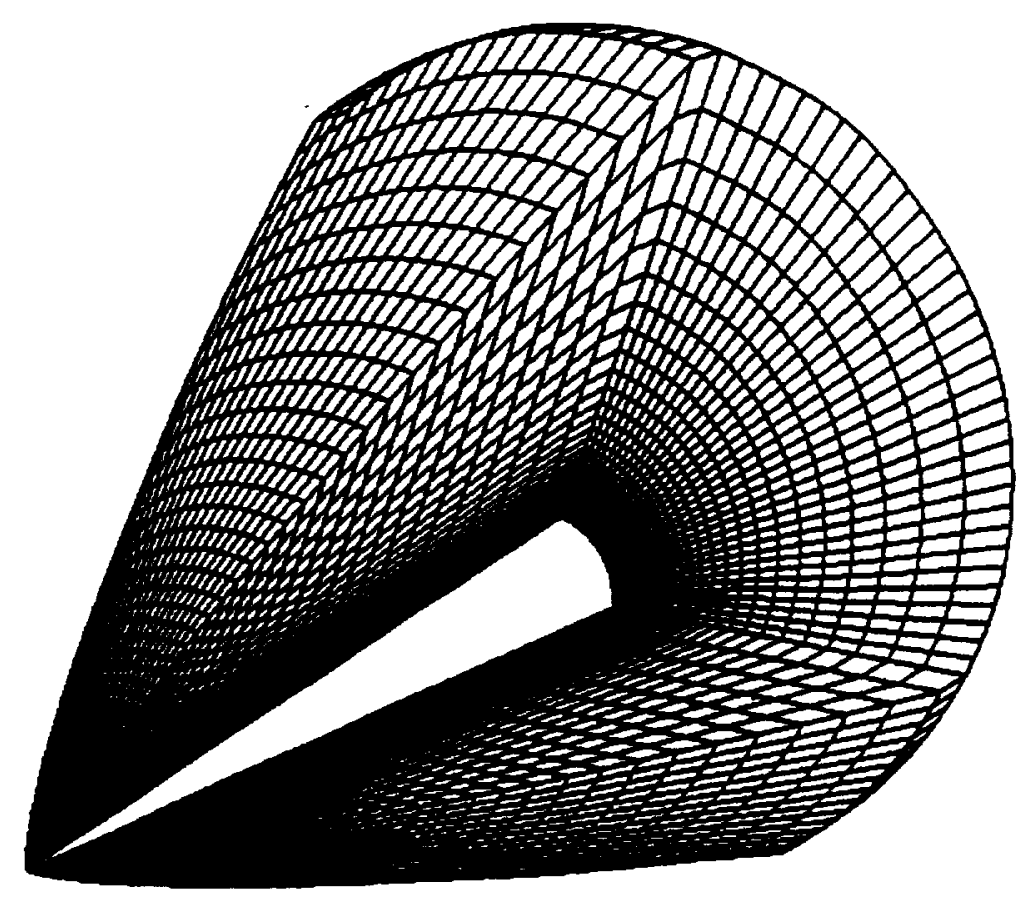

Fig. 1. A typical three-dimensional grid around the cone, $161 \times 55 \times 65$.
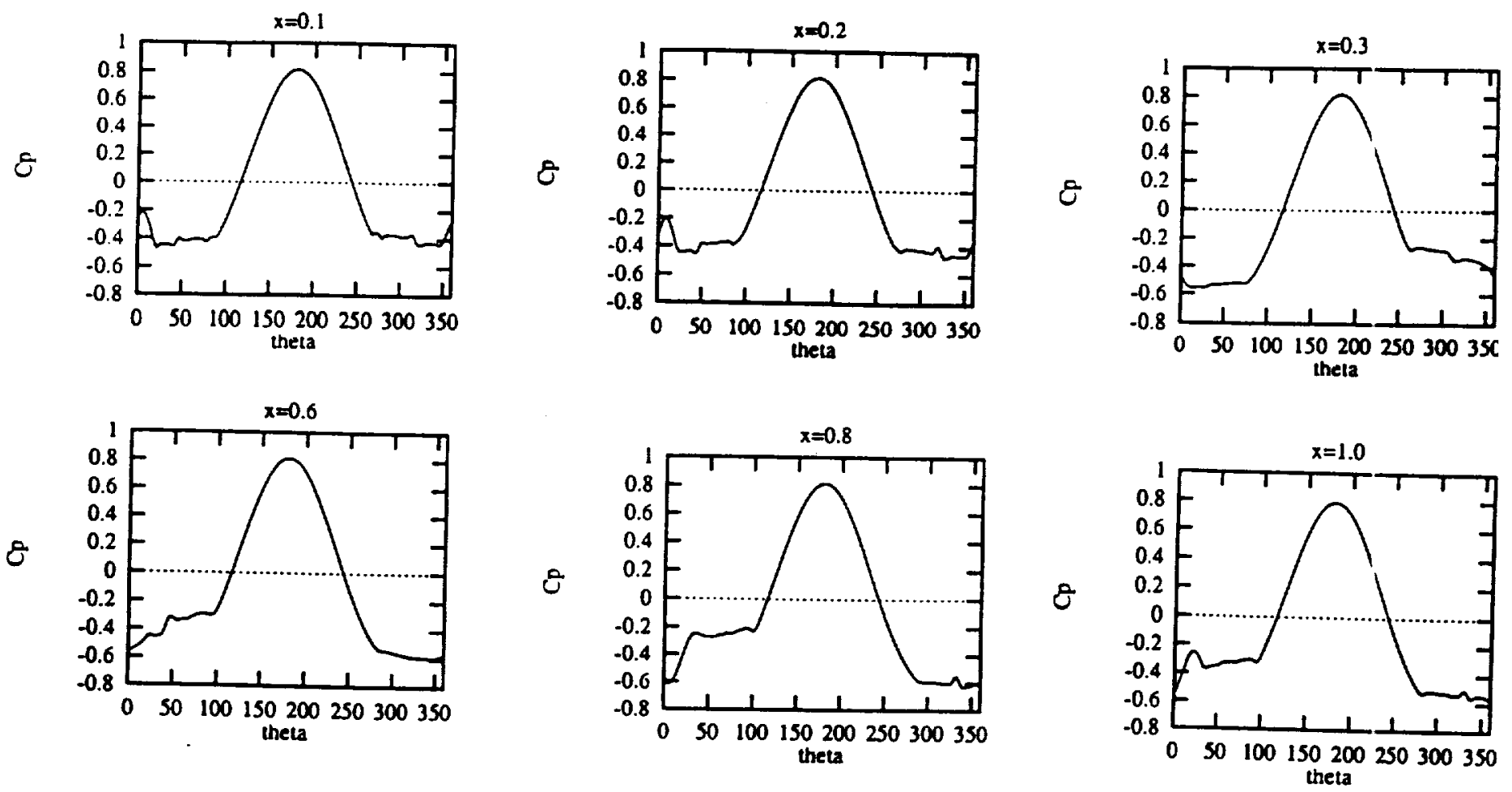

Fig. 2. Surface-pressure coefficient at different axial stations for a circular cone at $\alpha=40^{\circ}, M_{\infty}=1 . .4, R_{\varepsilon}=6 \times 10^{6}$. 

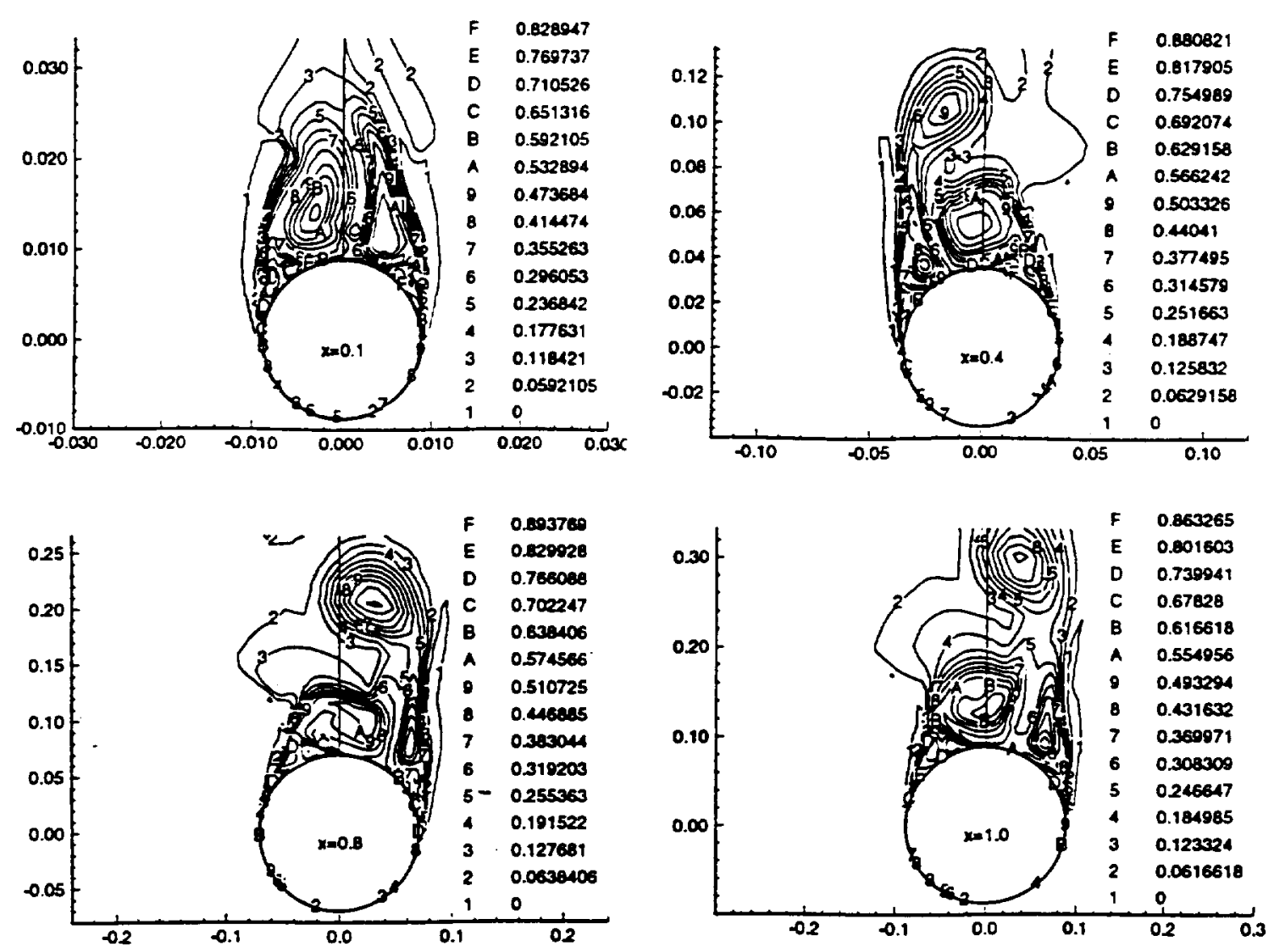

Fig. 3. Total pressure loss contours at different axial stations for a circular cone at $\alpha=40^{\circ}, M_{\infty}=1 . .4, R_{e}=6 \times 10^{6}$.

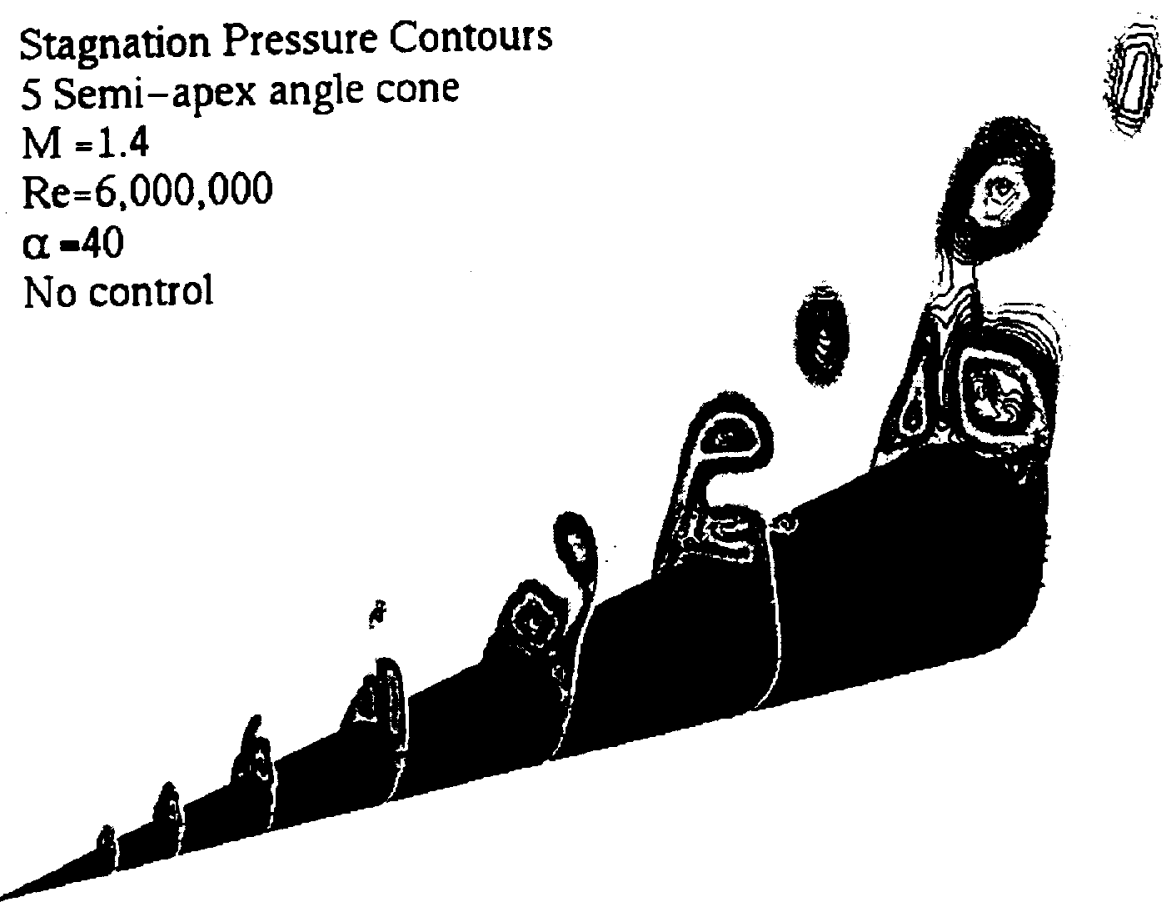

Fig. 4. Stagnation pressure contours at different axial 

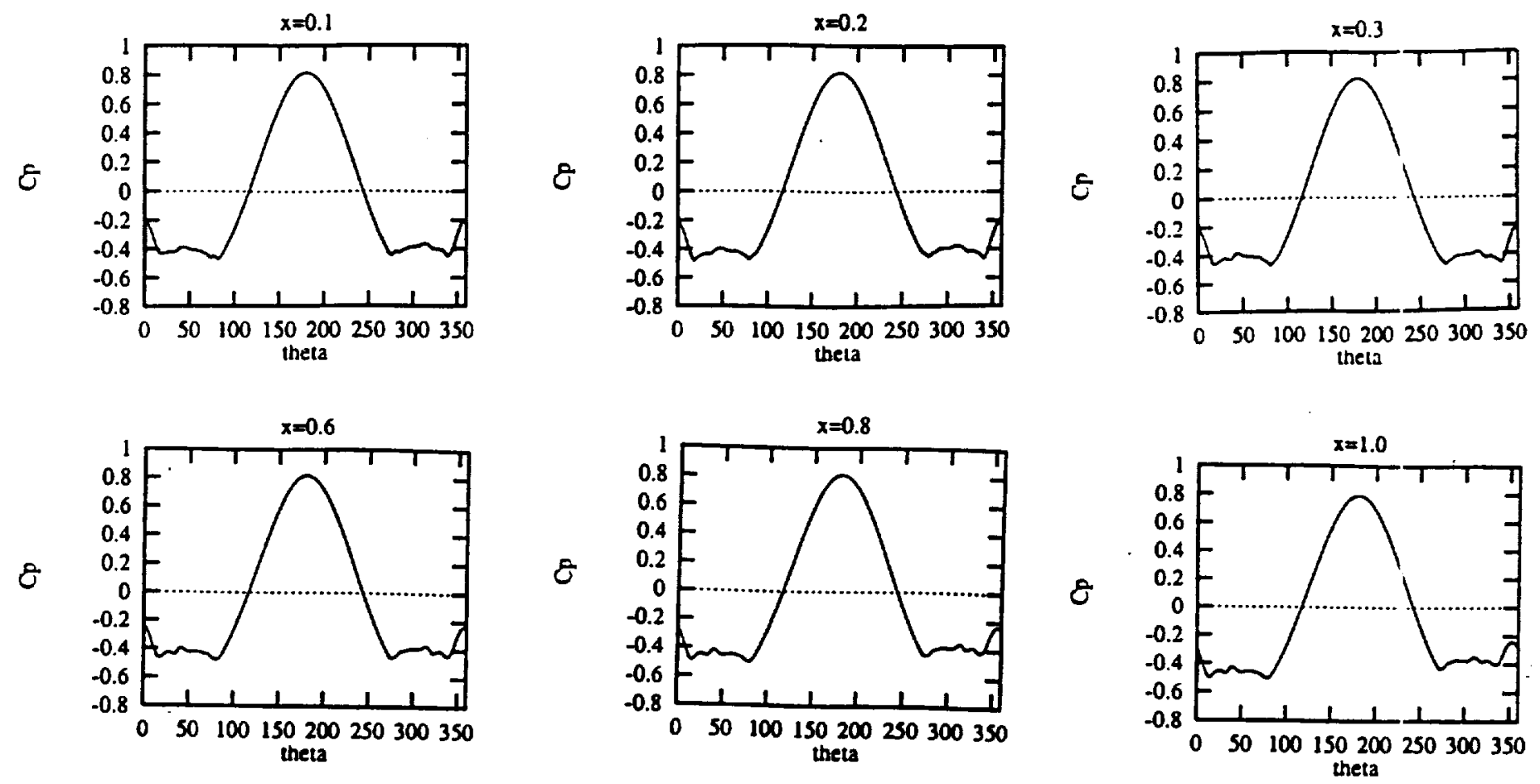

Fig. 5. Surface pressure coefficient at different axial stations for a circular cone with normal injection, $\alpha=40^{\circ}, M_{\infty}=1.4, R_{e}=6 \times 10^{6}, l_{\text {eff }}=0.01, \theta_{e f f}=+67.5^{\circ} \rightarrow-67.5^{\circ}$, $\dot{m}_{\max }=0.05$.
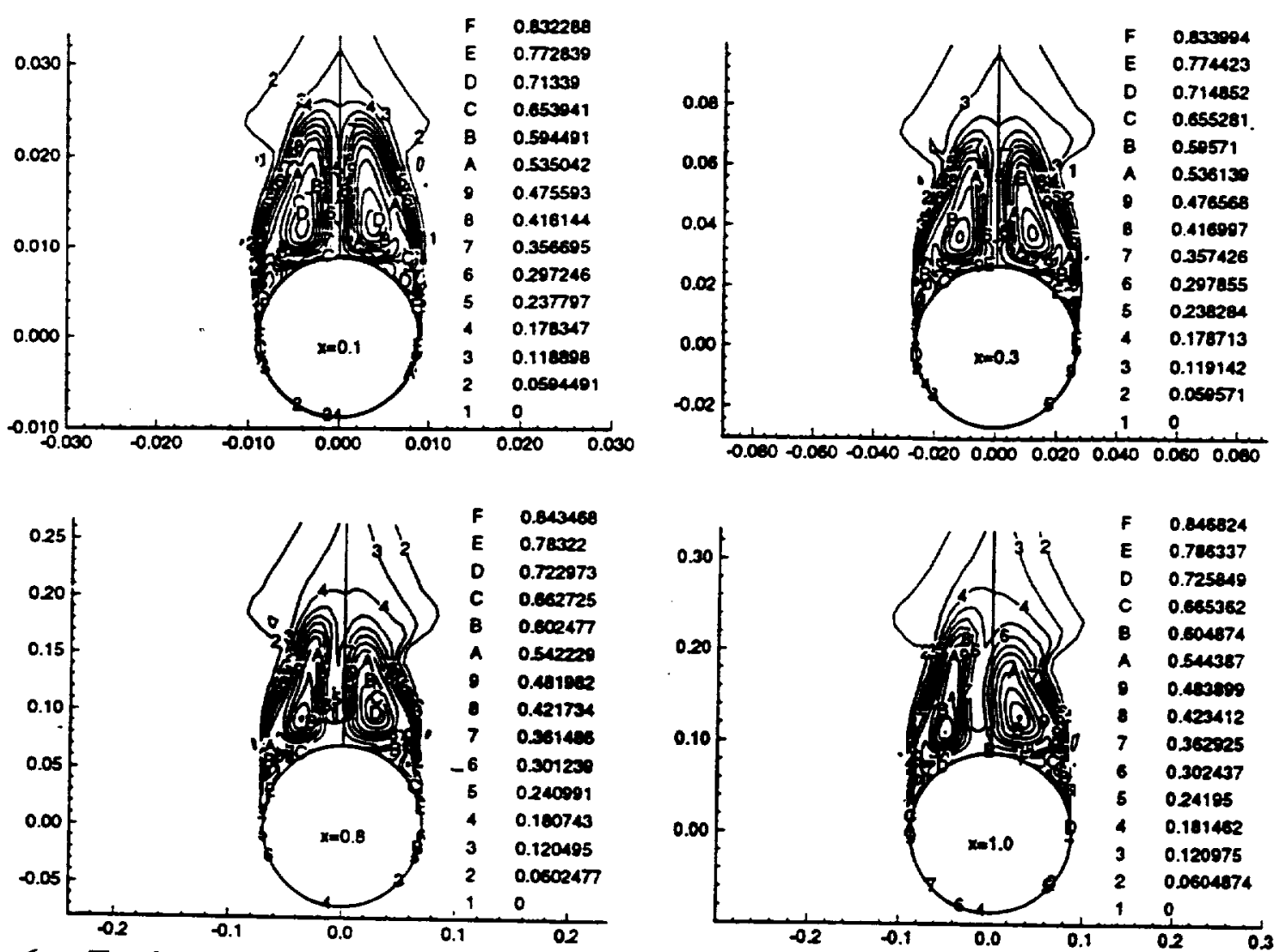

Fig. 6. Total pressure loss contours at different axial stations for a circular cone with norma! injection at $\alpha=40^{\circ}, M_{\infty}=1.4, R_{e}=6 \times 10^{6}, l_{\text {eff }}=0.1, \theta_{\text {eff }}=+67.5^{\circ} \rightarrow-67.5^{\circ}$, $\dot{m}_{\max }=0.05$. 
Stagnation Pressure Contours

5 Semi-apex angle cone

$\mathrm{M}=1.4$

$\operatorname{Re}=6,000,000$

$\alpha=40$

Active control using normal injection

Effective injection length $=0.10$

Effective injection angle $=-67.5$ to 67.5

$\mathrm{m}_{\max }^{*}=0.05$

Fig. 7. Stagnation pressure at different axial stations.
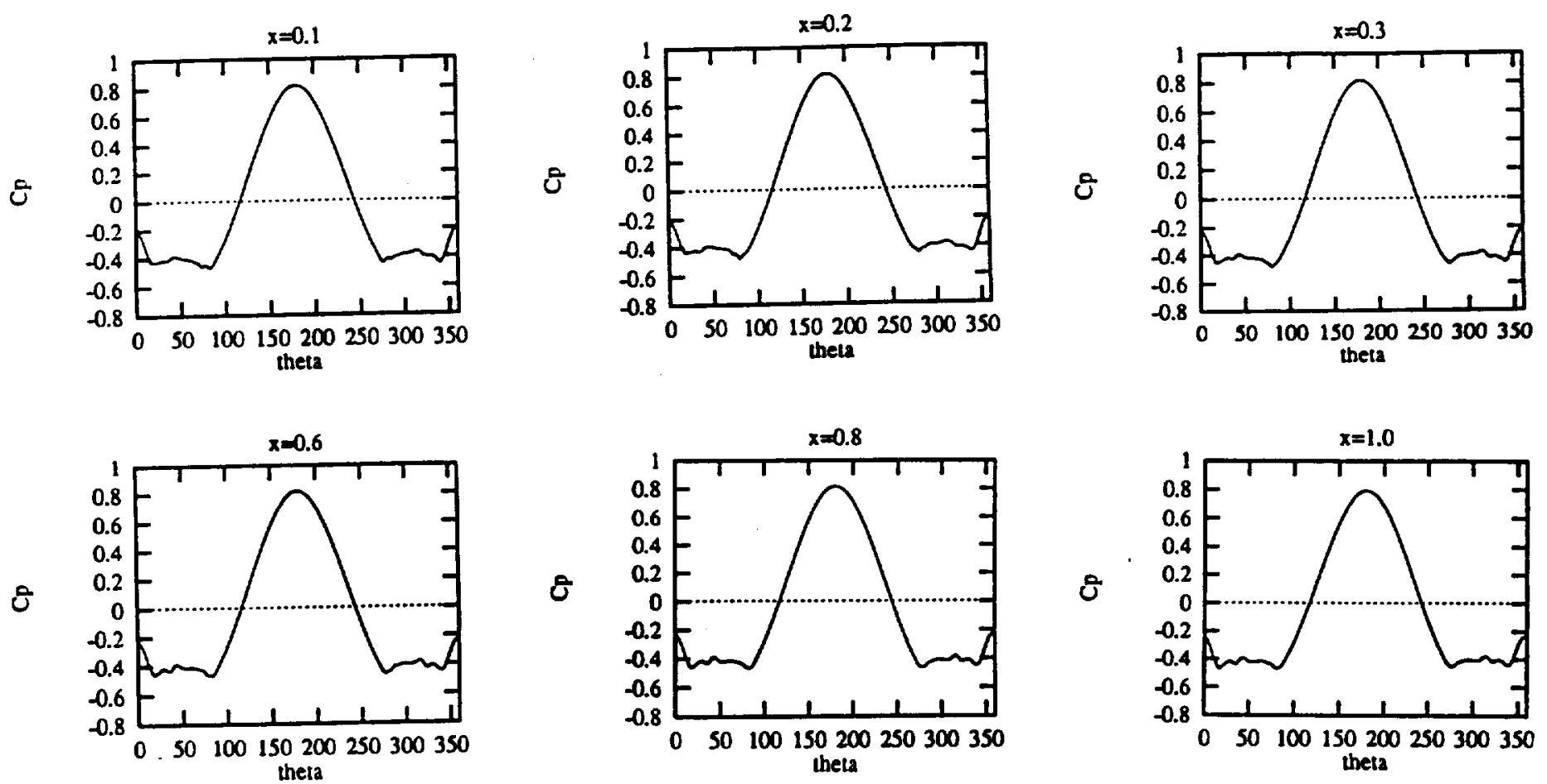

Fig. 8. Surface pressure coefficient at different axial stations for a circular cone at $\alpha=40^{\circ}$, $M_{\infty}=1.4, R_{e}=6 \times 10^{6}, l_{\text {eff }}=0.26, \theta_{\text {eff }}=+67.5^{\circ} \rightarrow-67.5^{\circ}, \dot{m}_{\max }=0.05$. 

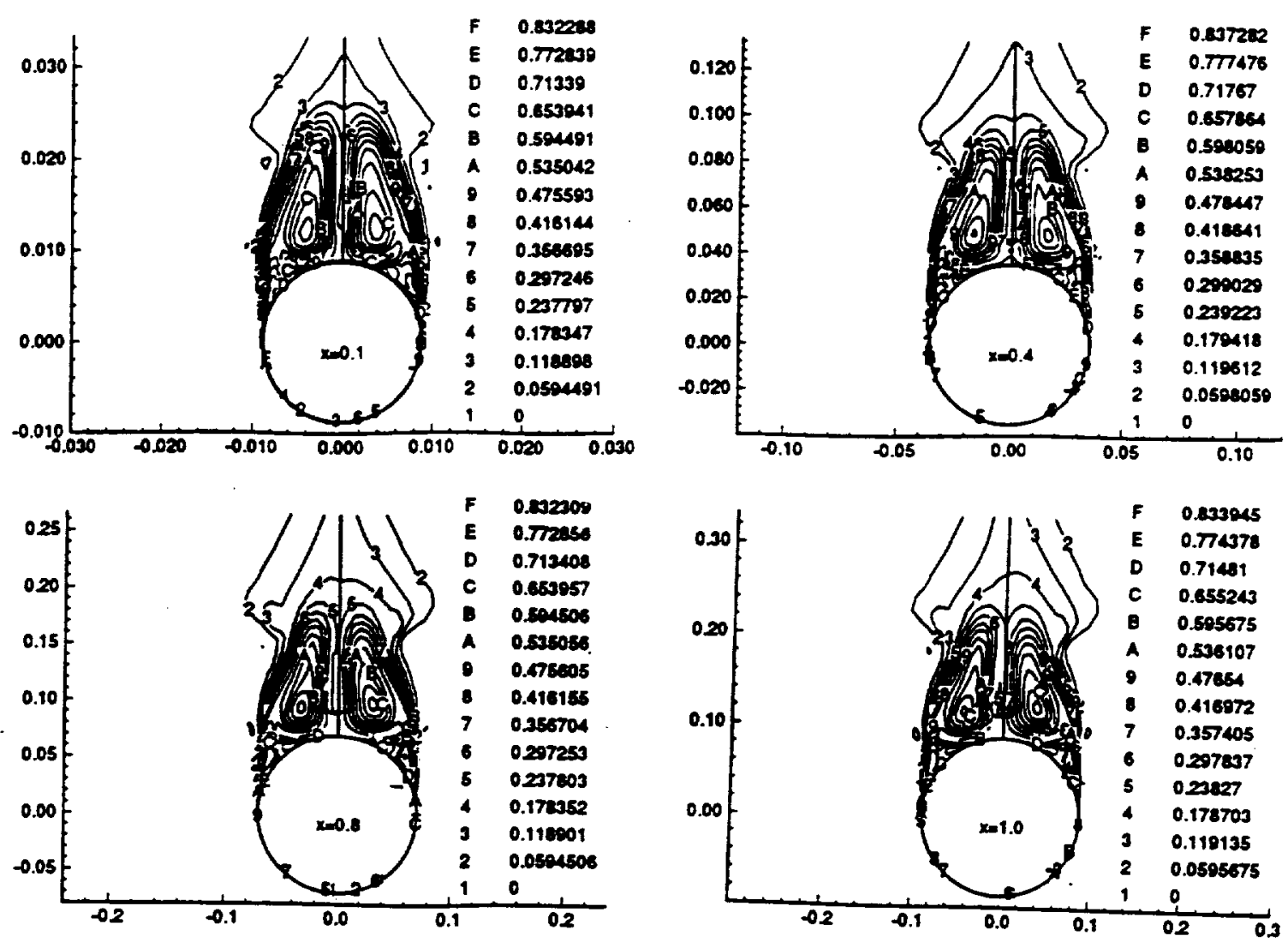

Fig. 9. Total pressure loss contours at different axial stations for a circular cone at $\alpha=4.0^{\circ}$, $M_{\infty}=1.4, R_{e}=6 \times 10^{6}, l_{\text {eff }}=0.26, \theta_{\text {eff }}=+67.5^{\circ} \rightarrow-67.5^{\circ}, \dot{m}_{\max }=0.05$.

Stagnation Pressure Contours

5 Semi-apex angle cone

$\mathrm{M}=1.4$

$\operatorname{Re}=6,000,000$

$\alpha=40$

Active control using normal injection

Effective Injection length $=0.26$

Effective injection angle $=-67.5$ to 67.5 $\mathrm{m}_{\mathrm{max}}^{*}=0.05$ 



Fig. 11. Surface pressure coefficient at different axial stations for a circular cone with tangential injection at $\alpha=40^{\circ}, M_{\infty}=1.4, R_{e}=6 \times 10^{6}, l_{\text {eff }}=0.1, \theta_{\text {eff }}=+67.5^{\circ} \rightarrow-67.5^{\circ}$, $\dot{m}_{\max }=0.05$.
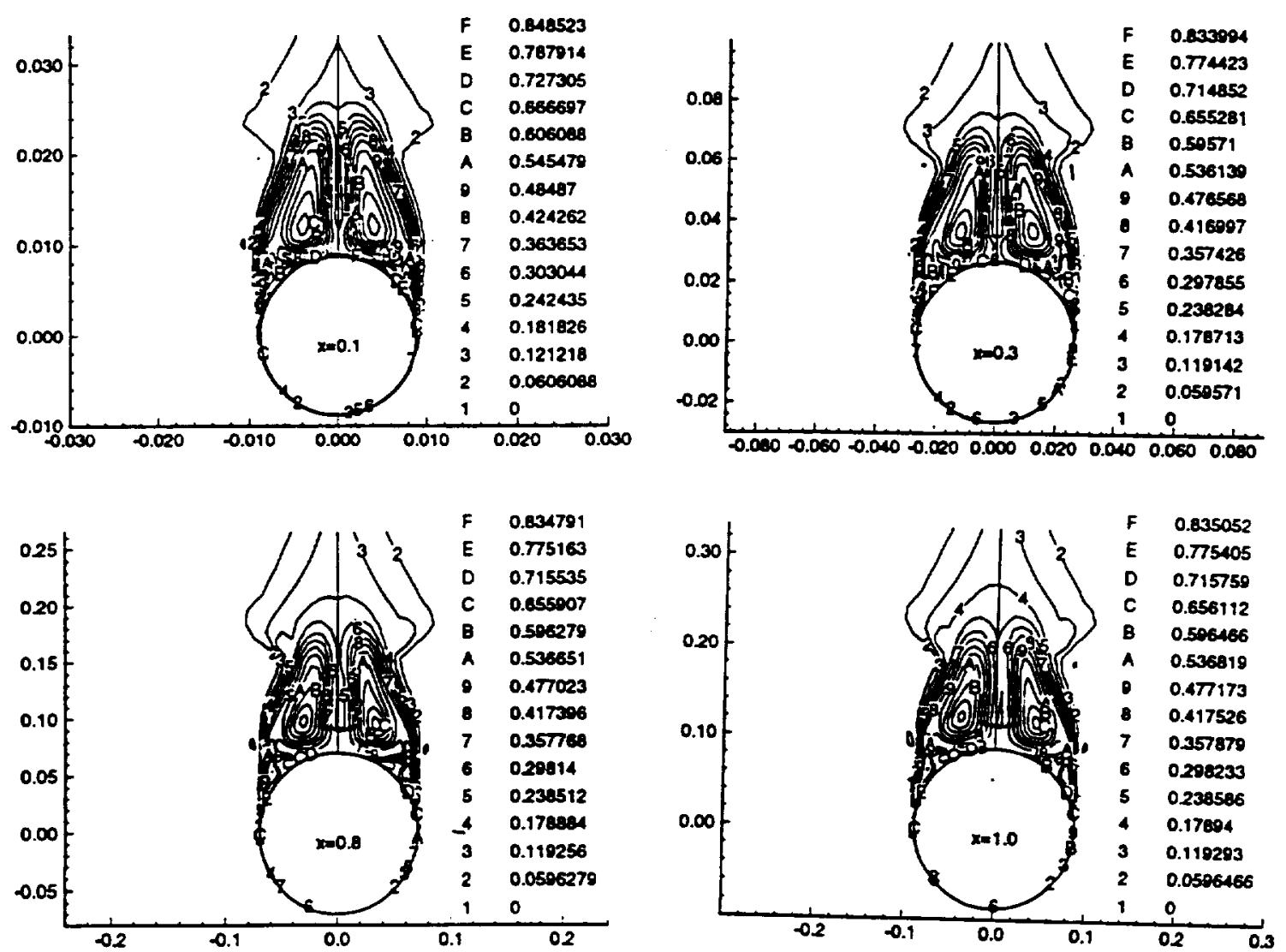

Fig. 12. Total pressure loss contours at different axial stations for a circular cone with tangential injection at $\alpha=40^{\circ}, M_{\infty}=1.4, R_{e}=6 \times 10^{6}, l_{\text {eff }}=0.1, \theta_{\text {eff }}=+67.5^{\circ} \rightarrow-67.5^{\circ}$, $\dot{m}_{\max }=0.05$. 
Stagnation Pressure Contours

5 Semi-apex angle cone

$\mathrm{M}=1.4$

$\operatorname{Re}=6,000,000$

$\alpha=40$

Active control using tangential injection

Effective injection length $=0.10$

Effective injection angle $=-67.5$ to 67.5 $\mathrm{m}_{\max }^{*}=0.05$



Fig. 13. Stagnation pressure at different axial stations. 


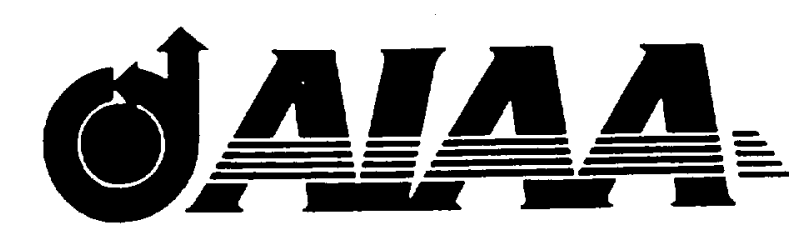

AIAA-94-2383

\section{TURBULENT FLOW OVER A 747/747 GENERATOR/FOLLOWER CONFIGURATION AND ITS DYNAMIC RESPONSE}

Osama A. Kandil and Tin-Chee Wong Old Dominion University, Norfolk, VA 23529

Chen-Huei Liu

NASA Langley Research Center, Hampton, VA

\section{5th AIAA Fluid Dynamics Conference}

June 20-23, 1994 / Colorado Springs, CO 



\title{
TURBULENT FLOW OVER A 747/747 GENERATOR/FOLLOWER CONFIGURATION AND ITS DYNAMIC RESPONSE
}

\author{
Osama A. Kandil" and Tin-Chee Wong*" \\ Aerospace Engineering Department \\ Old Dominion University, Norfolk, VA 23529 \\ and \\ Chen-Huei Liu".. \\ Computational Aerodynamics and Acoustics Branch \\ NASA Langley Research Center, Hampton, VA 23681
}

\begin{abstract}
The multidisciplinary interaction of the aerodynamics and rigid-body dynamics between a single tip vortex (representing a 747 generator wing) and a trailing wing (representing a $\mathbf{7 4 7}$ follower wing) is computationally investigated. The three-dimensional computational model consists of a tip vortex with prescribed location and flow profiles at the inlet boundary of the computational domain, and a 747 follower wing with prescribed location relative to the generator tip vortex and prescribed mass-moment of inertia around the wing axis of symmetry. Keeping the follower wing stationary, the problem is solved for the flowfield using the Reynolds-averaged, Navier-Stokes (NS) equations. With this solution serving as initial conditions, the follower wing is released to roll under the effect of the rolling moment induced by the generator tip vortex. At each time step, the NS equations and the dynamics equation for rolling motion are solved sequentially for the flowfield, the rolling moment and the follower-wing rolling motion. The computational grid is allowed to roll according to the wing rolling motion. The problem is solved for laminar and turbulent flows using coarse and fine grids.
\end{abstract}

\section{INTRODUCTION}

Since the introduction of wide-body and jumbo jets for civil air transport in the early 70's, the problem of hazardous effect of wake vortices trailing behind these aircraft on follower aircraft has received significant research efforts. The vortex trails are characterized with high intensity and turbulence, and may produce high rolling moments on follower aircraft which could exceed its available roll control. Moreover, the follower aircraft, depending on its location with respect to these vortex trails, could suffer a loss of altitude or climb rate in addition to structural damages. These vortex trails may persist up to several miles and for long periods of time before their decay, and therefore they play a major role in sequencing

\footnotetext{
- Professor, Eminent Scholar and Department Chaiman, Associate Fellow AIAA

- Research Associare, Member AIAA

-. Senior Scientist, Associate Fellow AIAA

Copyright $(0) 1994$ by Osama A. Kandil. Published by the American

Institute of Aeronautics and Astronautics, Inc. with permission.
}

landing and take-off operations at busy airports. For example, a minimum safe-separation distance between aircraft need to be specified which depends on the vortex. intensity, wind shear, atmospheric turbulence and temperature gradient; among others.

The literature shows a few experimental and computational investigations that attempt to study and analyze vortex-wake flow interaction, merging, decay and its hazardous effects on follower aircraft. Hallock and Eberle ${ }^{i}$ presented a review of the state of the an of aircraft wake vortices covering the research efforts in the United States until the mid-seventies. Experimental wind tunnel and airport measurements of the vortex-wake flow were conducted by Dee and Nicholas ${ }^{2}$, Harvey and Perry ${ }^{3}$, ElRamly ${ }^{4}$, Wood and McWilliams ${ }^{5}$, Gardoz ${ }^{6}$, Cliffone and Lonzo', and Olwi and Ghazi ${ }^{8}$.

Mathematical models and computational schemes were developed using inviscid analysis by Chorin and Bernard ${ }^{9}$. Hacket and Evans ${ }^{10}$, Yates ${ }^{11}$, Iversen and Bemstein ${ }^{12}$, and Rossow ${ }^{13}$. Although an inviscid model cannot describe the wake aging including its diffusion, it is still capable of producing the wake shape and its dynamics. The mathematical models used in the above references were based on the use of the point vortex method to compute the motion of a finite number of point vortices which model the vorticity behind a wing. The first threedimensional inviscid model was introduced by Kandil, et. al $^{14}$, where the nonlinear vortex-lattice method, which was also developed by Kandil, et. al ${ }^{15}$, was used to compute the interference flow between wings and the vortexwake flows and the resulting hazardous effects.

Viscous modeling of trailing vortices was first introduced by McCormick, et. al ${ }^{16}$. Viscous interactions of vortex wakes and the effects of background turbulence, wind shear and ground on two-dimensional vortex pairs were presented by Bilanin, et. al ${ }^{17,18}$. Liu and his co-workers ${ }^{19-21}$ studied the interaction, merging and decay of vortices in two-dimensional space and of threedimensional vortex filaments. For the two-dimensional flow simulation, the incompressible Navier-Stokes equations, expressed in terms of vorticity-stream function formulation, were used. For the three-dimensional flow simulation, the incompressible Navier-Stokes equations, expressed in terms of the vorticity-velocity vector potential formulation, were used. An extensive review of this work 
is given in Ref. 22. To estimate the effects of density stratification, turbulence and Reynolds number on vortex wakes, an approximate model was recently developed by Greene ${ }^{23}$. Later on, Greene and his co-workers ${ }^{24}$ presented selected results of aircraft vortices which include a juncture vortex, a lifting-wing vortex and a wake vortex.

In a recent paper ${ }^{25}$ by the present authors, the unsteady, compressible, thin-layer, Reynolds-averaged, Navier-Stokes equations were used to compute and analyze vortex-wake flows of isolated and interacting wings. A C-O grid was used to carry out the computations with a computational domain that extends 15 chords behind the leading wing. The emphasis of the paper was to study the effects of the near-wake vortex flow on a small follower wing for two vortex-wake interference cases. The first flow-interference case was called the "alongtrack penetration through vortex center" and the second flow-interference case was called the "along-track penetration between vortices." The computations showed that the first-interference case was much more hazardous to the follower wing in comparison with the second flowintereference case. It was demonstrated that the follower wing experienced large rolling moments if the follower wing is along-track penetration through vortex center. For the second flow-interference case, it was demonstrated that the follower wing experienced a loss of lifting force.

In a later paper by Wong, Kandil and $\mathrm{Liu}^{26}$, the wake-vortex flows of the wing considered in Ref. 25 were recomputed using fine grids and thin-layer and full Navier-Stokes equations. The flux limiter in the solver was rumed on and off to study its numerical diffusive effect. It has been shown that the solution obtained using the full Navier-Stokes equations without flux limiter gives the least numerically-diffused tip-vortex core in comparison with the other solutions. However, the tipvortex core diffused rapidly beyond the trailing edge. This result calls for more accurate computation of the tip-vorex core to minimize the numerical diffusion.

In the present paper, the multidisplinary interaction of a tip vortex (representing a 747 generator wing) and a 747 trailing wing (representing the follower wing) is studied. The follower wing is initially set at zero angle of attack and held stationary. The flowfield is obtained using the solution of the NS equations, and the initial rolling moment induced by the generator tip vortex on the follower wing is computed. The follower wing is then released from rest and both the NS equations and the dynamics equation of rolling motion are sequentially solved at each time step. The response of the follower wing and its interaction with the generator tip vortex are obtained. The problem is solved for laminar and turbulent flows using coarse and fine grids.

\section{FORMULATION}

\section{Fluid Flow Equations:}

The vector form of the governing equations is developed in terms of an inertial frame of reference, and hence there are no source terms on the right-hand side of the equations. Hence, the components of the flow-field vector $[\rho, \rho \bar{V}, \rho e]^{t}$ are absolute quantities. This is unlike the earlier development of the governing equations by the principal author of this paper (Ref. 27), where the equations are developed in terms of a non-inertial franie of reference (translating and rotation frame of reference) and source terms appear on the right-hand side of the equations.

The conservative form of the dimensionless, unsteady, compressible, full NS equations in terms of timedependent, body-conformed coordinates $\xi^{1}, \xi^{2}$ and $\xi^{3}$ is given by

$$
\frac{\partial \bar{Q}}{\partial t}+\frac{\partial \bar{E}_{m}}{\partial \xi^{m}}-\frac{\partial\left(\bar{E}_{v}\right)_{g}}{\partial \xi^{2}}=0 ; m=1-3, s=1-3
$$

where

$$
\begin{gathered}
\xi^{m}=\xi^{m}\left(x_{1}, x_{2}, x_{3}, t\right) \\
\bar{Q}=\frac{\hat{q}}{J}=\frac{1}{J}\left[\rho, \rho u_{1}, \rho u_{2}, \rho u_{3}, \rho e\right]^{t} \\
\bar{E}_{m} \equiv \text { inviscid flux in } \xi^{m} \text { direction } \\
=\frac{1}{J}\left[\partial_{k} \xi^{m} \hat{E}_{k}+\frac{\partial \xi^{m}}{\partial t} \hat{q}\right]^{t} \\
=\frac{1}{J}\left[\rho U_{m}, \rho u_{1} U_{m}+\partial_{1} \xi^{m} p, \rho u_{2} U_{m}\right. \\
+\partial_{2} \xi^{m} p, \rho u_{3} U_{m}+\partial_{3} \xi^{m} p,(\rho e+p) U_{m} \\
\left.-\frac{\partial \xi^{m}}{\partial t} p\right]^{\prime}
\end{gathered}
$$

$$
\begin{gathered}
\left(\bar{E}_{v}\right), \equiv \text { viscous and heat-conduction flux in } \xi^{s} \\
\text { direction } \\
=\frac{1}{J}\left[0, \partial_{k} \xi^{s} \tau_{k 1}, \partial_{k} \xi^{s} \tau_{k 2}, \partial_{k} \xi^{s} \tau_{k 3}\right. \\
\left.\partial_{k} \xi^{s}\left(u_{n} \tau_{k n}-q_{k}\right)\right]^{t} ; \quad k=1-3, n=1-3 \\
U_{m}=\partial_{k} \xi^{m} u_{k}+\frac{\partial \xi^{m}}{\partial t}
\end{gathered}
$$

and $\frac{\partial \xi^{m}}{\partial t}$ is the grid speed. The three momentum elemens of Eq. (5) are given by

$$
\begin{aligned}
\partial_{k} \xi^{s} \tau_{k} j & =\frac{M_{o o} \mu}{R e}\left[\left(\partial_{k} \xi^{s} \partial_{j} \xi^{n}-\frac{2}{3} \partial_{j} \xi^{s} \partial_{k} \xi^{n}\right) \frac{\partial u_{k}}{\partial \xi^{n}}\right. \\
& \left.+\partial_{k} \xi^{s} \partial_{k} \xi^{n} \frac{\partial u_{j}}{\partial \xi^{s}}\right] ; j=1-3
\end{aligned}
$$


The last element of Eq. (5) is given by

$$
\begin{gathered}
\partial_{k} \xi^{s}\left(u_{p} \tau_{k p}-q_{k}\right) \equiv \frac{M_{\infty} \mu}{R e}\left[\left(\partial_{k} \xi^{s} \partial_{p} \xi^{n}\right.\right. \\
\left.-\frac{2}{3} \partial_{p} \xi^{s} \partial_{k} \xi^{n}\right) u_{p} \frac{\partial u_{k}}{\partial \xi^{n}}+\partial_{k} \xi^{s} \partial_{k} \xi^{n} u_{p} \frac{\partial u_{p}}{\partial \xi^{n}} \\
\left.+\frac{1}{(\gamma-1) P_{r}} \partial_{k} \xi^{s} \frac{\partial\left(a^{2}\right)}{\partial \xi^{n}}\right] ; p=1-3
\end{gathered}
$$

The reference parameters for the dimensionless form of the equations are $L, a_{\infty}, L / a_{\infty}, \rho_{\infty}$ and $\mu_{\infty}$ for the length, velocity, time, density and molecular viscosity, respectively. The Reynolds number is defined as $R e=$ $\rho_{\infty} V_{\infty} L / \mu_{\infty}$, where $L$ is the wing root-chord length. The pressure, $p$, is related to the total energy per unit mass, $e$, and density, $\rho$, by the gas equation

$$
p=(\gamma-1) \rho\left(e-\frac{1}{2} u_{n} u_{n}\right)
$$

The viscosity, $\mu$, is calculated from the Sutherland law

$$
\mu=T^{3 / 2}\left(\frac{1+C}{T+C}\right), \quad C=0.4317
$$

and the Prandtl number $\mathrm{Pr}=0.72$.

In Eqs. (1)-(10), the indicial notation is used for convenience. The subscripts $j, k$ and $n$ are summation indices, the superscript or subscript $s$ is a summation index and the superscript or subscript $m$ is a free index. The range of $j, k, n, s$ and $m$ is $1-3$, and $\partial_{k} \equiv \partial / \partial x_{k}$. In Eqs. (1)-(10), $u_{n}$ is the Cartesian velocity component, $U_{m}$ the contravariant velocity component, $\tau_{m}$ the Cartesian component of the shear stress tensor, $q_{k}$ the Cartesian component of heat flux vector, $a$ the local speed of sound and $M_{\infty}$ the free-stream Mach number.

\section{Turbulent Flow:}

For the turbulent flow, the Navier-Stokes equations are transformed to the Reynolds-averaged equations by replacing the coefficient of molecular viscosity, $\mu$, and the coefficient of thermal conductivity, $k$, with

$$
\begin{gathered}
\mu_{e}=\mu+\mu_{t}=\mu\left(1+\mu_{t} / \mu\right) \\
k_{t}=k+k_{t}=\frac{\mu C_{p}}{P_{r}}\left(1+\frac{\mu_{t}}{\mu} \frac{P_{r}}{P_{r_{t}}}\right)
\end{gathered}
$$

where $\mu_{e}$ is the effective viscosity, $k_{e}$ the effective thermal conductivity, $\mu_{t}$ the turbulent viscosity, $P_{r}$ the laminar Prandtl number, $P_{r}$ the turbalent Prandtl number and $C_{p}$ the specific heat under constant pressure. The turbulent viscosity $\mu_{t}$ is obtained by using the two-layer algebraic eddy viscosity model which was first developed by $\mathrm{Cebeci}^{28}$ for the boundary-layer equations and modified later by Baldwin and Lomax ${ }^{29}$ for the Navier-Stokes equations. The details of the turbulent model are given in Ref. (30) by Wong, Kandil and Liu.

\section{Dynamies Equation of Rolling Motion:}

The Euler equation of rigid-body dynamics for rolling motion of the follower wing is given by

$$
I_{x z} \ddot{\theta}=M_{r}
$$

where $I_{x x}$ is the mass-moment of inertia of the follower wing around its axis, $\theta$ the roll angle (positive when measured in the counter-clockwise direction looking in the upstream direction), and $M_{x}$ the net aerodynamic rolling moment which includes the moment induced by the generator tip vortex and the aerodynamic dampingin-roll moment.

\section{Boundary and Initial Conditions and Grid Motion:}

Boundary conditions are explicitly implemented. They include inflow-outflow conditions and solidboundary conditions. At the inflow boundaries, the tip vortex profiles are prescribed and the Riemann-invariant boundary-type conditions are enforced. At the outflow boundaries, the Riemann-invariant boundary type conditions are also used.

Since the wing is undergoing a rolling motion, the grid is moved with the same angular motion as that of the wing. The grid speed, $\frac{\partial \xi^{m}}{\partial t}$, and the metric coefficient, $\frac{\partial \xi^{m}}{\partial x_{n}}$, are computed at each time step of the computational scheme. Consequently, the kinematical boundary conditions at the inflow-outflow boundaries and at the wing surface are expressed in terms of the relative velocities. For the dynamical boundary condition, $\frac{\partial p}{\partial n}$ at the wing surface is no longer equal to zero. This condition for the present rolling wing is modified as

$$
\left.\frac{\partial p}{\partial n}\right|_{w i n g}=-\rho \bar{a}_{w} \cdot \hat{n}=-\rho(\bar{\omega} \times \bar{\omega} \times \bar{r}+\dot{\bar{\omega}} \times \bar{r}) \cdot \hat{n}
$$

where $\bar{a}_{w}$ is the acceleration of a point on the wing surface, $\hat{n}$ the unit normal to the wing surface, $\bar{r}$ the position vector from the point to the roll axis and $\bar{\omega}\left(=\dot{\theta} \hat{e}_{x}\right)$ and $\dot{\bar{\omega}}\left(=\ddot{\theta} \hat{e}_{x}\right)$ are the angular velocity and acceleration of rolling motion. Finally, the boundary condition for the temperature is obtained from the adiabatic boundary condition, $\left.\frac{\partial T}{\partial n}\right|_{\text {wing }}=0$.

The initial conditions correspond to the flow solution around the stationary follower wing.

\section{COMPUTATIONAL SCHEME}

The implicit, upwind, flux-difference splitting, finitevolume scheme is used to solve the unsteady, compressible, Reynolds-averaged Navier-Stokes equations. The scheme uses the flux-difference splitting of Roe. The viscous- and heat-flux terms are linearized in time and the cross-derivative terms are eliminated in the implicit operator and retained in the explicit terms. The viscous 
terms are differenced using second-order accurate central differencing. The resulting difference equation is approximately factored and is solved in three sweeps in the $\xi^{1}, \xi^{2}$ and $\xi^{3}$ directions. The computational scheme is coded in the computer program "FTNS3D". For the dynamics equation of rolling motion, a four-stage RungeKutta scheme is used to integrate the equation to obtain $\theta$ and $\dot{\theta}$.

The method of solution consists of two steps. In the first step, the problem is solved while the wing is kept stationary. The NS equations are used to obtain the flowfield and the rolling moment induced by the generator tip vortex on the follower wing. Using this solution as initial conditions for the second step, the follower wing is released from rest and both the dynamics equation of rolling motion and the NS equations are integrated sequentially at each time step thereafter. At each time step, the wing and the grid are rotated according to the computed roll angle, and the metric coefficients of the coordinates and the grid speed are computed.

\section{COMPUTATIONAL RESULTS}

\section{Computational Model:}

For the follower wing, a 747-Boeing wing (without a dihedral angle) of aspect ratio of 6.3 is considered. The wing angle of attack is zero and the freestream Mach number is 0.3 . For the laminar flow, the Reynolds number is $0.1 \times 10^{6}$ and for the turbulent flow, the Reynolds number is $1 \times 10^{6}$. Two $\mathrm{C}-\mathrm{O}$ grids are used; a coarse grid of $97 \times 33 \times 65$ (Fig. 1) and a fine grid of $149 \times 49 \times 97$ in the wrap-around axial, normal and wrap-around spanwise directions, respectively. The inflow boundary is located at two wing root-chord lengths from the follower wing vertex. The center of the generator tip vortex is located at $1 / 4$ chord length above the follower wing on its plane of geometric symmetry. The other boundaries of the computational domain are located at a distance of 10 chord length. At the inflow boundary, the generator tip vortex has a tangential velocity profile given by

$$
V_{i}=\frac{M_{x} k_{i}}{r}\left[1-\exp \left(-\frac{r^{2}}{r_{m}^{2}}\right)\right]
$$

where $M_{x}$ is the freestream Mach number, $V_{\theta}$ is the tangential velocity at some radial distance, $r$. The constants $k$, and $r_{m}$ define the swirl ratio, $\beta$, which is the ratio between the maximum tangential velocity and the axial velocity at the inflow boundary, and its radial position (e.g. for $r_{m}=0.2$ and $k_{r}=0.1, \beta=0.32$ is at $r=0.224$ ). Looking in the upstream direction, the sense of rotation of the generator tip vortex is in the counter-clockwise direction. The radial velocity is set to zero. The corresponding pressure profile is obtained by integrating the inviscid radial momentum equation, and the density, $\rho$, is then found from the definition of the speed of sound. The resulting profiles represent a compatible set for the generator tip vortex. Figure 2 shows the compatible profiles of the generator tip vortex.

\section{Laminar Flow-Coarse Grid:}

Figures 3-5 show the results for the laminar-flow si)lution for a Reynolds number of $0.1 \times 10^{6}$ on a coarse grid at the $t=0$ (initial conditions). In Fig. 3, the totalpressure-coefficient (CPT) contours are shown at cros;flow planes passing through the follower wing and the generator tip vortex. Looking in the downstream dire:tion, the sense of rotation of the generator tip vortex is in the clockwise direction. The boundary-layer flow in the spanwise direction on the upper left side of the follower wing experiences separation, and that on the lower right side of the follower wing experiences separation also. The tip vortex on the left side of the follower wing is much smaller than its tip vortex on the right side. Figure 4 shows the upper and lower surface pressure-coefficierit (CP) contours of the follower wing. The adverse pressure gradients in the spanwise directions on the upper left side and the lower right side are clearly noticed. Figure 5 shows the CPT contours in cross-flow planes looking in the upstream direction (sense of the generator tip voltex is in the counter-clockwise direction). The separated boundary-layer flows on the upper and lower surfaces are clearly noticed. The core of the generator tip vortex moves to the left (looking downstream) and closer to the wing upper surface, as it advances in the downstream d:rection. Moreover, it becomes tighter downstream than its size upstream. These results clearly show the aercdynamic interference effects on the generator tip vortex and the boundary-layer flow of the follower wing. TEble 1 gives the values of lift, drag and rolling-momert coefficient for $\mathrm{t}=0$.

Next, the follower wing is released from rest with $\theta_{0}=\dot{\theta}_{0}=0$ and is allowed to roll under the initially ir duced rolling moment of the generator tip vortex. Figures 6-8 show a snapshot of the results at $t=10$. Figure 6 shows that the separated boundary-layer flow on the ufper left side is larger than that at $t=0$, and the separated boundary-layer flow on the lower right side is smaller than that at $t=0$. The tip vortex on the left side is on the lower surface and the tip vortex on the right side decreases in size in comparison with its size at $t=0$. Figure 7 shows the upper and lower CP contours which show the locations of the separated flow on the upper and lower left side of the follower wing. Figure 8 shows the CP' contours in cross-flow planes looking in the upstream d:rection. It is clearly noticed that the vortex core of the generator tip vortex becomes tighter as it advances in the downstream direction. It also moves to the left side of the follower wing and closer to its upper surface. The sepa-rated-boundery-layer-flow on the upper left side and the tip vortex on the lower left side are clearly seen at $x=1.9$. At this time level, $t=10$, the follower wing rolled $5.7^{\circ}$ in the clockwise direction looking in the downstream direction. During the course of the accurate time stepping, It was noticed that the follower-wing flow is strongly time dependent with frequent vortex shedding at the right tis of the wing. Figure 9 shows the variations of the rolling 
moment, $M_{x}$, the roll angle, $\theta$, the roll rate, $\dot{\theta}$, and the roll acceleration, $\ddot{\theta}$. The $M_{x}$ and $\ddot{\theta}$ decreases oscillatorly with time and $\theta$ and $\dot{\theta}$ increases with time. Eventually, $M_{x}$ and $\ddot{\theta}$ reach to zero and $\dot{\theta}$ reaches a constant value while $\theta$ continues to grow. Table 1 shows that the lift and rolling-moment coefficients decrease substantially and the drag coefficient decreases slightly.

The rolling moment $M_{x}$ has been fitted using analytic functions representing the restoring moment $\left(M_{\mathrm{r}}\right)$ and the damping-in-roll moment $\left(M_{d}\right)$. It is represented as

$$
M_{x}=M_{\tau}+M_{d}
$$

where

$$
\begin{aligned}
& M_{r}=a_{1} \theta+a_{3} \theta^{3}+a_{5} \theta \dot{\theta}^{2} \\
& M_{d}=a_{2} \dot{\theta}+a_{4} \theta^{2} \dot{\theta}+a_{6} \dot{\theta}^{3}
\end{aligned}
$$

Figure 10 shows the variation of the $M_{x}$ and its fitted function with time and the variations of the restoring and damping-in-roll moments with time. It is seen that $M_{r}$ is positive and $M_{d}$ is negative with $M_{r}>\left|M_{d}\right|$. The difference between $M_{r}$ and $M_{d}$ vanishes as $t$ increases until $M_{x}$ becomes 0 . Thereafter, the wing rotates with a constant rate.

\section{Turbulent Flow-Coarse Grid:}

Figures $11-12$ and 13-17 show the results for the turbulent-flow solution for a Reynolds number of $1 \times 10^{6}$ (using the Baldwin and Lomax model) with a coarse grid for $t=0$ and $t=10$, respectively. At $t=0$, it is noticed that the boundary-layer separations on the follower wing vanished in comparison with those of the laminarflow solution. Figure 11 shows higher suction pressures on the upper surface of the follower wing than those of the laminar-fiow solution. At $x=1.1$ and 1.9, Fig. 12 shows that the boundary-layer separations vanished due to the large flow momentum of the turbulent flow. At $t=10$. Fig. 13 shows that the boundary-layer separation on the upper left side of the follower wing occurs. It is not as strong as that of the laminar-flow solution. The tip vortex on the right side of the follower wing disappeared and the one on the left side is smaller in comparison with that of the laminar flow. The locations and sizes of the core of the generator tip vortex (Fig. 15) are similar to those of the laminar flow. Figure 16 shows $M_{s}, \theta, \dot{\theta}$ and $\ddot{\theta}$ variations with time up to $\mathrm{t}=10$. It is noticed that $M_{r}$ and $\ddot{\theta}$ decrease aperiodically and both $\theta$ and $\dot{\theta}$ increase. The rolling moment and acceleration reach close to zero, while $\dot{\theta}$ reaches a constant -value of 0.95 and $\theta$ reaches a value of $6.7^{\circ}$. This roll angle is larger than the one obtained for the laminar-flow solution. Figure 17 shows the variations of $M_{x}$ and its fitted function, $M_{\mathrm{r}}$ and $M_{d}$ with time. Both $M_{\mathrm{r}}$ and $M_{d}$ of the turbulent flow are higher than those of the laminar flow. Table 1 shows the lift, drag and rolling-moment coefficients for the follower wing with and without a generator tip vortex.
The generator tip vortex decreases the lift and drag coefficients. The rolling of the follower wing slightly reduces the lift coefficient and substantially increases the drag coefficient. The lift coefficient is substantially higher than that of the laminar flow while the drag coefficient is substantially lower than that of the laminar flow, particularly as the wing is rolling.

\section{Turbulent Flow-Fine Grid:}

The grid is refined in the three directions, and the problem is solved for the turbulent flow with a Reynolds number of $1 \times 10^{6}$. Figures $18-20$ show the results at the time level $t=10$. The fine-grid results show more resolution in the boundary-layer flow on the follower wing and more resolution in the core of the generator tip vortex, than those of the turbulent flow solution with a coarse grid. At $t=10$, Fig. 21 shows slightly higher roll rate, $\dot{\theta}$, and slightly higher roll angle, $\theta$, than those of the turbulent-flow solution with a coarse grid. It also shows slightly lower rolling moment and roll acceleration than those of the coarse-grid solution. Table 1 shows slightly lower lift coefficients at $\mathrm{t}=0$ and $\mathrm{t}=10$ than those of the coarse-grid solution. It also shows substantially lower drag coefficients at $t=0$ and $t=10$ than those of the coarse-grid solution.

\section{CONCLUDING REMARKS}

The multidisciplinary interaction which includes the aerodynamics and rigid-body dynamics of a 747-Boeing follower wing and a generator tip vortex is investigated in the present paper. The problem is solved using two sets of equations which include the unsteady, compressible, Reynolds-averaged NS equations and the dynamics equation of rolling motion. The problem is solved for laminar and turbulent flows using coarse and fine grids. The turbulent model is the modified Baldwin and Lomax model. The NS equations are solved using the implicit, upwind, flux-difference splitting, finite-volume scheme and the dynamic equation is solved using a four-stage Runge-Kutta scheme. The initial conditions for the rolling-wing problem are obtained by solving for the flowfield with the wing kept stationary. The profiles of the generator tip vortex are prescribed at the inflow boundary of the computational domain. Having obtained the initial conditions, the follower wing is released from rest to roll under the effect of the induced rolling moment of the generator vortex. At each time step of the solution, the NS equations are used to obtain the flowfield and the rolling moment on the follower wing, the dynamics equation of rolling motion is used to obtain the motion $(\theta, \dot{\theta}$ and $\ddot{\theta})$, the computational grid is allowed to roll according to the wing roll angle, and the metric coefficients of the coordinates and the grid speed are calculated. .

The laminar flow solution showed initial flow separations on the upper and lower surfaces of the follower wing. As the wing rolls, the flow separation on the upper 
surface increased and vortex shedding from the wing tip develops. The flow is substantially unsteady with oscitlatory decaying lift and rolling-moment coefficients. The turbulent flow solution shows substantially smaller initial flow separation, in comparison with the laminar solution, on the follower wing. As the wing rolls, the flow separation increases on the upper surface of the wing. The lift coefficients at the initial time and during the wing rolling motion are substantially higher than those of the laminar solution. The decay of the lift coefficient is not as substantial as that of the laminar case. The decay of the rolling-moment coefficient and the wing acceleration are aperiodic and approach zero while the roll rate reaches a constant value and the roll angle increases. For the same time level, the turbulent-flow solution shows higher roll angle than that of the laminar-flow solutio 1. The turbulent-flow solution with a fine grid shows more resolutions of the boundary-layer flow and the generatior tip vortex. It shows slightly higher roll angle and rell rate than those of the coarse-grid solution. It also show's slightly lower lift coefficient and substantially lower drag coefficient than those of the coarse-grid solution. It is also concluded from the results of the laminar- and turbulentflow solutions for the generator tip vortex that the Baliwin and Lomax turbulent model is inadequate for the generator tip vortex.

Table 1. Lift, Drag and Rolling-Moment Coefficient

\begin{tabular}{|c|c|c|c|}
\hline \multicolumn{2}{|c|}{ Laminar Flow-Coarse Grid } & \multicolumn{2}{|c|}{$\operatorname{Re}=1 . e 5(97 \times 33 \times 65)$} \\
\hline & $\mathrm{Cl}$ & $\mathrm{Cd}$ & $\mathrm{Cmx}$ \\
\hline$t=0$ & 0.048004 & 0.014941 & 0.021202 \\
\hline$t=10$ & 0.017775 & 0.014775 & 0.0069693 \\
\hline$t=20$ & -0.007207 & 0.015429 & 0.0014347 \\
\hline \multicolumn{2}{|c|}{ Turbulent Flow-Coarse Grid } &.$e 6(97 \times 33$ & \\
\hline & $\mathrm{Cl}$ & $\mathrm{Cd}$ & $\mathrm{Cmx}$ \\
\hline No Vortex & 0.14338 & 0.013 & 0. \\
\hline$t=0$ & 0.12961 & 0.0049181 & 0.033690 \\
\hline$t=10$ & 0.12579 & 0.0077610 & 0.0017480 \\
\hline$t=20$ & 0.11984 & 0.0076206 & $-0.808 e-4$ \\
\hline \multicolumn{2}{|c|}{ Turbulent Flow-Fine Grid } & $.6(149 \times 4)$ & \\
\hline & $\mathrm{Cl}$ & $\mathrm{Cd}$ & $\mathrm{Cmx}$ \\
\hline$t=0$ & 0.12141 & 0.0021379 & 0.035289 \\
\hline$t=10$ & 0.11838 & 0.0055305 & 0.0014577 \\
\hline
\end{tabular}

\section{ACKNOWLEDGMENT}

For the first two authors, this work is supported by the NASA Langley Research Center under grant no. NAG-1994. The authors would like to thank Mr. George Greene and Mr. Daniel Vickroy of NASA Langley Research Center for supporting this work. The computational resources provided by the NASA Langley Research Center and the NAS Center at Ames are acknowledged and appreciated.

\section{REFERENCES}

1. Hallock, J. N. and Eberle, W. R., "Aircraft Wake Vortices: A State-of-the-Art Review of the United States R\&D Program," FAA Rept. FAA-RD-77-23, February 1977.

2. Dee, F. W. and Nicholas, O. P., "Flight Measurements of Wing Tip Vortex Motion Near the Ground," CP
1065, British Aeronautical Research Council, Lordon, 1968.

3. Harvey, J. K. and Perry, F. J., "Flowfield Produced by Trailing Vortices in the Vicinity of the Ground." AIAA Joumal, Vol. 9, Aug. 1977, pp. 1659-1660.

4. El-Ramly, Z., "Induced Rolling Moment on Trailing Wings," AIAA 10th Fluid \& Plasmadynamics Contference, Albuquerque, NM, June 1977.

5. Wood, W. D. and McWilliams, T. G., "Wake Turbulence Detection and Economic Impact of Proposed Improvements," SAE Air Transportation Meeting, Washington, D.C., May 1977.

- 6. Gardoz, L. J., "Federal Aviation Administration FullScale Aircraft Vortex Wake Turbulence Flight Test Investigations: Past, Present, Future," AIAA Paper No. 71-97, January 1971. 
7. Cliffone, D. L. and Lonzo, C., Jr., "Flow Visualization of Vortex Interactions in Multiple Vortex Wakes Behind Aircraft," NASA TMX 62, 459, June 1975.

8. Olwi, I. A. and Ghazi, M. A., "An Experimental Investigation of the Turbulence Effect of a Leading Wing on a Trailing Aircraft," AlAA 91-3309-CP, AIAA 10th Applied Aerodynamics Conference, September 1991, pp. 830-837.

9. Chorin, A. J. and Bernard, P. S., "Discretization of a Vortex Sheet, with an Example of Roll-Up," Journal of Computational Physics, Vol. 13, November 1973, pp. $423-429$.

10. Hackett, J. E. and Evans, M. R., "Vortex Wakes Behind High Lift Wings," Journal of Aircraft, Vol. 8, May 1971, pp. 334-340.

11. Yates, J. E., "Calculation of Initial Vortex Roll-Up in Aircraft Wakes," Journal of Aircraft, Vol. 11, July 1974, pp. 397-400.

12. Iversen, J. D. and Bernstein, S., "Trailing Vortex Effects on Following Aircraft," Joumal of Aircraft, Vol. I1, January 1974, pp. 60-61.

13. Rossow, V. J., "Inviscid Modeling of Aircraft Trailing Vortices," Proceedings of NASA Symposium on Wake Vortex Minimization," Washington, D.C., February 1976, pp. 4-54.

14. Kandil, O. A., Mook, D. T. and Nayfeh, A. H., "Application of the Nonlinear Vortex-Lattice Concept to Aircraft-Interference Problems," Advances in Engineering Science, NASA CP-2001, Vol. 4, November 1976, pp. 1321-1326.

15. Kandil, O. A., Mook, D. T. and Nayfeh, A. H., "Nonlinear Prediction of the Aerodynamics Loads on Lifting Surface," Joumal of Aircraft, Vol. 13, No. 1, January 1976, pp. 22-28.

16. McCormick, B. W., Tangler, J. L. and Sherrieb, H. E., "Structure of Trailing Vortices," Journal of Aircraft, Vol. 5, No. 3, May-June 1968, pp. 260-267.

17. Bilanin, A. J., Teske, M. E. and Williamson, G. G., "Vortex Interactions and Decay in Aircraft Wakes," AIAA Joumal, Vol. 15, No. 2, Feb. 1977, pp. 250-260.

18. Bilanin, A. J., Teske, M. E. and Hirsh, J. E., "Neutral Atmospheric Effects on the Dissipation of Aircraft Vortex Wakes," AlAA Joumal, Vol. 16, No. 9, September 1978, pp. 956-961.
19. Liu, C. H. and Ting, L., "Interaction of Decaying Trailing Vortices in Spanwise Shear Flow," Computer and Fluids, Vol. 15, No. 1, 1987, pp. 77-92.

20. Weston, R. P., Ting, L. and Liu, C. H., "Numerical Studies of the Merging Vortices," AlAA 86-0557, January 1986.

21. Liu, C. H., Tavantzis, J. and Ting, L., "Numerical Studies of Motion and Decay of Vortex Filaments," AIAA Journal, Vol. 24, No. 8, August 1986, pp. 1290-1297.

22. Liu, C. H., Krause, E. and Ting, L., "VortexDominated Flow with Viscous Core Structure," AIAA 85-1556, invited paper, July 1985.

23. Greene, G. C., "An Approximate Model of Vortex Decay in the Atmosphere," Joumal of Aircraft, Vol. 23, No. 7, July 1986, pp. 566-573.

24. Greene, G. C., Lamar, J. E. and Kubendran, L. R., "Aircraft Vortices: Juncture, Wing and Wake," AIAA 88-3743, July 1988.

25. Kandil, O. A., Wong, T. C. and Liu, C. H., "Analysis and Computation of Trailing Vortices and Their Hazardous Effects," FAA International Symposium, Washington, D.C., Oct. 29-31, 1991, Vol. 2, pp. 36.1-36.24.

26. Wong, T. C., Kandil, O. A. and Liu, C. H., "Computation of Wake-Vortex Flows and Control of Their Effects on Trailing Wings," AIAA 4429-92-CP, August 1992, Vol. 1, pp. 280-292.

27. Kandil, O. A. and Chuang, H. A., "Unsteady NavierStokes Computations Past Oscillating Delta Wing at High Incidence," AIAA-89-0081 January 1989. Also AIAA Journal, Vol. 28, No. 9, September 1990, pp. 1565-1572.

28. Cebeci, T., "Calculation of Compressible Turbulent Boundary Layers with Heat and Mass Transfer," AIAA Paper 70-741, June 1970.

29. Baldwin, B. S. and Lomax, H., "Thin-Layer Approximation and Algebraic Model for Separated Turbulent Flows," AIAA Paper 78-257, January 1978.

30. Wong, T. C., Kandil, O. A. and Liu, C. H., "NavierStokes Computations of Separated Vortical Flows Past Prolate Spheroid at Incidence," AIAA 89-0553, January 1989. 




Fig. 1 A typical coarse grid for the follower wing.
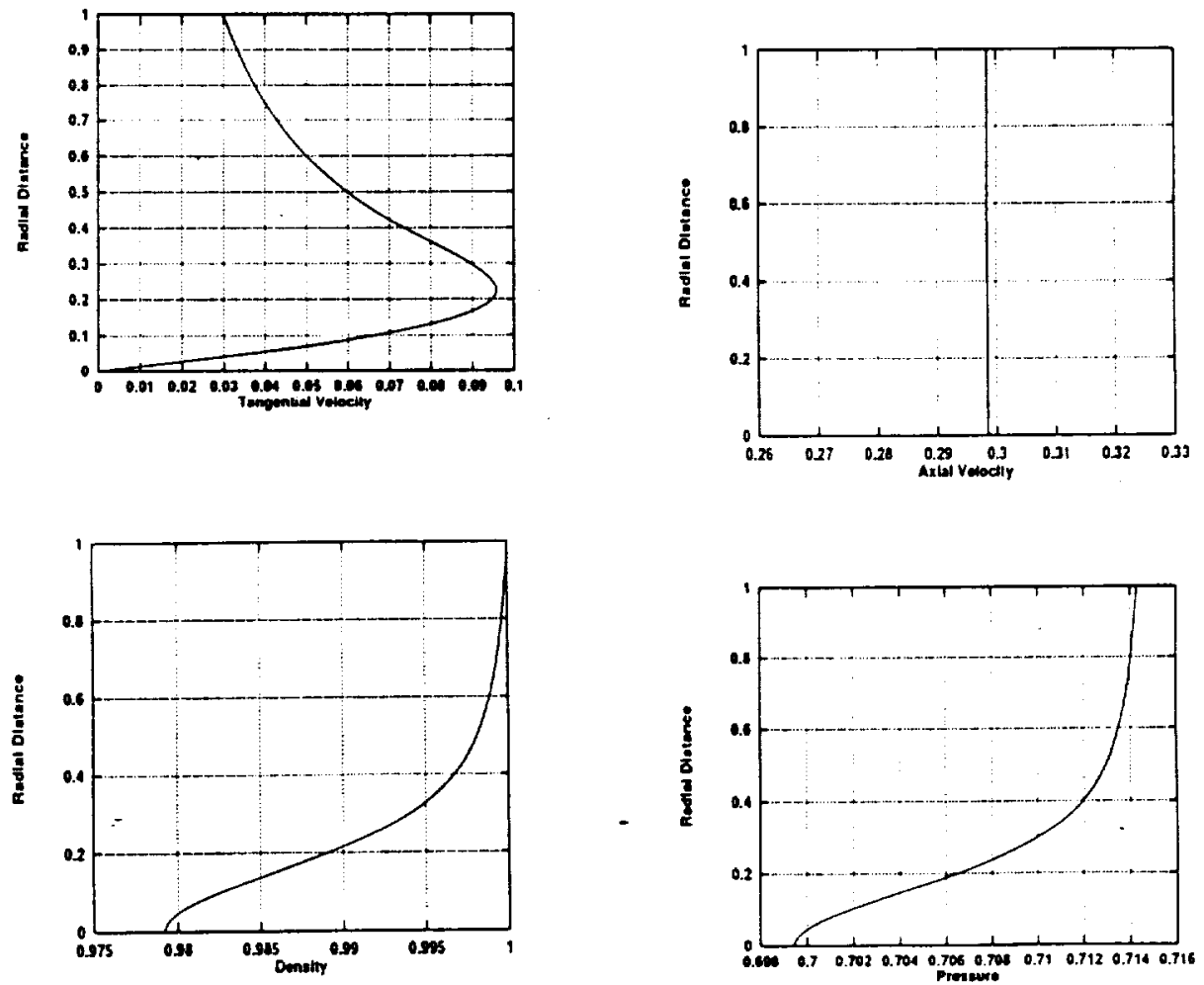

Fig. 2 Flow profiles of the generator tip vortex at the inflow boundary. 


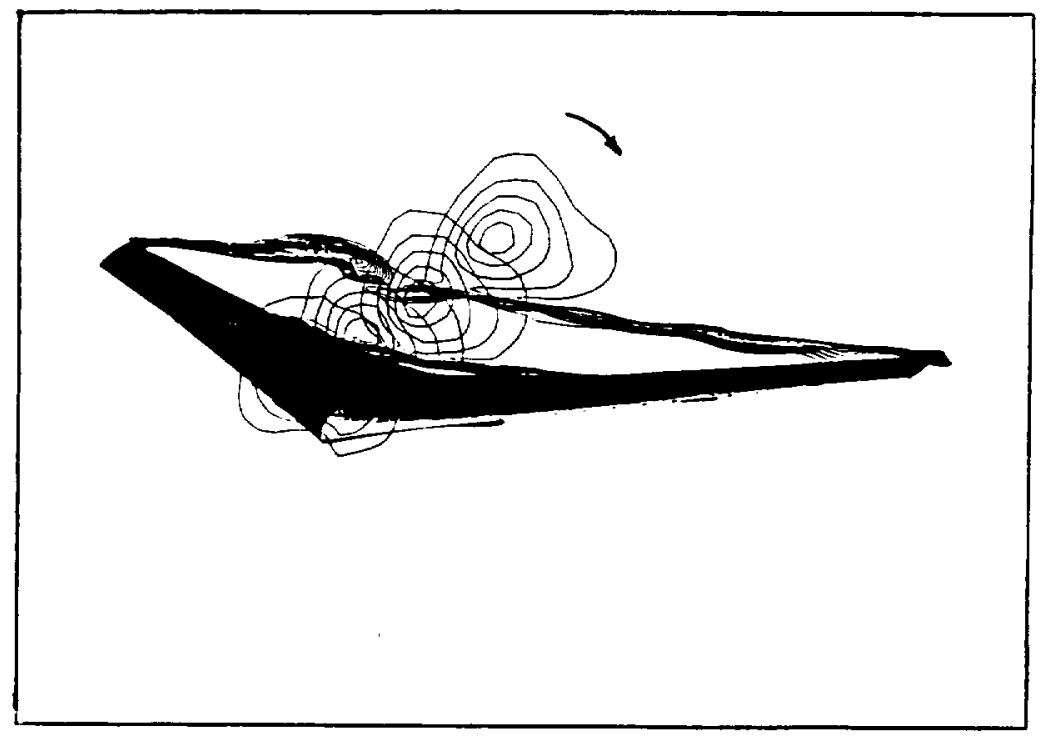

Fig. 3 CPT-contours at cross-flow planes of the follower wing and generator tip vortex, laminar flow, coarse grid, $t=0$.

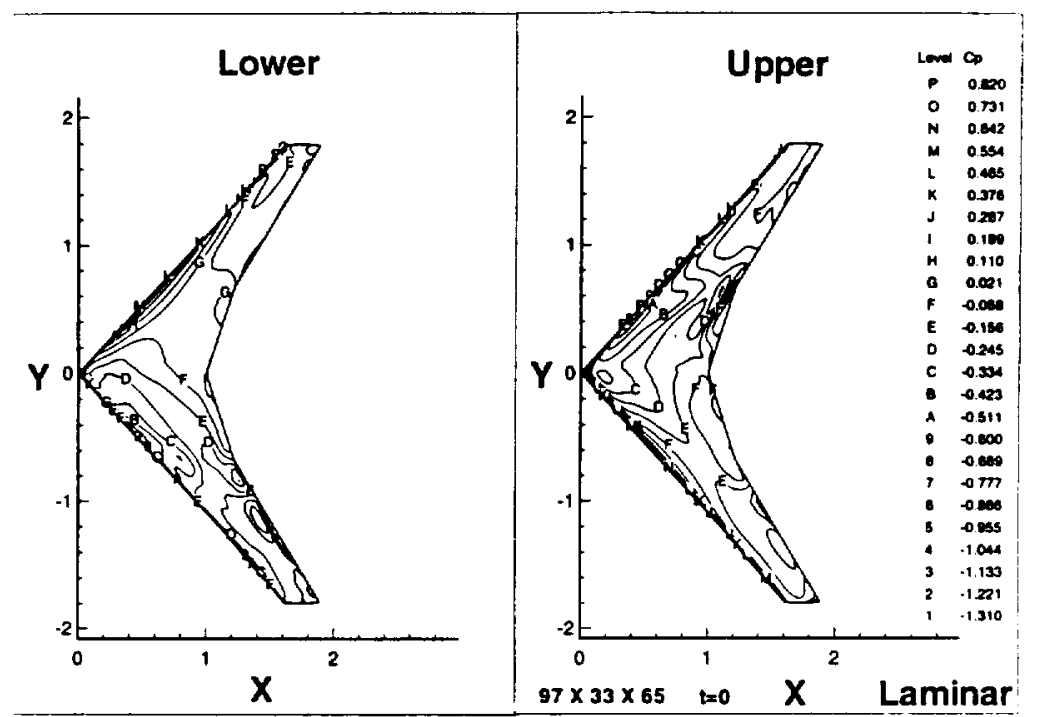

Fig. 4 Upper and lower surface CP-contours on the follower wing, laminar flow, coarse grid, $t=0$.


Fig. 5 CPT-contours in cross-flow planes of the follower wing and generator tip vortex, laminar flow, coarse grid, $\mathrm{t}=0$. 


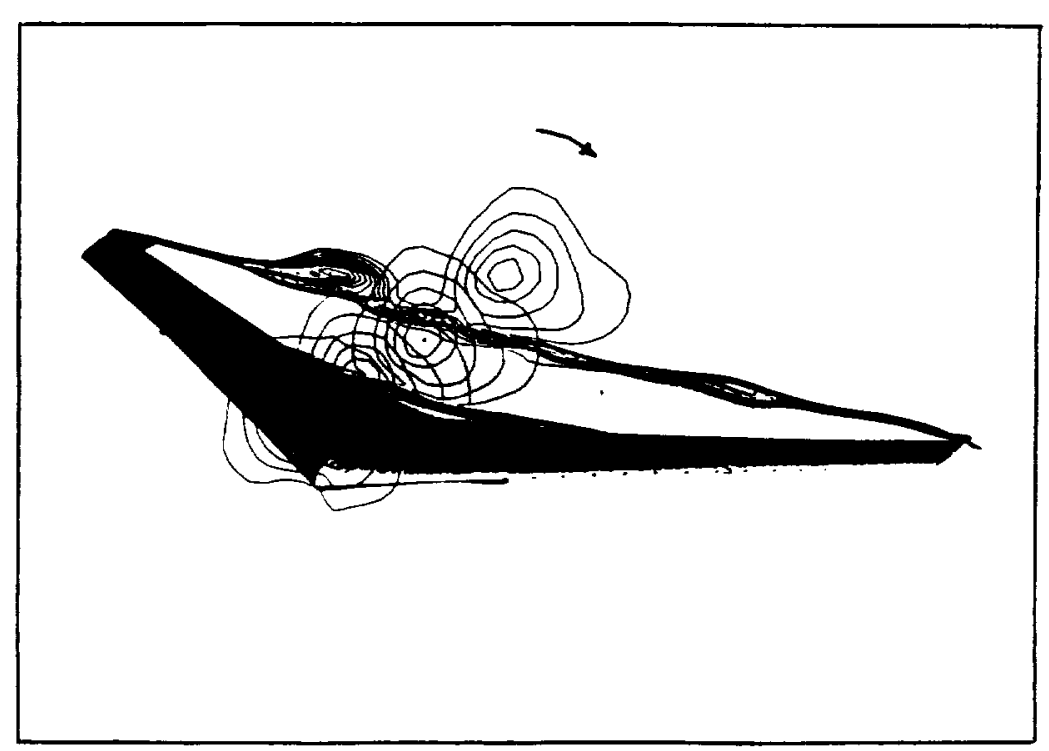

Fig. 6 CPT-contours at cross-flow planes of the follower wing and generator tip vortex, laminar flow, coarse grid, $\mathrm{t}=10$.



Fig. 7 Upper and lower surface CP-contours on the follower wing, laminar flow, coarse grid, $t=10$.
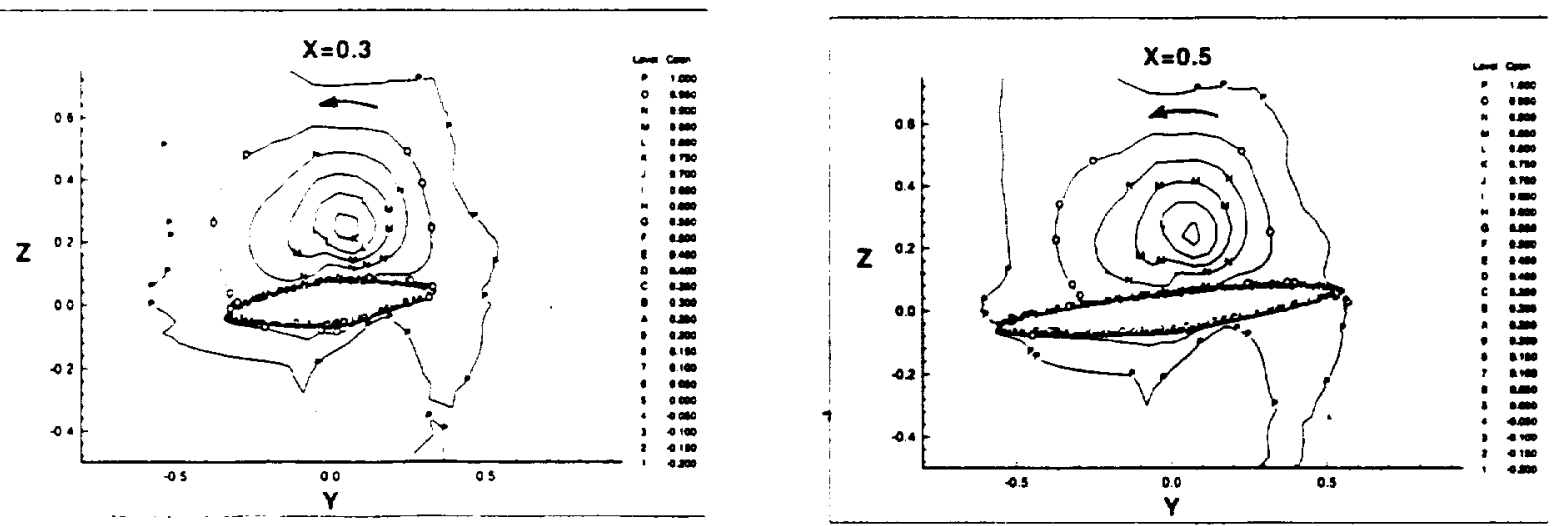

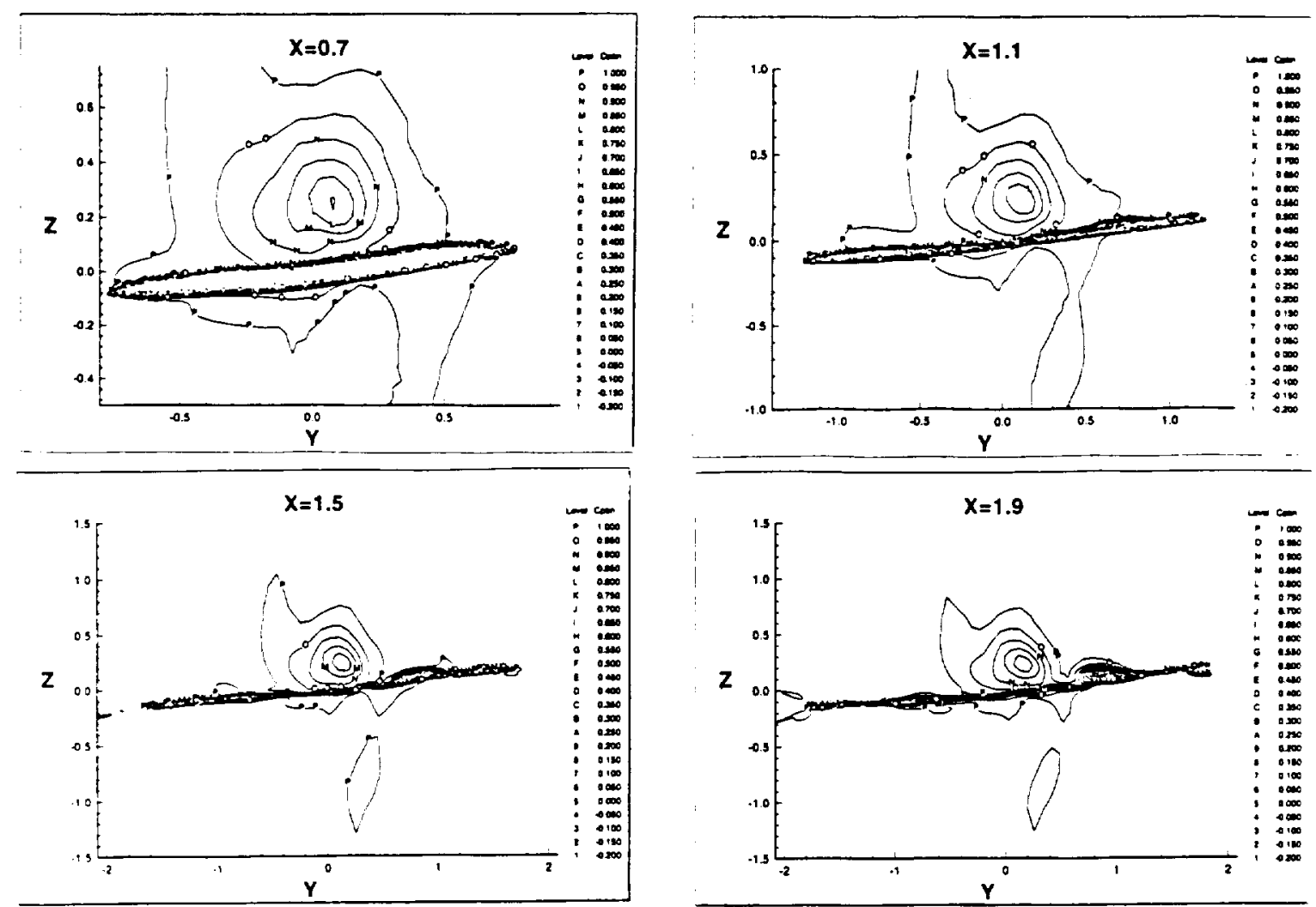

Fig. 8 CPT-contours in cross-flow planes of the follower wing and generator tip vortex, laminar flow, coarse grid, $t=10$.
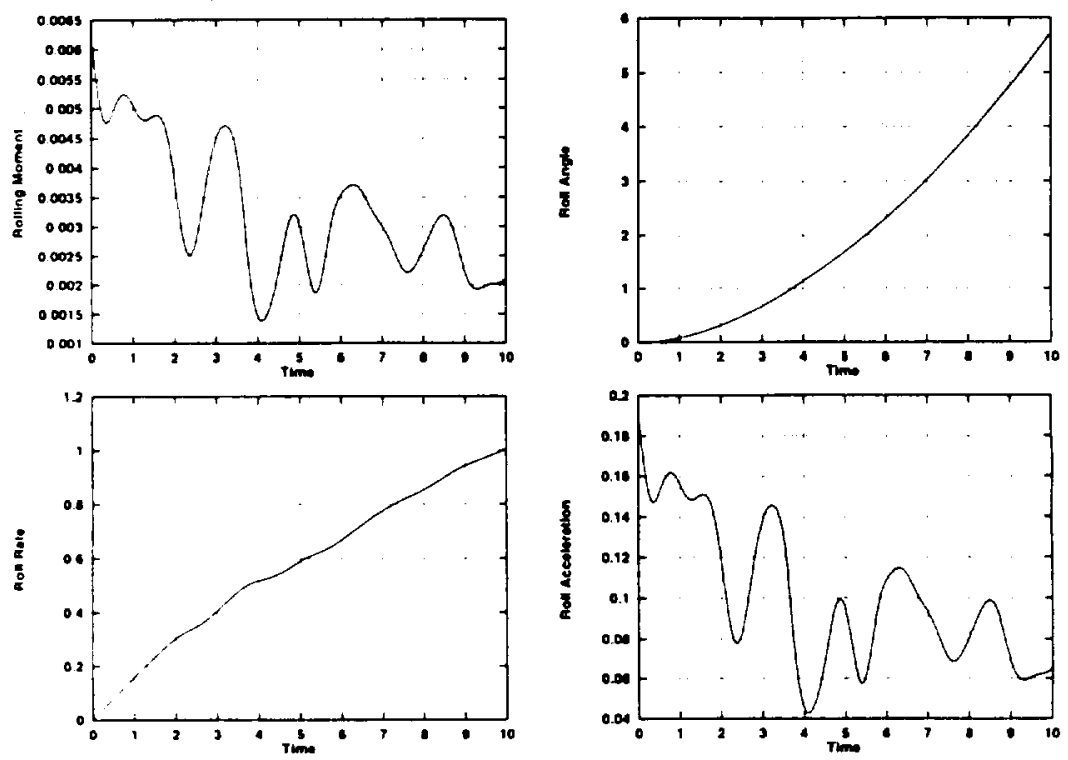

Fig. 9 Variations of $M_{x}, \theta, \dot{\theta}$ and $\ddot{\theta}$ with time, laminar flow, coarse grid.


Fig. 10 Variations of $M_{x}, M_{d}$ and $M_{r}$ with time, laminar flow, coarse grid. 


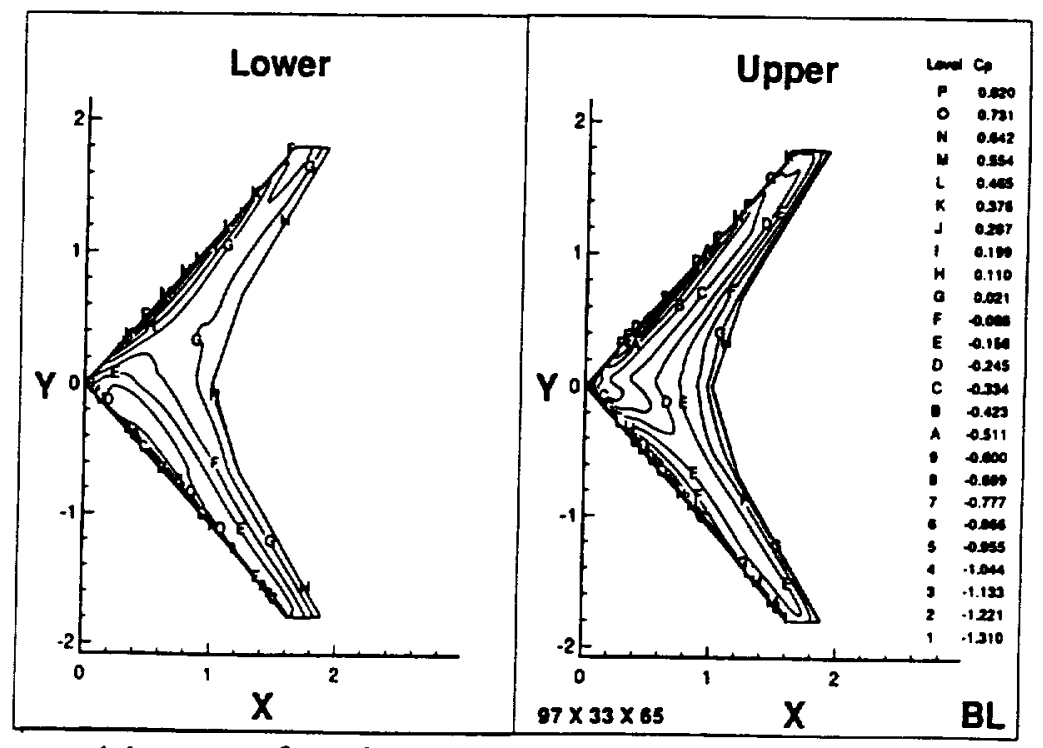

Fig. 11 Upper and lower surface CP-contours on the follower wing, turbulent flow, coarse grid, $\mathrm{t}=0$.
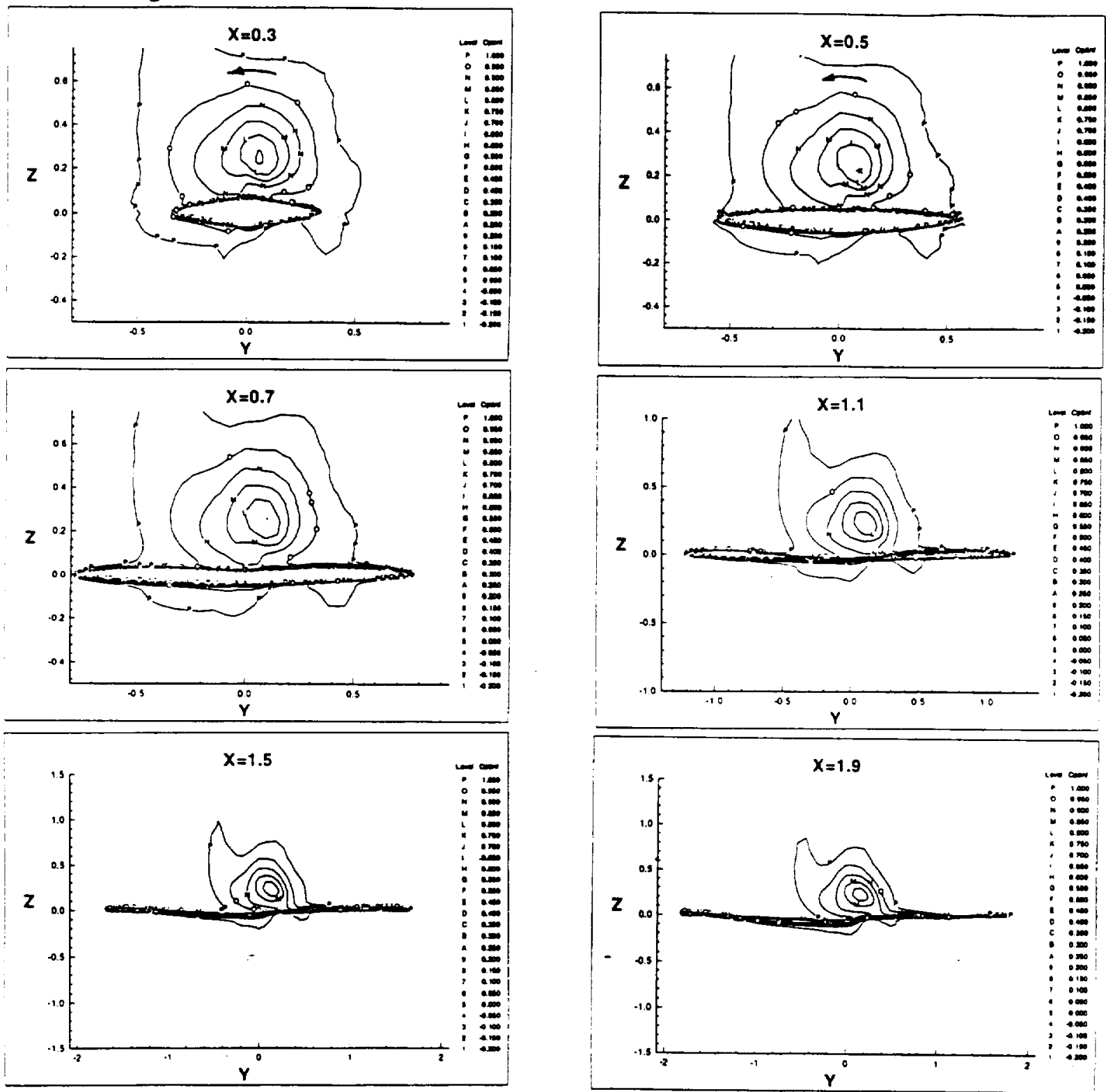

Fig. 12 CPT-contours in cross-flow planes of the follower wing and generator tip vortex, turbulent flow, coarse grid, $\mathrm{t}=0$. 


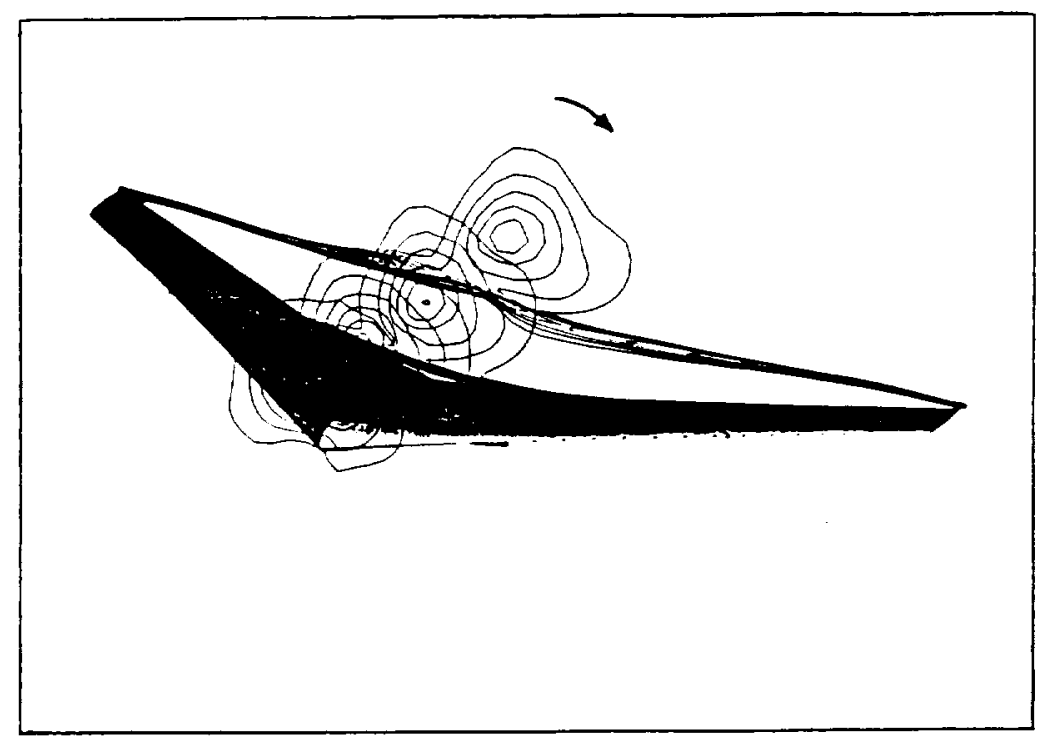

Fig. 13 CPT-contours at cross-flow planes of the follower wing and generator tip vortex, turbulent flow, coarse grid, $t=10$.

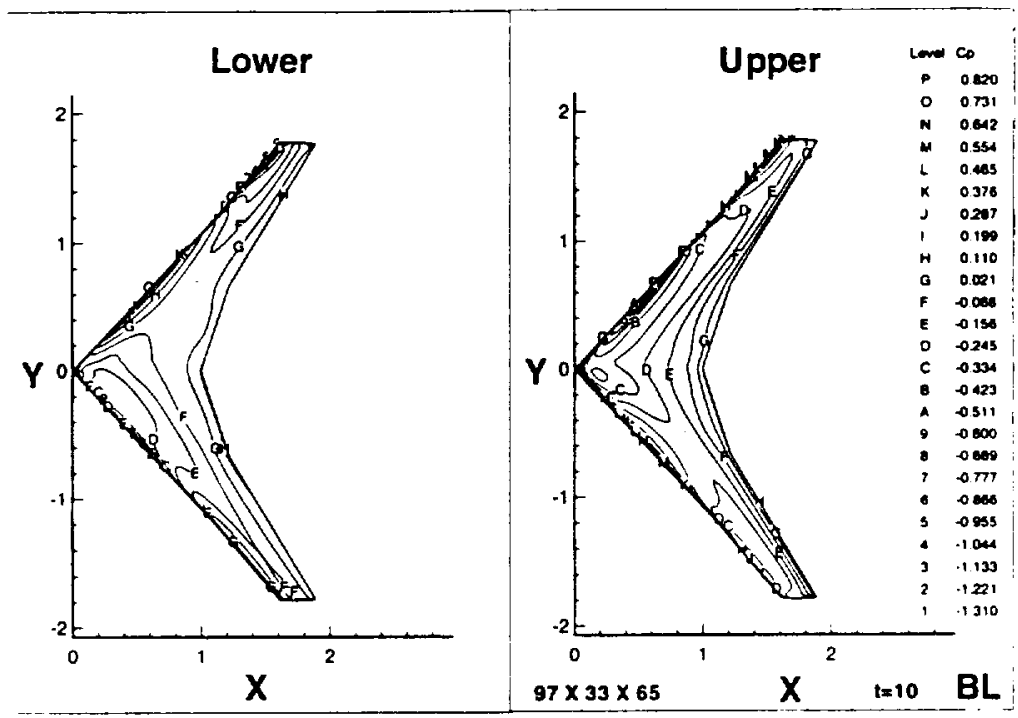

Fig. 14 Upper and lower surface CP-contours on the follower wing, turbulent flow, coarse grid, $\mathrm{t}=10$.



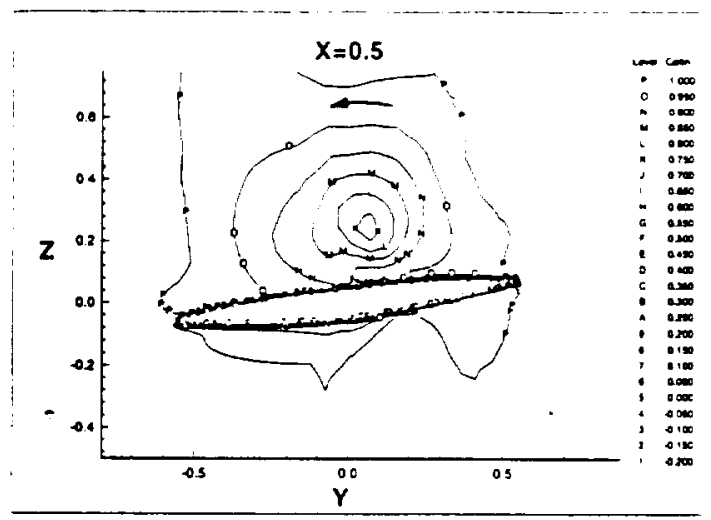

13 

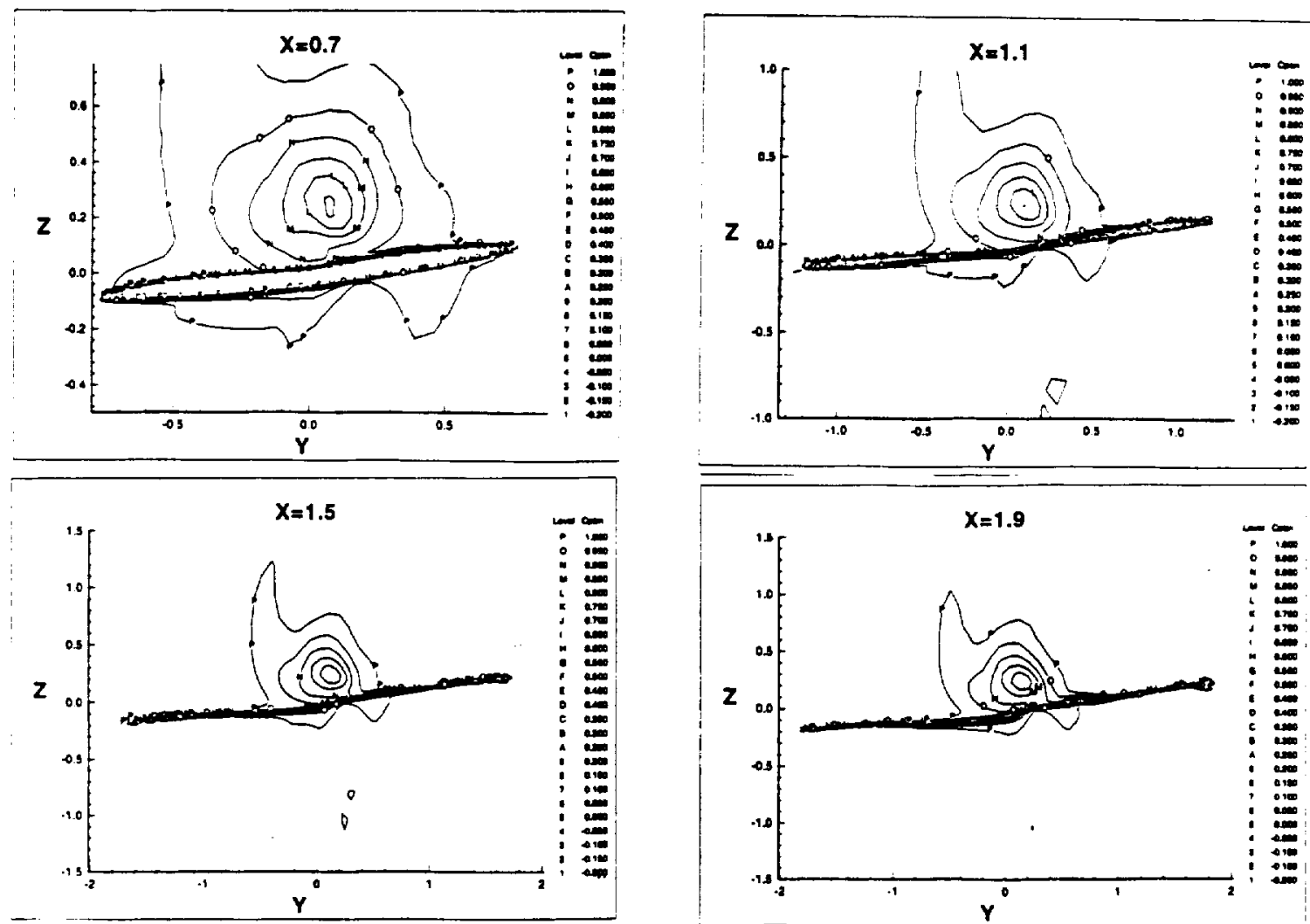

Fig. 15 CPT-contours in cross-flow planes of the follower wing and generator tip vortex, turbulent flow, coarse grid, $t=10$.
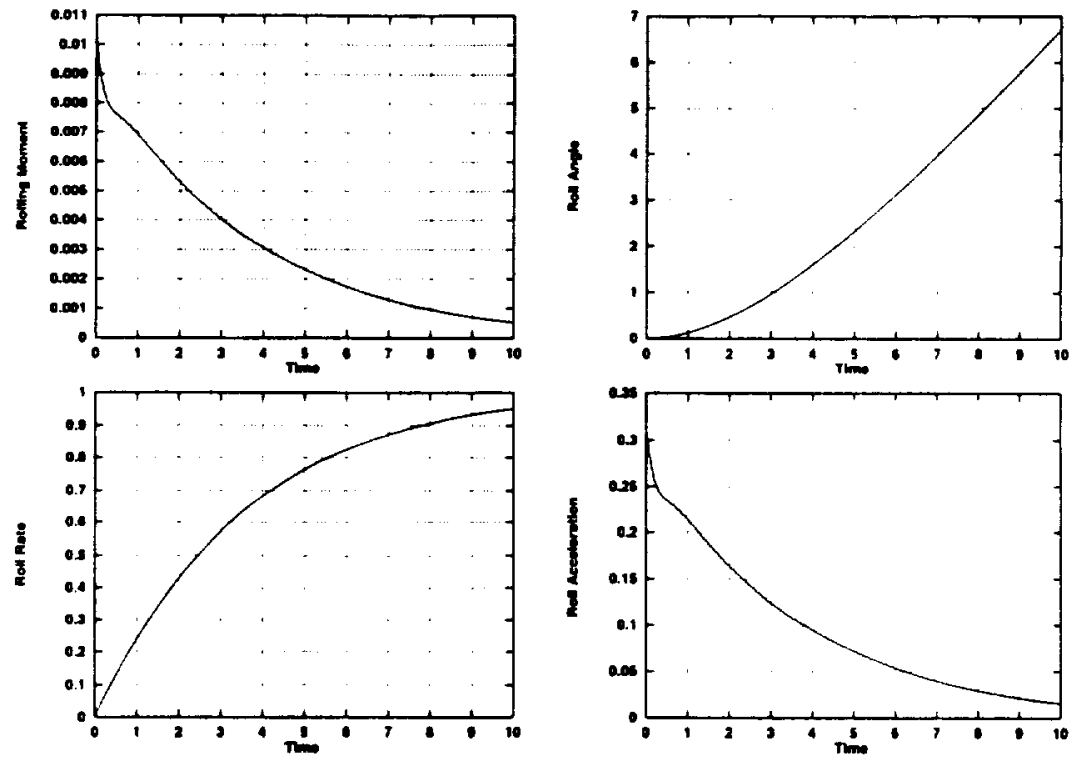

Fig. 16 Variations of $M_{x}, \theta, \dot{\theta}$ and $\ddot{\theta}$ with time, turbulent flow, coarse grid.
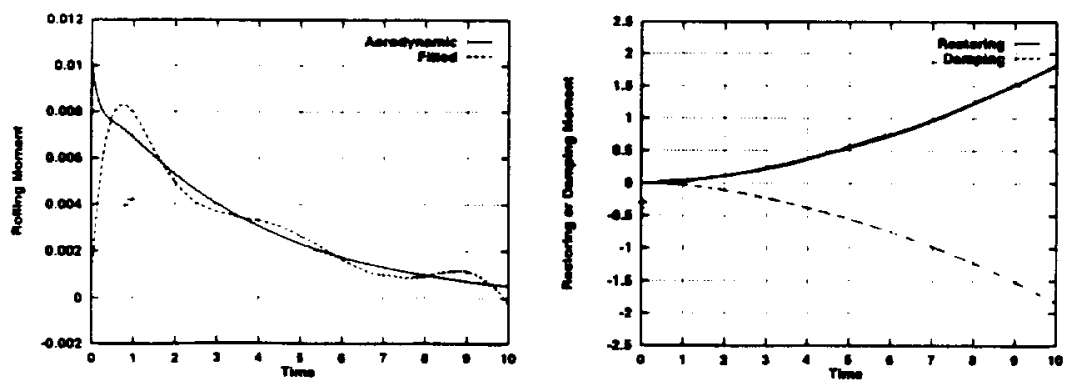

Fig. 17 Variations of $M_{x} . M_{d}$ and $M_{r}$ with time, turbulent flow, coarse grid. 


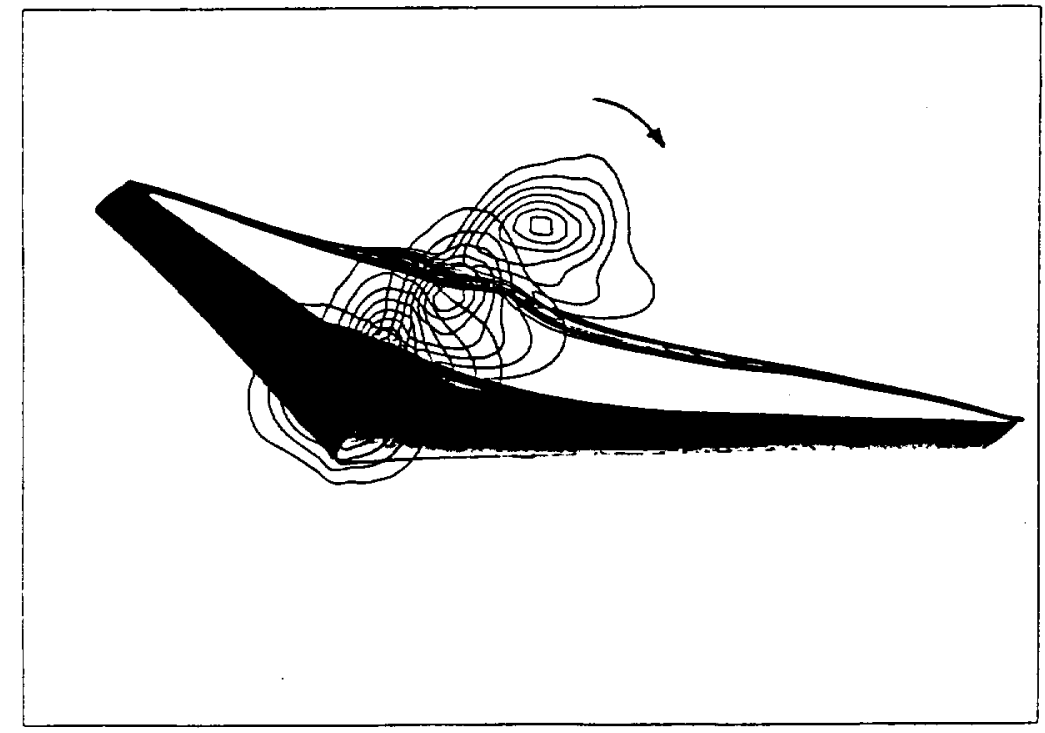

Fig. 18 CPT-contours at cross-flow planes of the follower wing and generator tip vortex, turbulent flow, fine grid $(149 \times 49 \times 97), t=10$.

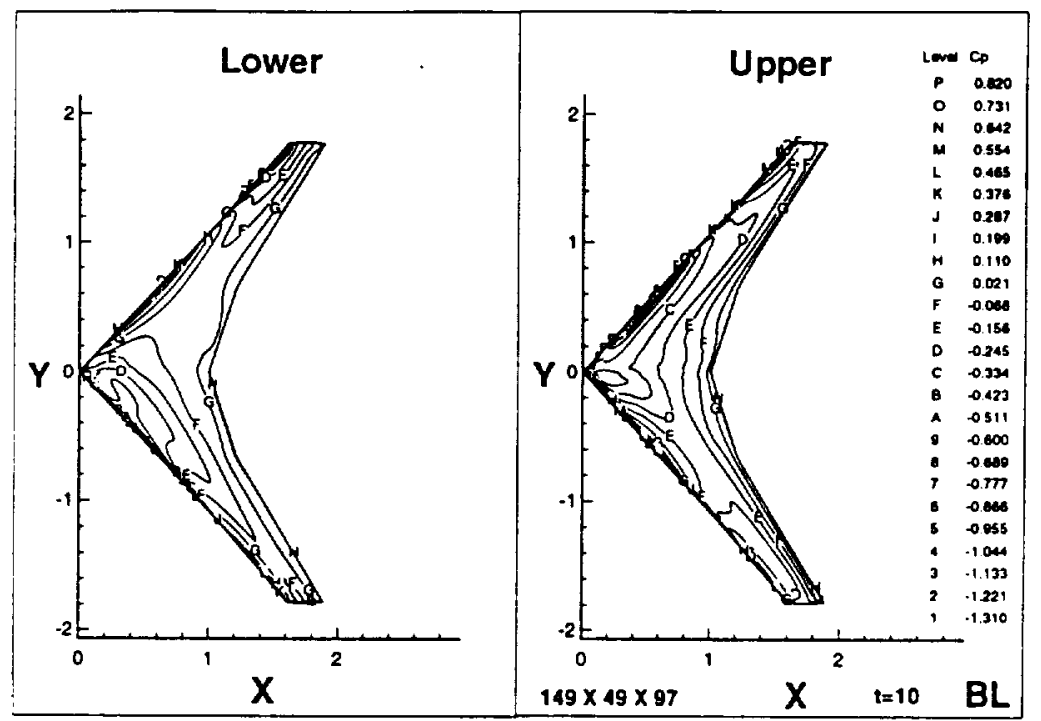

Fig. 19 Upper and lower surface CP-contours on the follower wing, turbulent flow, fine grid, $\mathrm{t}=10$.
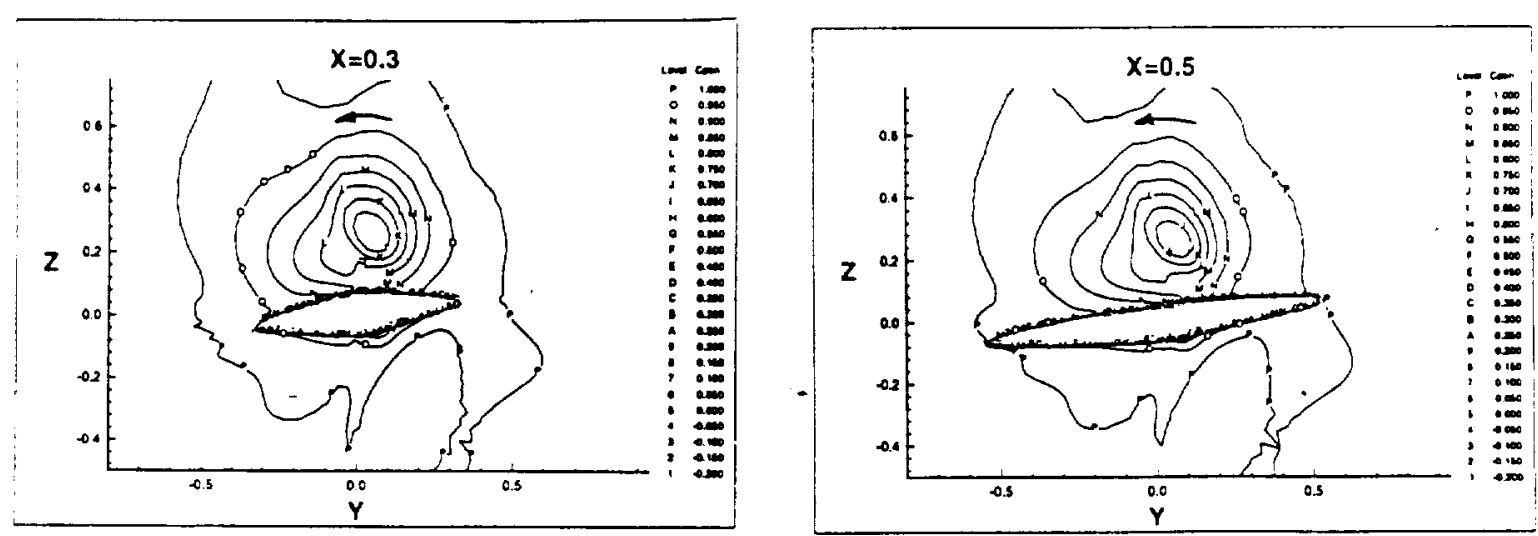

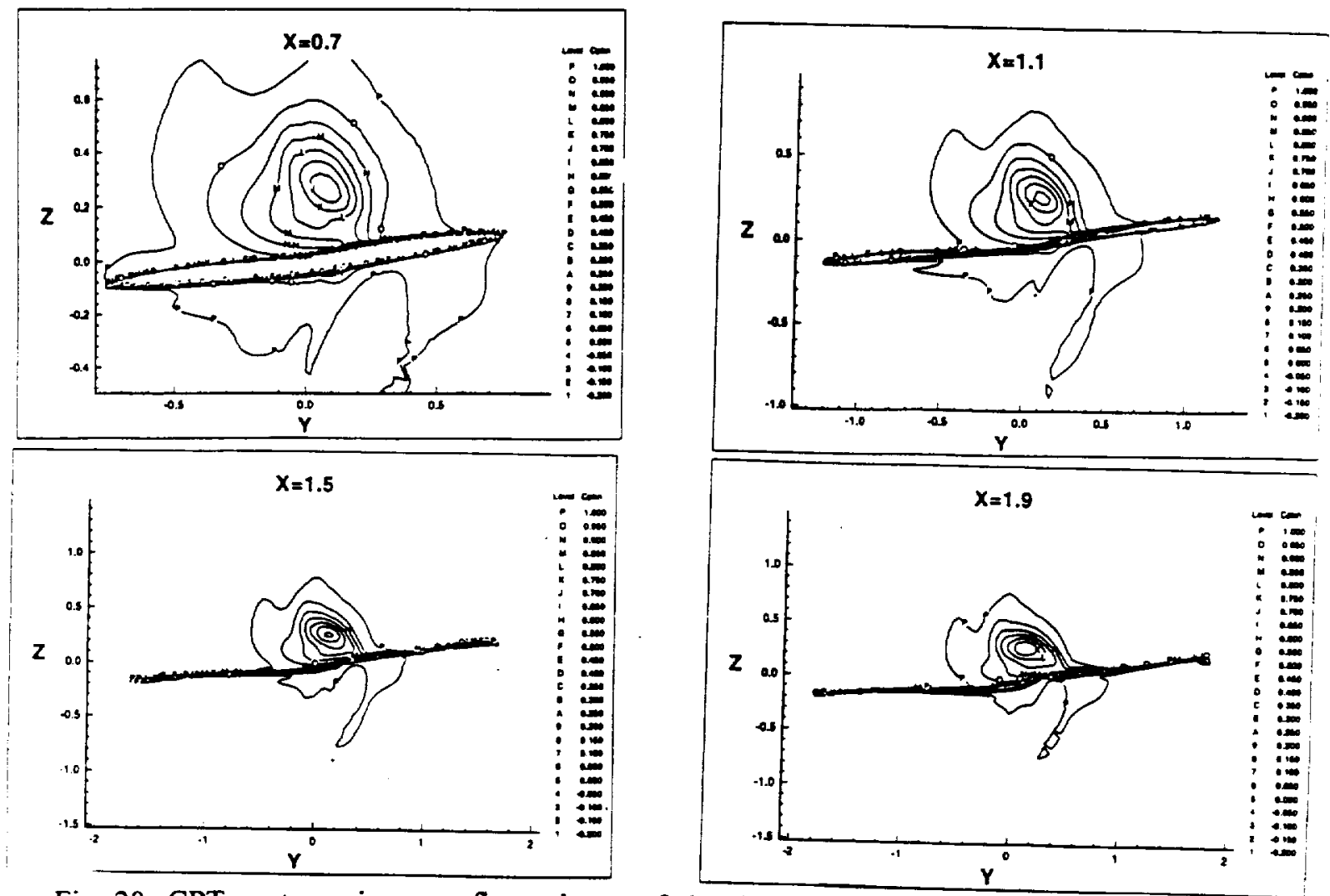

Fig. $20 \mathrm{CPT}$-contours in cross-flow planes of the follower wing and generator tip vortex, turbulent flow, fine grid, $t=10$.
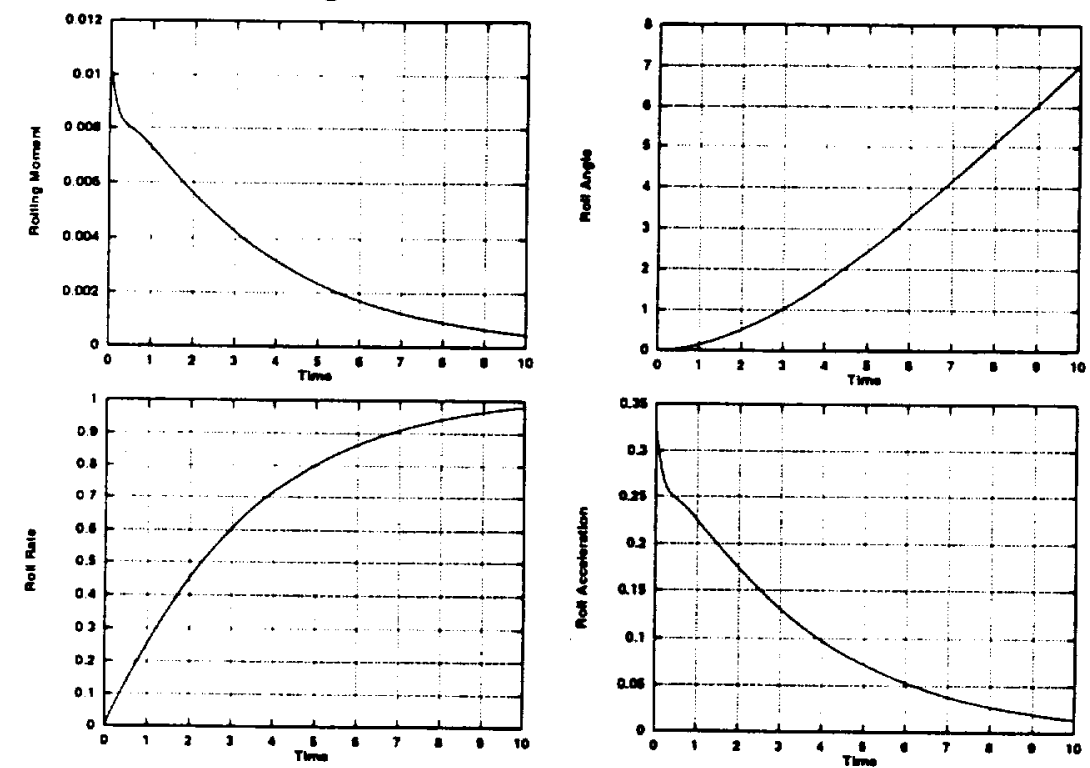

Fig. 21 Variation of $M_{x}, \theta, \dot{\theta}$ and $\ddot{\theta}$ with time, turbulent flow, fine grid.
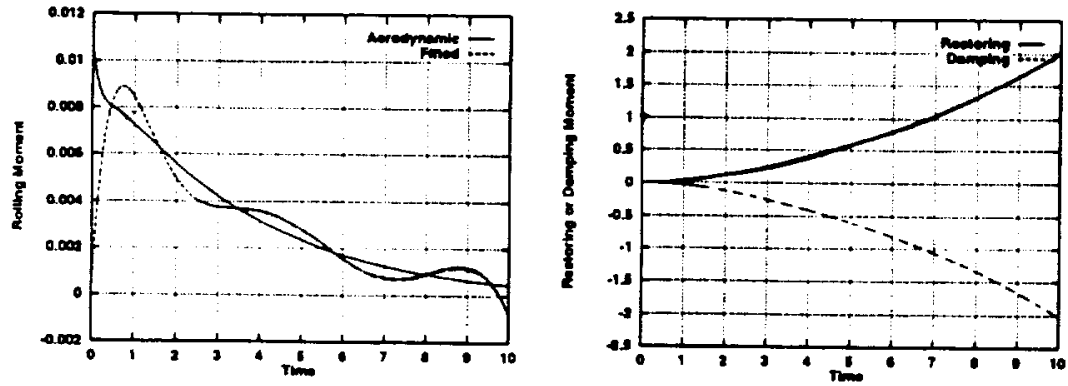

Fig. 22 Variations of $M_{x}, M_{d}$ and $M_{\tau}$ with time, turbulent flow, fine grid. 


\title{
AIAA 95-3470-CP
}

\section{PREDICTION OF NEAR-AND \\ FAR-FIELD VORTEX-WAKE \\ TURBULENT FLOWS}

Osama A. Kandil, Tin-Chee Wong, and Ihab Adam Old Dominion University, Norfolk, VA 23529, USA

C. H. Liu

NASA Langley Research Center, Hampton, VA 23681, USA

\author{
AIAA Atmospheric Flight \\ Mechanics Conference \\ Baltimore, MD, August 7-9, 1995
}





\title{
Prediction of Near- and Far-Field Vortex-Wake Turbulent Flows
}

\author{
Osama A. Kandil ${ }^{1}$, Tin-Chee Wong ${ }^{2}$, and Ihab Adam ${ }^{3}$ \\ Dept. of Aerospace Engineering \\ Old Dominion University, Norfolk, VA 23529, USA \\ and \\ C. H. Liu ${ }^{4}$ \\ Aerodynamic and Acoustic Methods Branch \\ NASA Langley Research Center, Hampton, VA 23681, USA
}

\begin{abstract}
Prediction of both the near- and far-field vortex-wake turbulent flows are presented. The Reynolds-averaged Navier-Stokes (NS) equations are solved using the implicit, upwind Roe-fluxdifferencing scheme. The turbulence models of Baldwin and Lomax, one-equation model of Spalart and Allmaras and two-equation shear stress transport model of Menter are implemented with the NS solver for turbulent-flow calculation. For the near-field study, computations are carried out on a fine grid for a rectangular wing with a NACA-0012 airfoil section and a rounded tip. The wing has an aspect ratio of 1.5 and is mounted inside a wind tunnel at an angle of attack of $10^{\circ}$. The focus of study is the tip-vortex development, the near vortex wake roll-up, and validating the results with the available experimental data. For the far-field study, the computations of vortexwake interaction with the exhaust plume of a single engine are carried out using overlapping zonal method for a long distance downstream of a Boeing 727 wing in a holding condition. The results are compared with those of an incompressible parabolized NS solver known as the UNIWAKE code.
\end{abstract}

\section{INTRODUCTION}

Recently, the volume of civil air transport using subsonic aircraft has increased at an alarming rate. With this increase in air traffic, several hazardous effects have recently become of primary concern. First, the landing and takeoff operations safety at busy airports of small and medium size aircrafts when they encounter high-intensity turbulent vortices emanating from large aircraft. The trailing aircraft, under the influence of those vortex trails, could suffer high rolling moments, loss of climb and structural damages. The vortices persist up to a few miles and several minutes before they decay.

Second, the adverse effects of the engine exhaust on the stratosphere and troposphere during cruise and holding conditions. A complex flow regime develop behind those aircraft which include the exhaust jet plume and the wake vortices that entrain the exhaust plumes and even- tually breal-up producing exhaust-atmosphere mixing region. Substantial adverse effects on the stratosphere and tropsphere are expected when the new fleet of High Speed Civil Transport (HSCT) is introduced in the early years of the next century. Recent research efforts are currently directed at understanding the adverse atmospheric effects of exhaust products from subsonic and supersonic civil transport aircrafts. These efforts include predicting the effects of exhaust plume on the dynamical, chemical and radiative stratospheric processes. A recent NASA report on these issues is published under the Atmospheric Effects of Aviation Project (AEAP), Ref. 1.

The origins of these hazardous effects are the vortex-wake flows and the engine jet exhaust plume and its interaction with the vortex-wake flows. The vortex-wake flows include the tipvortex development and roll-up formation while

\footnotetext{
${ }^{1}$ Professor, Eminent Scholar and Chairman of the Dept. Associate Fellow AIAA.

${ }^{2}$ Research Associate, Aerospace Engineering Department.

${ }^{3}$ Research Assistant, Member AIAA

'Senior Research Scientist, Associate Fellow AIAA.

copyright (C) 1995 by Osama A. Kandil. Published by the American Institute of Aeronautics and Astronautics, Inc. with permission.
} 
the jet exhaust plume include exhaust products, temperature field, and their fluid mechanics. At some distance downstream, the vortexwake flows entrain the exhaust plume and lateron the vortex-wake breaks up and dillutes the exhaust plume in the stratosphere.

The literature shows some experimental and computational investigations that model and analyze the roll-up of a tip vortex, the wakevortex interaction, and the merging and decay, as well as the hazardous effects of these phenomena on trailing aircraft. Hallock and Eberle ${ }^{2}$ gave a comprehensive review of the research on aircraft wake vortices in the United States through the mid-1970's.

Mathematical models and computational methods were developed with inviscid analysis 3-6. Although an inviscid model cannot describe the aging of the wake including its diffusion, it is still capable of representing the wake shape and its dynamics. The mathematical models used in the above references were based on the use of the point-vortex method to compute the motion of a finite number of point vortices. The threedimensional inviscid model which is based on the nonlinear vortex-lattice method, was used to compute the interference flow between the wings and the vortex-wake flows and to examine the hazardous effects. ${ }^{7}$

Viscous modeling of trailing vortices was studied in Ref. 8. Viscous interactions of vortex wakes and the effects of background turbulence, wind shear, and the ground on twodimensional vortex pairs with the Navier-Stokes equations were presented in Refs. 9 and 10, and the computer program is known as UNIWAKE. The interaction, merging, and decay of vortices in two- and three-dimensional spaces were studied in Refs. 11 and 12. A comprehensive review on the subject of viscous vortical flows can be found in a book by Ting and Klein. ${ }^{13}$ To estimate the effects of density stratification, turbulence, and Reynolds number on vortex wakes, an approximate model was recently developed by Greene. ${ }^{14}$ Later, Greene and his coworkers ${ }^{15}$ presented selected results for different aircraft vortices, including a juncture vortex, a lifting-wing vortex, and a wake vortex.

In recent papers by the present authors ${ }^{16,17}$, the compressible Reynoldsaveraged NS equations were used to compute and analyze vortex-wake flows of isolated and interacting wings. The emphasis of the papes was to study the effects of the near-wake vor tex flow on a small follower wing for two flow interference cases. The flux limiter in the flow solver was turned on and off to study it numer ical diffusive effect. The solution obtained witl: the full NS equations without a flux limiter gave the least numerically diffused tip-vortex core ir comparison with those solutions for which a flus limiter was used.

The multidisciplinary interaction of the aerodynamics and rigid-body dynamics betweer a single tip vortex and a trailing wing was com putationally investigated by present authors ${ }^{18}$ The time-accurate solutions of the unsteady Reynolds-averaged NS and Euler equations for rigid wing rolling motion provided the growt rate of the vortex-core size and the rolling. motion response of the wing. The Baldwin anc Lomax turbulence model was used for this case

Very recently, research interest has alsc, been focused on the near-field and far-field vortex-wake interaction with the engine exhaust plume including vortex-wake breaks up for both subsonic and high speed civil transport (HSCT', aircraft. Computational fluid dynamics plays a significant role in the prediction of the near-field and far-field vortex-wake flows. Once this is accomplished, the next step is to include the exhaust plume products and chemical reactions. and its interaction with the vortex-wake flows including vortex wake break-up.

Recently, more advanced turbulence models became readily available for use with NS solvers. In this paper, the algebraic Baldwin and Lomax (BL) turbulence model ${ }^{19}$, the oneequation Spalart and Allmaras (SA) model ${ }^{20}$, and the two-equation $k \omega(\mathrm{KW})$ model developed by Menter ${ }^{21}$ are used to study the tip-vortex and wake flows and the interaction of a tip vortex with the temperature field of an exhaust plume of a Boeing 727. Three key ingredients are considered for achieving accurate prediction of these flows. These are the grid fineness, turbulence model and computational efficiency. The results using different models are validated with the available experimental data or the results of the UNIWAKE solver.

\section{FORMULATIONS}

Two sets of the NS equations are used for this paper; a compressible set and an incom- 
pressible set. The compressible set is solved using a computer program known as FTNS3D which is used in reference 18 . This is the modified version of the well known CFL3D code. The incompressible set is solved using a computer program known as UNIWAKE which is used in references 9 and 22 .

The FTNS3D solver, described in detail in reference 18, uses an upwind, fluxdifference splitting, finite-volume scheme solving the unsteady, compressible, Reynolds-averaged NS equations. For the exhaust plume/tip vortex interaction case, the buoyancy body force caused by temperature difference is added as a source term without any approximation in the NS equations. For all results in this paper, upwind-biased spatial differencing is used for the inviscid terms, and flux limiter is not used. The viscous terms are differenced using second-order accurate central differencing. The resulting difference equations are solved implicitly in time with the use of the three-factor approximate factorization scheme. The one- and two- equation turbulence models are decoupled from the NS equations and partial differential equation(s) for turbulence model are solved sequentially at each time step thereafter.

The UNIWAKE solver consists of four computational modules: (1) Vortex Lattice: A program to compute the lift circulation distribution on an aircraft wing based on the given aerodynamic parameters and wing planform shape. (2) Betz: A program to generate the initial position and strength of rolled-up trailing edge vortices, given the lift circulation distribution. (3) Wake: A program to merge and decay these vortices downstream, interacting with engine jet exhaust temperature and chemical products, by solving the incompressible parabolized NS equations with fourth-order compact scheme in uniformly Cartesian system. The second derivatives in the streamwise direction is neglected in the governing equations. The effects of the turbulence are included through the algebraic Reynolds stress turbulence model. (4) Pinch: A program to follow the inviscid line vortex filament interaction of these vortices to instability and pinching, utilizing curved vortex elements. Recently, some aspects of the compressibility and density variation are taken into account in the latest version of UNIWAKE. It should be noted that the buoyancy body caused by temperature difference is based on the Boussinesq approximations which are not valid for high temperature differences. The detail of the governing equations and recent enhancements can be found in Ref. 22.

\section{BOUNDARY AND INITIAL CONDITIONS}

Boundary conditions are explicitly implemented. They include inflow-outflow conditions and solid boundary conditions. At the inflow boundaries, the velocity profiles are either prescribed or interpolated from the experimental data, while the Riemann-invariant boundarytype conditions are used. Temperature distribution is specified for the engine exhaust plume problem. At the outflow boundaries, pressure profile either interpolated from the experimental data or extrapolated from interior domain, while the other variables are determined as part of the solution. At the geometric plane of symmetry, periodic conditions is set. For tip-vortex and near-wake flow case, the tunnel walls are treated as inviscid surface, except for the root wall.

The initial conditions correspond to the uniform flow with no-slip and no-penetration conditions are used.

\section{RESULTS AND DISCUSSION}

\section{Near-Field Computation of the Tip- Vortex}

A rectangular wing with a NACA-0012 airfoil section and a rounded wingtip is considered. The wing has an aspect ratio of 1.5 and is mounted inside a wind tunnel at an angle of attack of $10^{\circ}$. The experimental work ${ }^{23}$ was done at the Fluid Mechanics Laboratory at NASA Ames research center. The flow is turbulent with a Reynolds number of $4.6 \times 10^{6}$, based on the root-chord length of the wing (c), and the flow Mach number is 0.3 .

A C-O grid is used with $197 \times 53 \times 97$ grid points in the streamwise wraparound, normal, and spanwise directions, respectively. A typical grid used in this study is shown in Fig. 1. The computational domain of the grid is generated based on the dimension of the test section and is nondimensionalized by the root-chord length. The origin of the axis is located at the quarter chord of the wing, the upper and lower walls are $x / c=0.3333$ above and below the wing, 
and the far-side wall is $x / c=1.0$ from the mounting wall. The inflow $(x / c=-0.4)$ and outflow $(x / c=1.42)$ conditions from the experimental data are imposed as the boundary conditions. The grid is clustered in the normal direction with the spacing of $5 \times 10^{-5}$ near the body and is also clustered at the leading and trailing edges of the wing. The mounting side and tip region of the wing are also clustered to have better flowfield resolution.

The steady-state solutions of the near-field have been obtained using two-level of multi-grid with $\mathrm{BL}, \mathrm{SA}$ and $\mathrm{KW}$ turbulence models. The typical convergent histories of the residual error and lift coefficient for the SA model is shown in Fig. 2. The residual error drops about two order of magnitude and lift coefficient gets to within $0.5 \%$ of its final values in 1800 cycles. The final lift coefficient is 0.52 at 2400 cycles. On the Cray-YMP computer, a typical case takes about 13 hours.

Comparison of surface-pressure coefficients (Cp) with the experimental data at three constant spanwise stations (left column) and rounded tip regions (right column) with $\mathrm{BL}, \mathrm{SA}$ and $\mathrm{KW}$ models is shown in Fig. 4. The definition of the $\theta$ (theta) at the wing-tip region is shown in Fig. 3. The results with $\mathrm{BL}$ and SA model are better than those with KW model on the wing surface. Obviously, there is massively separated region between $x / c=0.4$ and $x / c=0.7$ at the wing-tip region. The KW model poorly predicts the $\mathrm{Cp}$ particularly at the trailing edge of the wing.

The side-by-side comparison of the crossflow total-pressure contours ( $\mathrm{Cpt}$ ) at two chordwise stations at $x / c=0.63$ (on the wing) and $x / c=1.19$ (near wake) are shown in Figures 5 and 6 . One can see the roll-up of the vortex around the tip from the low surface to the upper surface, which corresponds to the large pressure gradient at the wing-tip region. Then, the vortex moves upward and outboard as moving in the downstream direction. The development of the wing tip-vortex shows evidence of a good qualitative agreement with experimental data. The location of the tip-vortex using BL and SA models is in fair agreement with that of the experimental data while the results of the $\mathrm{KW}$ model show the vortex is located more outboard and closer to the surface. However, the results predicted by the KW model show better compari- son with experimental data in the wake region at the chord station $x / c=1.19$. The vortex-wake structure of the $\mathrm{KW}$ model show less diffusion than that of BL and SA models. The close-up of the crossflow velocity magnitude contours (Vc), shown in Fig. 7, confirms that results from the two-equation model predict tighter vortex core than those of the BL and SA models in the near wake. However, the tip-vortex core still shows diffusion in comparison with the experimental data due to the lack of grid resolution in the core region.

\section{Far-Field Computation of Tip- Vortex/Plume Interaction}

For this case, a tip-vortex/plume interaction of a Boeing 727 wing is considered. The study addresses the computation and analysi.; of the vortex-wake interaction with the exhaust plume for a long distance downstream of the wing. The tip-vortex of the Boeing 727 wing is assumed to be fully rolled-up and the genera. tion region is not included in the computation. The initial velocity and pressure profiles are gen. erated using the vortex-lattice and Betz modules: of the UNIWAKE.

The tip-vortex flow is assumed fully turbu. lent with a Reynolds number of $1 \times 10^{6}$, based or the half semi-span of the wing ( $s)$, and the flow Mach number is 0.3. The tip-vortex and exhaust. plume are located at $y / s=0.76, z / s=0.0$; and $y / s=0.4, z / s=-0.1$, respectively. The! peak temperature at the center of the engine is two times the ambient temperature. The inflow crossflow velocity $(\mathrm{Vc})$, and temperature distri. butions $(\mathrm{T})$ at $x / s=0.0$ are shown in Fig. 8 .

The NS equations are used to compute. the development of this vortex and its inter. action with the plume for a long distance up to $x / s=110$. The computations of FTNS3D solver are carried out using an overlapping zonal method and the schematic sketch is shown in Fig. 9. For each stage of computation, a fine grid zone is used. The downstream distance (a) and the overlapping or buffer zone (b) should be chosen such that the downstream effects can be minimized. In this study, the following values are chosen; $\mathrm{a} / \mathrm{s}=8.0, \mathrm{~b} / \mathrm{s}=2.0$, and $\mathrm{X} \max / s=110.0$ (equivalent to one mile behind the inflow plane). A rectangular grid of $201 \times 41 \times 51$ grid points in $\mathrm{x}, \mathrm{y}$, and $z$ directions, respectively, are used.

The computations are carried out start- 
ing from the inflow station of $x / s=0.0$ up to $x / s=110.0$ using the FTNS3D using KW model and UNIWAKE solvers on the same grid resolution in the crossflow plane. The results of the crossflow $\mathrm{T}$ and Vc contours at selected chordwise stations with FTNS3D (left column) and UNIWAKE (right column) solvers are shown in Figures 10-12. All the results are plotted in reference to the origin and the corresponding axes at the inflow section. The results show the evolution of the tip-vortex interaction with the plume as it is advanced in the downstream. The velocity field of the tip vortex induces the exhaust plume movement upward and wrapping around the tip-vortex while cooling it down.

The results of the FTNS3D code show that tip-vortex center first moves upward and inward, and then descends as it advances in the downstream direction. On the other hand, the UNIWKAE results show the tip-vortex center continuously descends and stays almost at the same lateral location of $y / s=0.76$. Since the UNIWAKE code is a space-marching NS solver, the step size in the streamwise direction is determined based on extrapolated changes in the flow variables at each station. The code also has a dynamic upwash adjustment that seeks to retain the perceived vortical mean location at the position of $z / s=0.0$. The upwash overcomes the inherent downwash of the typical vortical wake structure. The discrepancies between the two solvers are due to the dynamic upwash adjustment of the UNIWAKE code and the fully threedimensional computations of the FTNS3D code. The results with the UNIWAKE solver show more diffusion as compared with the FTNS3D results. One of the numerical parameters known as the turbulent macroscale $(\Lambda)$ in the UNIWAKE code has to be adjusted from the default values of 0.2 to 0.04 in order to obtain adequate lessdiffused results. The larger values of $\Lambda$ (results are not shown here) show even more diffusive effect as compared with the FTNS3D results.

\section{CONCLUDING REMARKS}

The computational solution of the unsteady, compressible, Reynolds-averaged NavierStokes equations is used to predict the near- and far-field vortex-wake turbulent flows. Three different turbulent models have been used with the NS equations which include the Baldwin and Lomax model, Spalart and Allmaras model and
KW model of Menter. For the near-field vortexwake application, the focus is directed on the development and roll-up of the tip vortex for a subsonic wing while for the far-field vortexwake application, the focus is directed on the interaction of a tip-vortex of a typical 727 Boeing wing with the temperature field of an engine exhaust plume. The results of the first application have been compared with the available experimental data. The comparison shows that the computed results with the BL and SA models are in good agreement with the experimental data than those results with the KW model. The results of the second application are compared with those of the UNIWAKE code. The UNIWAKE results show different motion of the vortex center along with the exhaust plume as it advances downstream, than that of the full Navier-Stokes code. The difference is attributed to the approximations associated with the UNIWAKE code.

\section{ACKNOWLEDGEMENT}

For the first three authors, this work is supported by the NASA Langley Research Center under Grant No. NAG-1-994. The computational resources provided by the NAS Center at Ames and the NASA Langley Research Center are appreciated and recognized.

\section{REFERENCES}

1. Stolarski, R. S. and Wesoky, H. L., Editors, "The Atmospheric Effects of Stratospheric Aircraft: A Fourth Program Report," NASA Ref. Pub. 1359, January 1995.

2. Hallock, J. N. and Eberle, W. R., "Aircraft Wake Vortices: A State-of-Art Review of the United States R\&D Program," FAA Rept. FAA-RD-77-23, Feb. 1977.

3. Chorin, A. J. and Bernard, P. S., "Discretization of a Vortex Sheet, with an Examples of Roll-Up," Journal of Computational Physics, Vol. 13, Nov. 1973, pp. 423429.

4. Hackett, J. E. and Evans, M. R., "Vortex Wakes Behind High Lift Wings," Journal of Aircraft, Vol. 11, July 1974, pp. 397-400. 
5. Iversen, J. D. and Bernstein, S., "Trailing Vortex Effects on Following Aircraft," Journal of Aircraft, Vol. 11, Jan. 1974, pp. 60-61.

6. Rossow, V. J., "Inviscid Modeling of Aircraft Trailing Vortices," Proceedings of NASA Symposium on Wake Vortex Minimization," Washington, D. C., Feb. 1976, pp. 4-54.

7. Kandil, O. A., Mook, D. T., and Nayfeh, A. H., "Application of the Nonlinear Vortex-Lattice Concept to AircraftInterference Problems," Advances in Engineering Science, NASA CP-2001, Vol. 4, Nov. 1976, pp. 1321-1326.

8. McCormick, B. W., Tangler, J. L., and Sherrieb, H. E., "Structure of Trailing Vortices," Journal of Aircraft, Vol. 5, No. 3, May-June 1968, pp. 260-267.

9. Bilanin, A. J., Teske, M. E., and Williammson, G. G., "Vortex Interactions and Decay in Aircraft Wakes," AIAA Journal, Vol. 15, No. 2, Feb. 1977, pp. 250-260.

10. Bilanin, A. J., Teske, M. E., and Hirsh, J. E., "Neutral Atmospheric Effects on the Dissipation of Aircraft Vortex Wakes," AIAA Journal, Vol. 16, No. 9, Sept. 1978, pp. 956-961.

11. Liu, C. H., Krause, E., and Ting, L., "Vortex Dominated Flow with Viscous Core Structure," AIAA 85-1556, July 1985.

12. Liu, C. H., Tavantzis, J., and Ting, L., "Numerical Studies of Motion and Decay of Vortex Filaments-Implementing the Asymptotic Analysis," AIAA Journal, Vol. 24, 1986, pp. 1290-1297.

13. Ting, L. and Klein R., Viscous Vortical Flows, Lecture Notes in Physics, Vol. 374, Springer-Verlag Berlin Heidelberg, 1991.

14. Greene, G. C., "An Approximate Model of Vortex Decay in the Atmosphere," Journal of Aircraft, Vol. 23, No. 7, July 1986, pp. $566-573$.
15. Greene, G. C., Lamar, J. E., and Kuben dran, L. R., "Aircraft Vortices: Juncture, Wing and Wake," AIAA Paper 88-3743, July 1988.

16. Kandil, O. A., Wong, T. C., and Liu, C. H., "Analysis and Computation of Trail. ing Vortices and Their Hazardous Effects,' FAA International Symposium, Washing. ton, D.C., Oct. 29-31, 1991, Vol. 2 . pp. 36.1-36.24.

17. Wong, T. C., Kandil, O. A., and Liu C. H., "Computation of Wake-Vortex Flows and Control of Their Effects on Trailing Wings," AIAA 4429-92-CP, Aug 1992, Vol. 1, pp. 280-292.

18. Kandil, O. A., Wong, T. C., and Liu. C. H., "Turbulent Flow over a $747 / 747$ Generator/Follower Configuration and its Dynamic Response," AIAA 94-2383, June 1994.

19. Baldwin, B., and Lomax, H., "Thin Layer Approximation and Algebraic Model for Separated Turbulent Flow," AIAA 78-257, Jan. 1978

20. Spalart P. R., and Allmaras, S. R., "A OneEquation Turbulence Model for Aerodynamics Flows," AIAA 92-0439, Jan. 1992.

21. Menter, F. R., and Rumsey, C. L., "Assessment of Two-Equation Turbulence Models for Transonic Flow," AIAA 94-2343, June 1994.

22. Quackenbush, T. R., Teske, M. E., and Bilanin, A. J., "Enhancement of UNIWAKE Exhaust Dynamics and Chemistry," C.D.I. Report No. 94-04.

23. Chow, J. S., Zilliac, G. G., and Bradshaw, $P$., "Measurement in the Near-Field of a Turbulent Wingtip Vortex," AIAA Paper 93-0551, Jan. 1993. 




Figure 1: Typical C-O mesh of $A R=1.5$ rectangular wing.
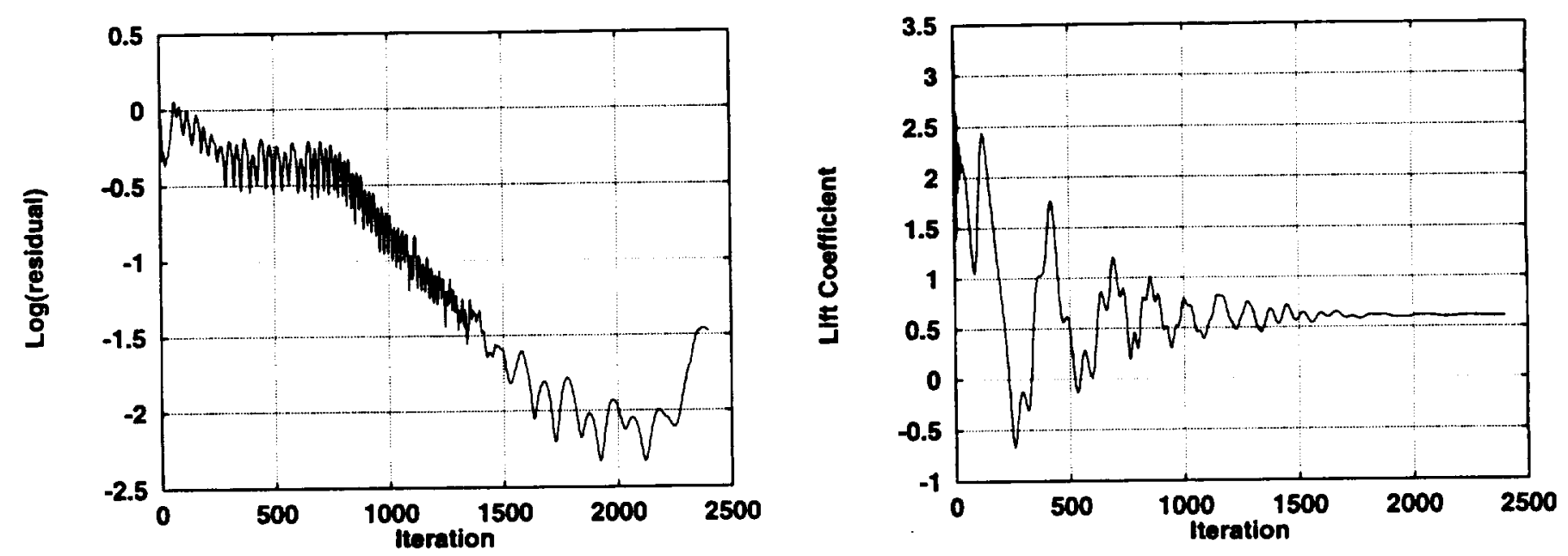

Figure 2: Typical convergent histories of $\log ($ residual) and lift coefficient; SA turbulence model.

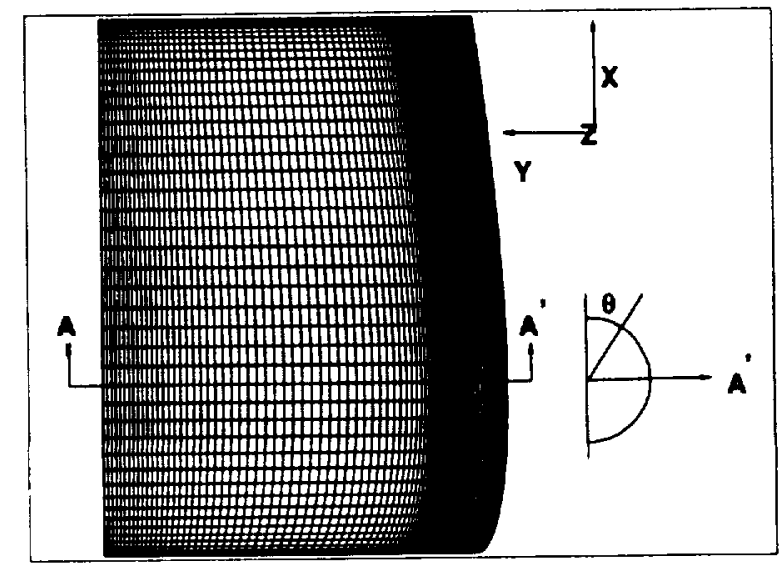

Figure 3: Definition of $\theta$ at the wing-tip region. 

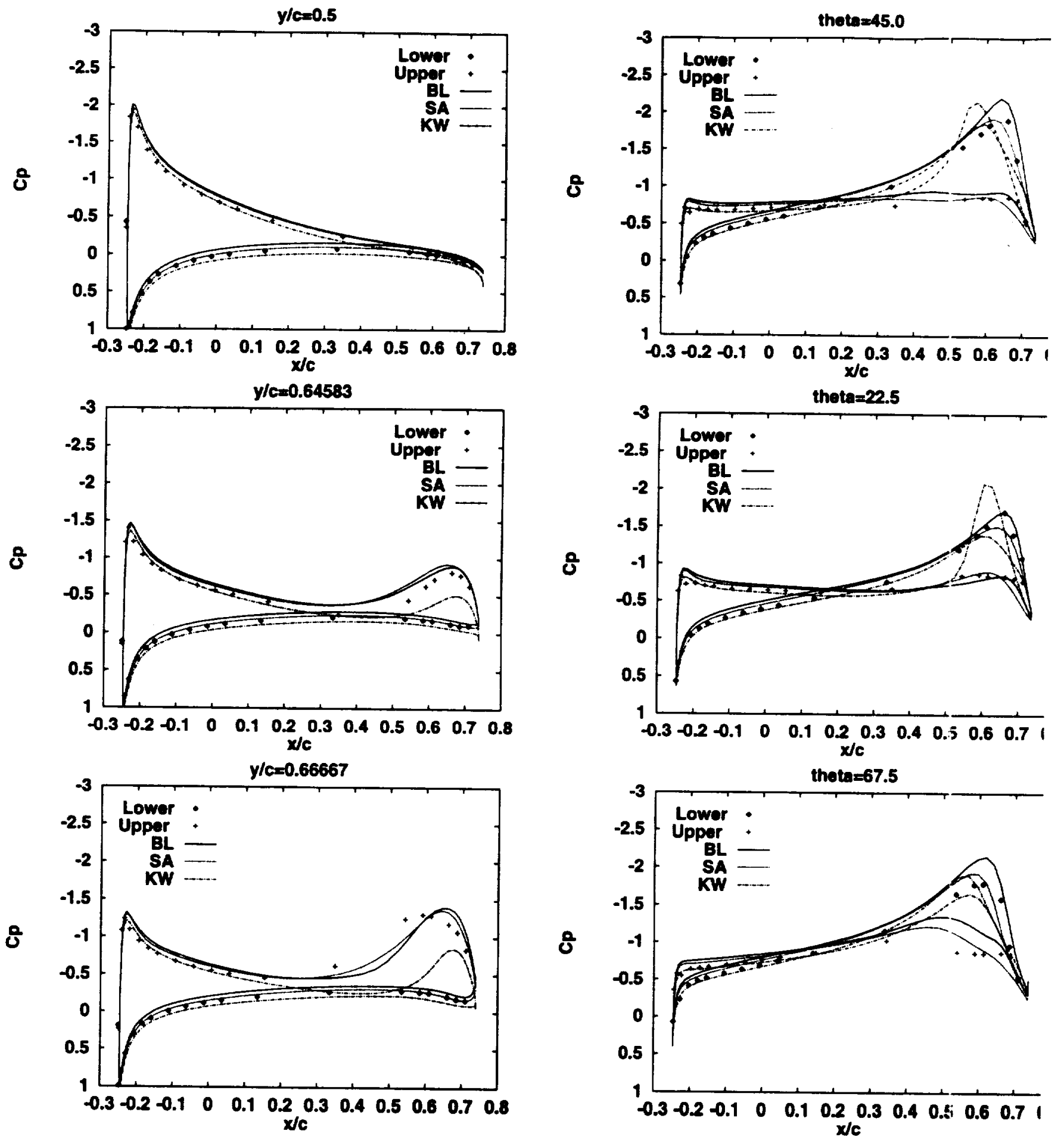

Figure 4: Comparison of surface-pressure coefficients with the experiment. 



Figure 5: Comparison of crossflow Cpt contours at two chordwise stations; top-experiment, secondBL, third-SA and bottom-KW. 

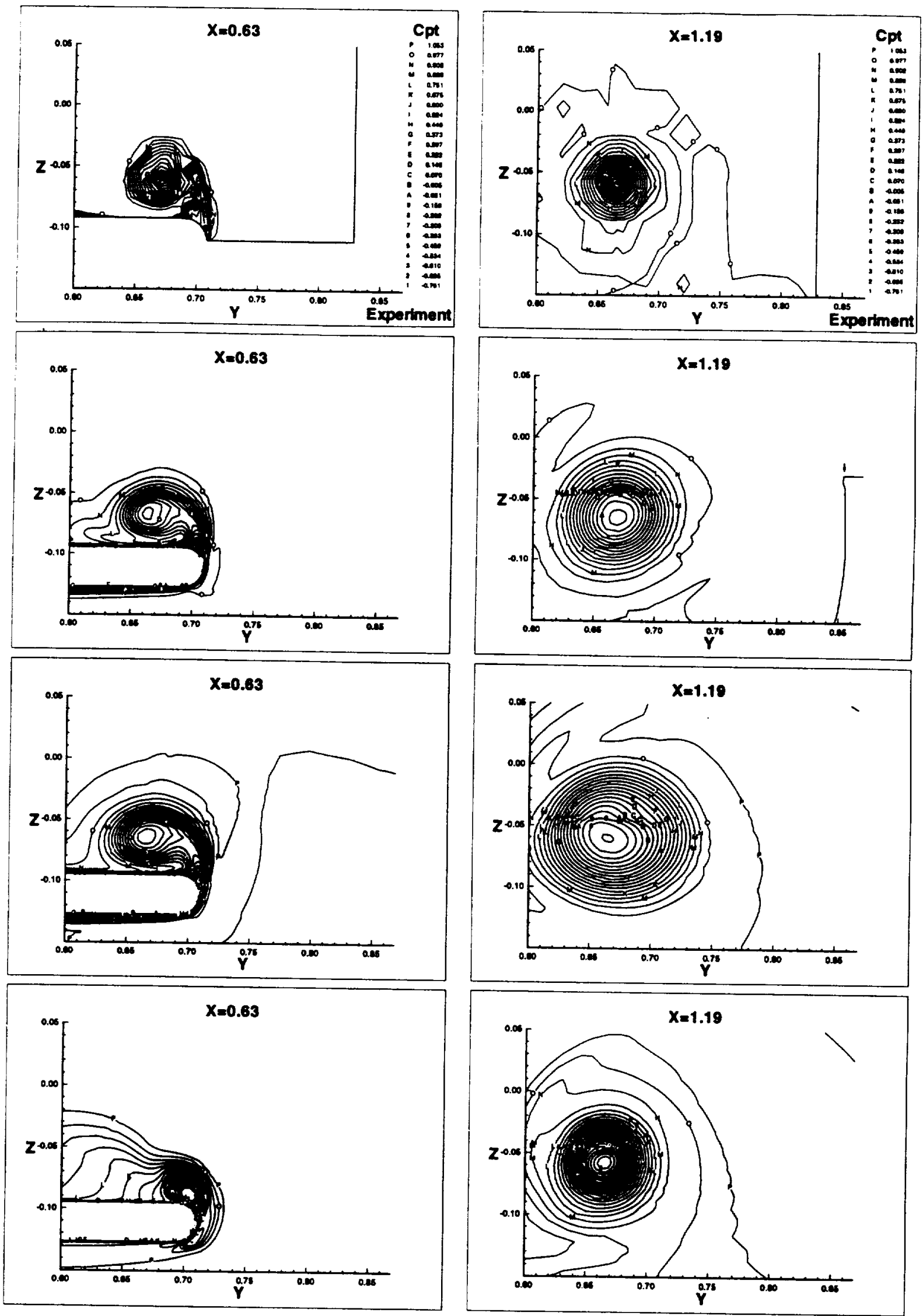

Figure 6: Close-up of crossflow Cpt contours at two chordwise stations; top-experiment, second-BL, third-SA and bottom-KW. 



Figure 7: Close-up of crossflow velocity contours at two chordwise stations; top-experiment, second$\mathrm{BL}$, third-SA and bottom-KW. 




Figure 8: Crossflow velocity and temperature contours at the inflow section.

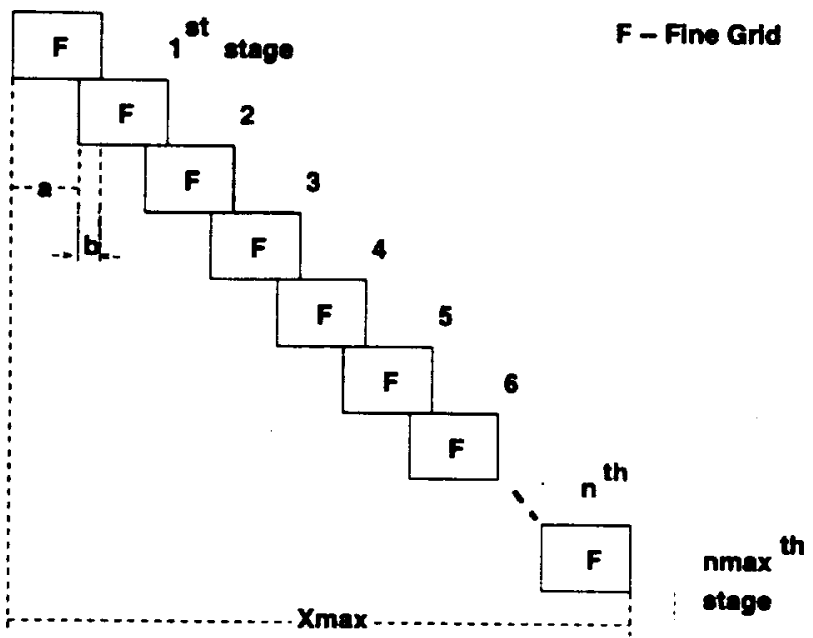

Figure 9: Schematic sketch of the overlapping zonal method.
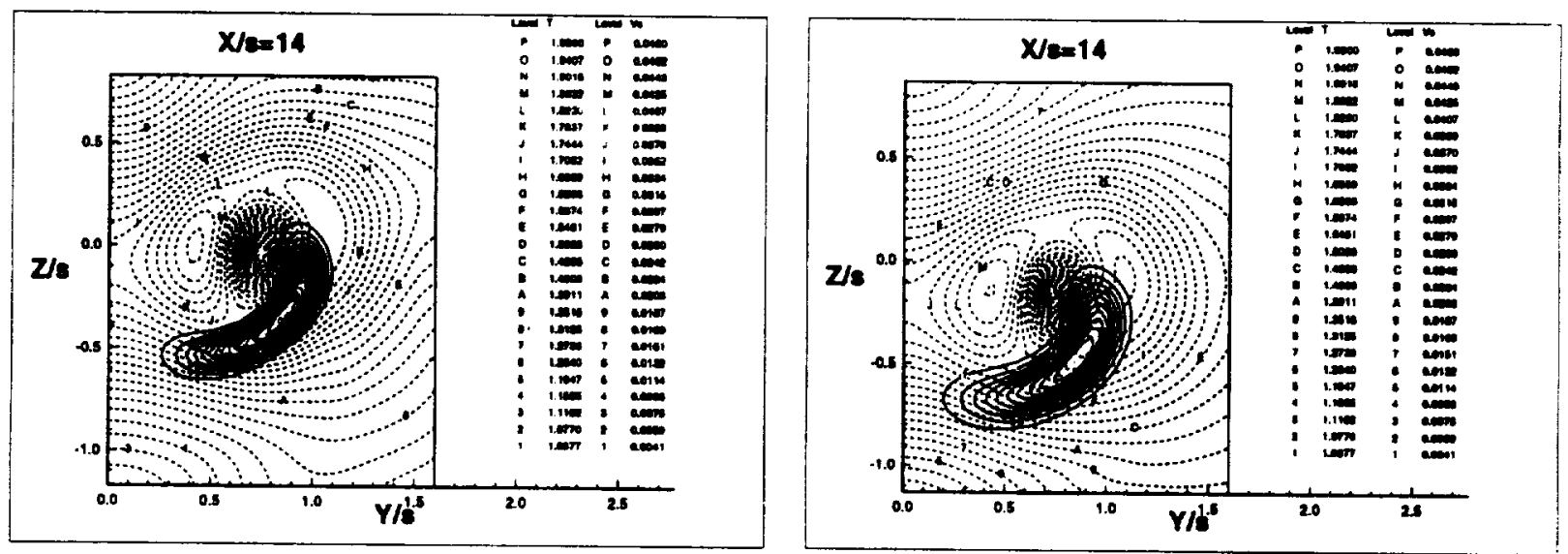

Figure 10: Comparison of crossflow $T$ and Vc contours at one downstream station; left-FTNS3D and right-UNIWAKE. 

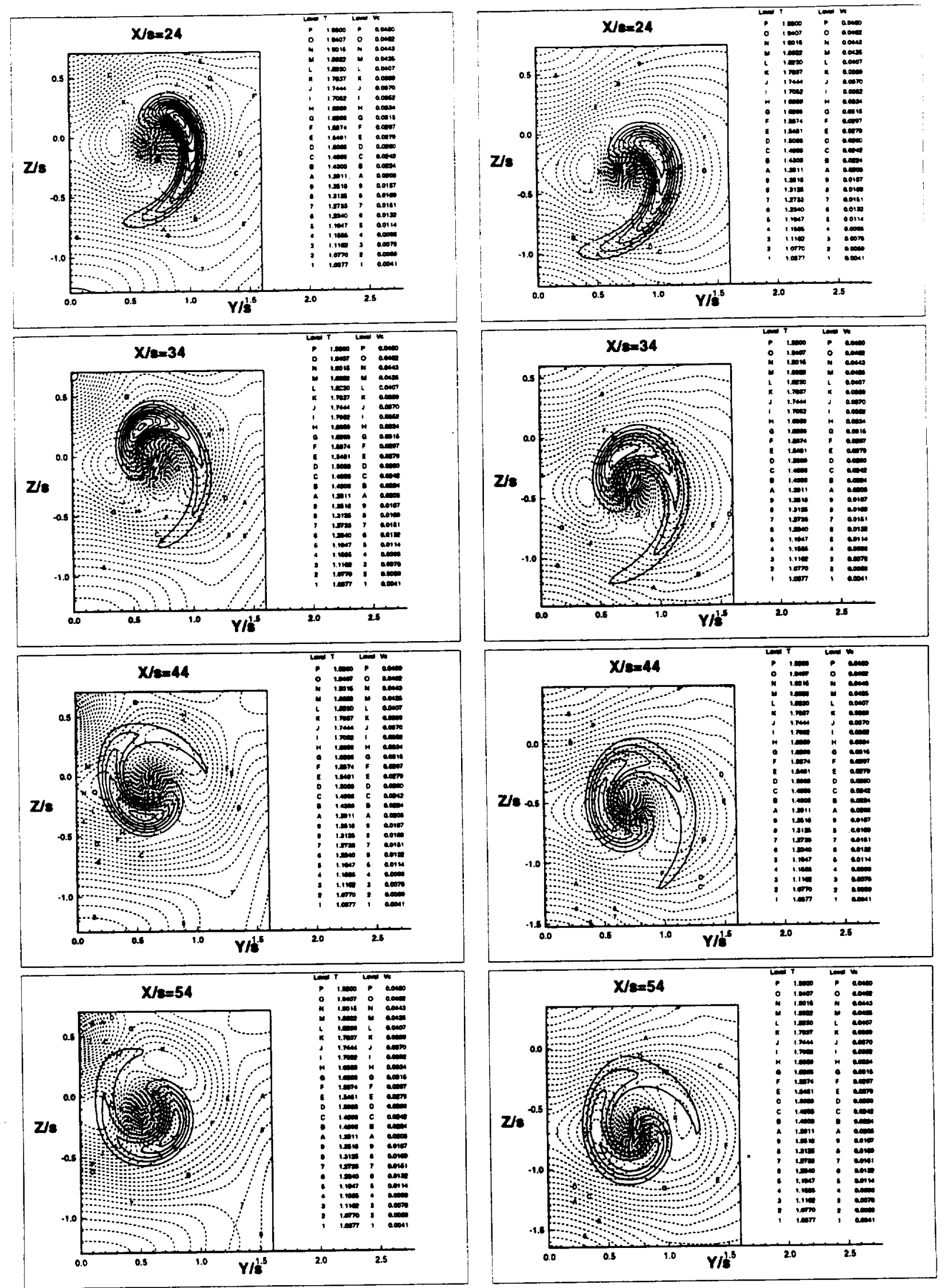

Figure 11: Comparison of crossflow $\mathrm{T}$ and Vc contours at four downstream stations; left-FTNS3D, and right-UNIWAKE. 

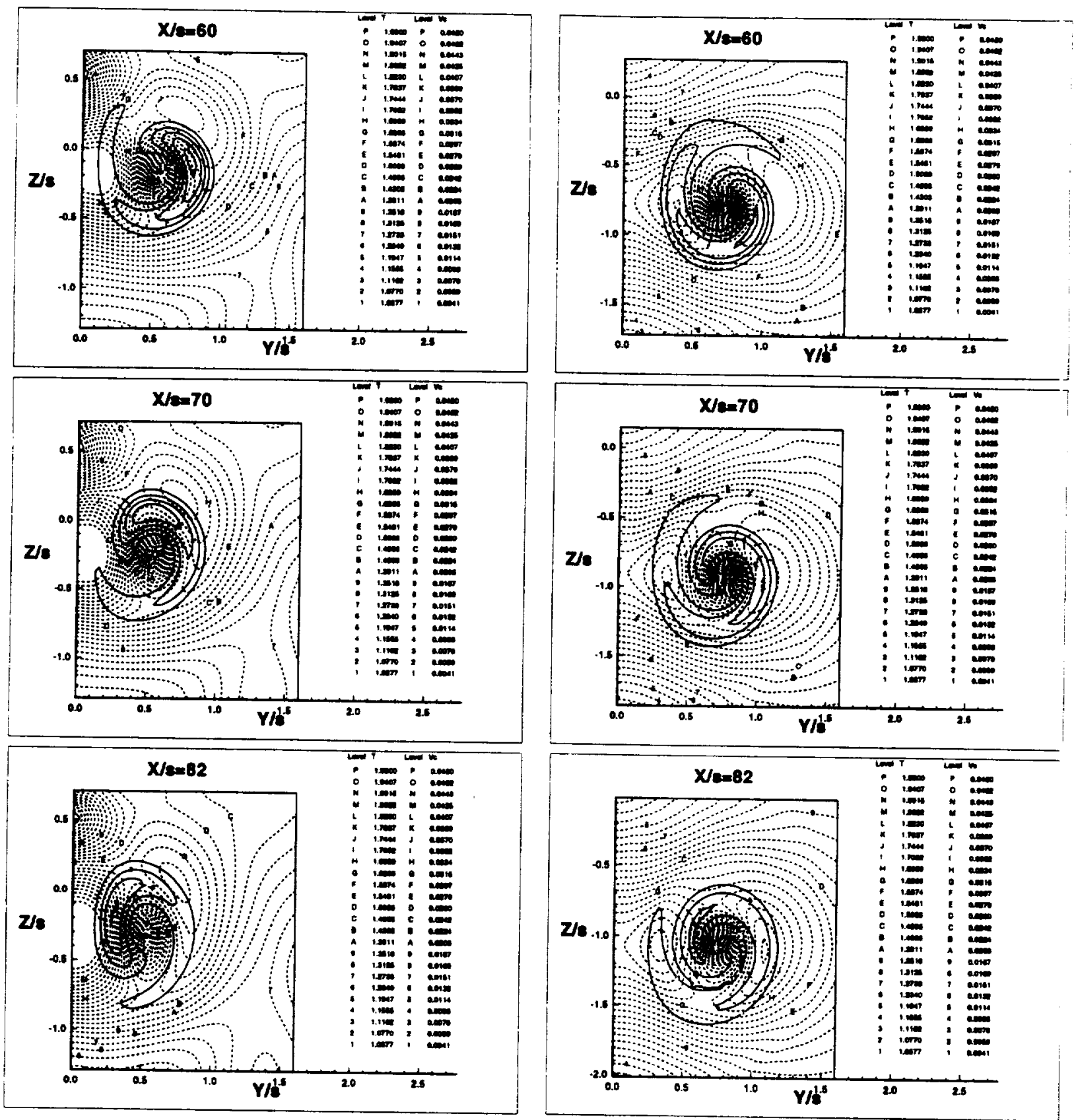

Figure 12: Comparison of crossflow $T$ and Vc contours at three downstream stations; left-FTNS3D, and right-UNIWAKE. 
AIAA 95-3464-CP

BUFFET RESPONSES OF A VERTICAL TAIL IN VORTEX BREAKDOWN FLOWS

Osama A. Kandil, Essam F. Sheta and Steven J. Massey

Aerospace Engineering Department Old Dominion University

Norfolk, VA 23529

AIAA Atmospheric Flight Mechanics Conference Baltimore, MD - August 7-9, 1995 


\title{
BUFFET RESPONSES OF A VERTICAL TAIL IN VORTEX BREAKDOWN FLOWS
}

\author{
Osama A. Kandil*, Essam F. Sheta ${ }^{\dagger}$ and Steven J. Massey ${ }^{\ddagger}$ \\ Aerospace Engineering Department \\ Old Dominion University, Norfolk, VA 23529-0247
}

\begin{abstract}
The tail buffet problem is a multi-disciplinary problem which is solved using three sets of equations. The first set is the unsteady, compressible, full Navier-Stokes equations which are used for obtaining the flow-field vector and the aerodynamic loads. The second set is the aeroelastic equations which are used for obtaining the bending and torsional deflections of the tail. The third set is the grid-displacement equations which are used for updating the grid coordinates due to the tail deflections. For the computational applications a sharp-edged cropped delta wing of aspect ratio 1.5 and a swept back vertical tail of aspect ratio 1.4 placed in the plane of geometric symmetry behind the wing are considered. The configuration is pitched at angles of attack of $20^{\circ}$ and $28^{\circ}$ which produce vortex breakdown flow of the delta wing primary vortices for the transonic regime at a Mach number of 0.85 . The results show the effects of the angle of attack and vortex breakdown on the uncoupled bending-torsional responses.
\end{abstract}

\section{INTRODUCTION}

The ability of modern fighter aircraft to fly and maneuver at high angles of attack and at high loading conditions is of prime importance. This capability is achieved, for example in the F/A-18 fighter, through the combination of the leadingedge extension (LEX) with a delta wing and the use of vertical tails. The LEX maintains lift at high angles of attack by generating a pair of vortices that trail aft over the top of the aircraft. The vortex entrains air over the vertical tails to maintain stability of the aircraft. This combination of
LEX, delta wing and vertical tails leads to the aircraft excellent high angle of attack performance. However, at some flight conditions, the vortices emanating from the highly-swept LEX of the delta wing breakdown before reaching the vertical tails which get bathed in a wake of unsteady highlyturbulent, swirling flow. The vortex-breakdown flow produces unsteady, unbalanced loads on the vertical tails which in turn produce severe buffet on the tails and has led to their premature fatigue failure.

Experimental investigation of the vertical tail buffet of the F/A-18 models have been conducted by several investigators such as Sellers at al ${ }^{1}$., Erickson at al ${ }^{2}$., Wentz $z^{3}$ and Lee and Brown ${ }^{4}$. These experiments showed that the vortex produced by the LEX of the wing breaks down ahead of the vertical tails at angles of attack of $25^{\circ}$ and higher and the breakdown flow produced unsteady loads on the vertical tails. Rao, Puram and $\mathrm{Shah}^{5}$ proposed two aerodynamic concepts for alleviating high-alpha tail buffet characteristics of the twin tail fighter configurations. Cole, Moss and Dogget $^{6}$ tested a rigid, $1 / 6$ size, full-span model of an F-18 airplane that was fitted with flexible vertical tails of two different stiffness. Verticaltail buffet response results were obtained over the range of angle of attack from $-10^{\circ}$ to $+40^{\circ}$, and over the range of Mach numbers from 0.3 to 0.95 . Their results indicated that the buffet response occurs in the first bending mode, increases with increasing dynamic pressure and is larger at $M=0.3$ than that at a higher Mach number.

An extensive experimental investigation has been conducted to study vortex-fin interaction

-Professor, Eminent Scholar and Department Chairman, Associate Fellow AIAA.

'Ph.D. Student and Research Assistant, Member AIAA.

'Ph.D. Student and Research Assistant, Member AIAA.

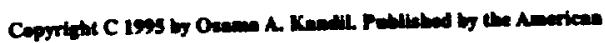


on a $76^{\circ}$ sharp-edged delta wing with vertical twin-fin configuration by Washburn, Jenkins and Ferman ${ }^{7}$. The vertical tails were placed at nine locations behind the wing. The experimental data showed that the aerodynamic loads are more sensitive to the chordwise tail location than its spanwise location. As the tails were moved toward the vortex core, the buffeting response and excitation were reduced. Although the tail location did not affect the vortex core trajectories, it affected the location of vortex-core breakdown. Moreover, the investigation showed that the presence of a flexible tail can affect the unsteady pressures on the rigid tail on the opposite side of the model. In a recent study by Bean and Lee ${ }^{8}$ tests were performed on a rigid $6 \%$ scale F/A-18 in a trisonic blowdown wind tunnel over a range of angle of attack and Mach number. The flight data was reduced to a non-dimensional buffet excitation parameter, for each primary mode. It was found that buffeting in the torsional mode occurred at a lower angle of attack and at larger levels compared to the fundamental bending mode.

Kandil, Kandil and Massey ${ }^{9}$ presented the first successful computational simulation of the vertical tail buffet using a delta wing-vertical tail configuration. A $76^{\circ}$ sharp-edged delta wing has been used along with a single rectangular vertical tail which was placed aft the wing along the plane of geometric symmetry. The tail was allowed to oscillate in bending modes. The flow conditions and wing angle of attack have been selected to produce an unsteady vortex-breakdown flow. Unsteady vortex breakdown of leading-edge vortex cores was captured, and unsteady pressure forces were obtained on the tail. These computational results are in full qualitative agreement with the experimental data of Washburn, Jenkins and Ferman ${ }^{7}$. An alternative simple model for simulation of the buffet problem was used by Kandil and Flanagan ${ }^{10}$ and Flanagan ${ }^{11}$. In this model, a configured circular duct was used to produce vortex-breakdown flow through the interaction of a supersonic swirling flow and a shock at the inlet of the duct. Downstream of the vortex-breakdown flow a cantilevered plate was placed. The problem was solved for the quasi-axisymmetric case.

Kandil, Kandil and Massey ${ }^{12}$ extended the technique used in Ref. 9 to allow the vertical tail to oscillate in both bending and torsional modes.
The total deflections and the frequencies of deflections and loads of the coupled bending-torsion case were found to be one order of magnitade higher than those of the bending case only. Also, it has been shown that the tail oscillations change the vortex breakdown locations and the unsteindy aerodynamic loads on the wing and tail.

Kandil, Massey and Sheta ${ }^{13}$ studied the effects of coupling and uncoupling the bending and torsional modes for a long computational time, and the flow Reynolds number on the buffet resporse.

In this paper, we consider the vortex breakdown flow in the transonic regime, $M_{\infty}=0.85$, and a delta wing-swept back tail configuration. Next, we address the effect of the angle of attack $\left(20^{\circ}\right.$ and $\left.28^{\circ}\right)$ on the deflection response of the vertical tail and the vortex breakdown flow.

\section{FORMULATION}

The formulation of the problem consists of three sets of governing equations along with certain initial and boundary conditions. The first set is the unsteady, compressible, full Navier-Stokes equations. The second set consists of the aeroelastic equations for bending and torsional modes. T'he third set consists of equations for deforming the grid according to the tail deflections. The literature shows various methods to move the grid. The simplest method uses simple interpolation functions such that the grid points adjacent to the aeroelastic surface move with the surface while the grid points at the computational-region boundary do not move ${ }^{14}$. The unsteady, linearized, Navierdisplacement equations have also been used successfully by Kandil at al. to move the grid dynamically ${ }^{15-16}$. In the present paper, we use simple grid interpolation to move the grid. Next, the governing equations for each set are given

\section{Fluid-Flow Equations:}

The conservative form of the dimensionless, unsteady, compressible, full Navier-Stokes equations in terms of time-dependent, body-conformed coordinates $\xi^{1}, \xi^{2}$ and $\xi^{3}$ is given by

$$
\frac{\partial \bar{Q}}{\partial t}+\frac{\partial \bar{E}_{m}}{\partial \xi^{m}}-\frac{\partial\left(\bar{E}_{v}\right)_{s}}{\partial \xi^{\prime}}=0 ; m=1-3, s=1-3
$$


where

$$
\begin{gathered}
\xi^{m}=\xi^{m}\left(x_{1}, x_{2}, x_{3}, t\right) \\
\bar{Q}=\frac{1}{J}\left[\rho, \rho u_{1}, \rho u_{2}, \rho u_{3}, \rho e\right]^{t},
\end{gathered}
$$

$\bar{E}_{m}$ and $\left(\bar{E}_{v}\right)$, are the $\xi^{m}$-inviscid flux and $\xi^{s}$-viscous and heat conduction flux, respectively. Details of these fluxes are given in Ref. 9.

\section{Aeroelastic Equations:}

The dimensionless, linearized governing equations for the coupled bending and torsional vibrations of a vertical tail that is treated as a cantilevered beam are considered. The tail bending and torsional deflections occur about an elastic axis that is displaced from the inertial axis. These equations for the bending deflection, $w$, and the twist angle, $\theta$, are given by

$$
\begin{aligned}
& \frac{\partial^{2}}{\partial z^{2}}\left[E I(z) \frac{\partial^{2} w}{\partial z^{2}}(z, t)\right]+m(z) \frac{\partial^{2} w}{\partial t^{2}}(z, t) \\
& +m(z) x_{\theta}(z) \frac{\partial^{2} \theta}{\partial t^{2}}(z, t)=N(z, t) \\
& \frac{\partial}{\partial z}\left[G J(z) \frac{\partial \theta}{\partial z}\right]-m(z) x_{\theta} \frac{\partial^{2} w}{\partial t^{2}}(z, t) \\
& -I_{\theta}(z) \frac{\partial^{2} \theta}{\partial t^{2}}(z, t)=-M_{t}(z, t)
\end{aligned}
$$

where $\mathrm{z}$ is the vertical distance from the fixed support along the tail length, $l_{t}, \mathrm{EI}$ and GJ the bending and torsional stiffness of the tail section, $\mathrm{m}$ the mass per unit length, $I_{\theta}$ the mass-moment of inertia per unit length about the elastic axis, $x_{\theta}$ the distance between the elastic axis and inertia axis, $\mathrm{N}$ the normal force per unit length and $M_{t}$ the twisting moment per unit length. The characteristic parameters for the dimensionless equations are $c^{*}, a_{\infty}^{*}, \rho_{\infty}^{*}$ and $c^{*} / a_{\infty}^{*}$ for the length, speed, density and time; where $c^{*}$ is the delta wing root-chord length, $a_{\infty}^{*}$ the freestream speed of sound and $\rho_{\infty}^{*}$ the freestream air density. The geometrical and natural boundary conditions on $w$ and $\theta$ are given by

$$
\begin{aligned}
w(0, t) & =\frac{\partial w}{\partial z}(0, t)=\frac{\partial^{2} w}{\partial z^{2}}\left(l_{t}, t\right) \\
& =\frac{\partial}{\partial z}\left[E I\left(l_{t}\right) \frac{\partial^{2} w}{\partial z^{2}}\left(l_{t}, t\right)\right]=0 \\
\theta(0, t) & =\frac{\partial \theta}{\partial z}\left(l_{t}, t\right)=0
\end{aligned}
$$

The solution of Eqs. (4) and (5) are given by

$$
\begin{gathered}
w(z, t)=\sum_{i=1}^{I} \phi_{i}(z) q_{i}(t) \\
\theta(z, t)=\sum_{j=i+1}^{M} \phi_{j}(z) q_{j}(t)
\end{gathered}
$$

where $\phi_{i}$ and $\phi_{j}$ are comparison functions satisfying the free-vibration modes of bending and torsion, respectively, and $q_{i}$ and $q_{j}$ are generalized coordinates for bending and torsion, respectively. In this paper, the number of bending modes, $\bar{I}$, is six and the number of torsion modes, $M-\bar{I}$, is also six. Substituting Eqs. (8) and (9) into Eqs. (4) and (5) and using the Galerkin method along with integration by parts and the boundary conditions, Eqs (6) and (7), we get the following equation for the generalized coordinates $q_{i}$ and $q_{j}$ in matrix form:

$$
\begin{gathered}
{\left[\begin{array}{ll}
M_{11} & M_{12} \\
M_{21} & M_{22}
\end{array}\right]\left(\begin{array}{c}
\ddot{q}_{i} \\
\ddot{q}_{j}
\end{array}\right)+\left[\begin{array}{cc}
K_{11} & 0 \\
0 & K_{22}
\end{array}\right]\left(\begin{array}{l}
q_{i} \\
q_{j}
\end{array}\right)} \\
=\left(\begin{array}{l}
\hat{N}_{1} \\
\hat{N}_{2}
\end{array}\right) \begin{array}{l}
; i=1,2, \ldots, \hat{I} \\
; j=\hat{I}+1, \ldots ., M
\end{array}
\end{gathered}
$$

where

$$
\left.\begin{array}{cc}
M_{11}= & \int_{0}^{l_{t}} m \phi_{r} \phi_{i} d z \\
M_{12}= & M_{21}=\int_{0}^{l_{t}} m x_{\theta} \phi_{r} \phi_{j} d z \\
M_{22}= & \int_{0}^{l_{t}} I_{\theta} \phi_{s} \phi_{j} d z
\end{array}\right\}
$$

Similar aeroelastic equations were developed for sonic analysis of wing flutter by Strganac ${ }^{17}$, and Strganac, Mook and Mitchum ${ }^{18}$. The numerical integration of Eqs. (11-13) is obtained using the trapezoidal method with 125 points to improve the accuracy of integrations. The solution of Eq. (10), for $q_{i} ; i=1,2, \ldots ., \hat{I}$, and $q_{j} ; j=\hat{I}+1, \ldots, M$, is obtained using the RungeKutta scheme. Next, $w$, and $\theta$ are obtained from Eqs. (8) and (9). 


\section{Grid Displacement Equations:}

Once $w$ and $\theta$ are obtained at the $n+1$ time step, the new grid coordinates are obtained using simple interpolation equations. In these equations, the tail bending displacement, $w_{i, j, k}^{n+1}$, and the tail displacement through the torsion angle, $\theta_{i, j, k}^{n+1}$ are interpolated through a cosine function. These equations for the $y$ and $z$ coordinates to the right side of the tail and a head of its elastic axis are given by

$$
\begin{aligned}
y_{i, j, k}^{n+1}= & y_{i, j, k}^{n}+\left[w_{i, j, k}^{n+1}+\left(X-x_{i, j, k}^{n}\right) \tan \theta_{i, j, k}^{n+1}\right] \\
& \cos \left(\frac{y_{i, j, k}^{n}}{Y} \frac{\pi}{2}\right) \\
z_{i, j, k}^{n+1}= & z_{i, j, k}^{n}-\left[\Delta z^{\circ}-\sqrt{\left(\Delta z^{\circ}\right)^{2}-\left(\Delta w^{n+1}\right)^{2}}\right] \\
& \cos \left(\frac{z_{i, j, k}^{n}}{Z} \frac{\pi}{2}\right)
\end{aligned}
$$

where $z_{i, j, k}^{n+1}$ and $y_{i, j, k}^{n+1}$ are the $z$ and $y$ coordinates of a grid point at the $n+1$ time step, $z_{i, j, k}^{o}$ is the original $z$ coordinate of a tail grid point and $\Delta z_{i, j, k}^{o}=z_{i, j, k}^{o}-z_{i, j, k-1}^{o}, \mathrm{Y}$ is the maximum $\mathrm{y}$ coordinate from the tail-surface grid point to the corresponding point at the right boundary of the computational domain, $\mathrm{Z}$ is the maximum $\mathrm{z}$ coordinate from the tail root to the upper boundary of the computational domain and $X$ is the $X$ coordinate of the tail elastic axis. These equations result in displacing a grid point on the tail by the total deflection due to bending and torsion and keeping a grid point at the boundary fixed. Similar equations are used for the other part of the computational domain.

\section{Boundary and Initial Conditions:}

Boundary conditions consists of conditions for the fluid flow and conditions for the aeroelastic bending and torsional deflections of the tail. For the fluid flow, the Riemann-invariant boundary conditions are enforced at the inflow and outflow boundaries of the computational domain. At the plane of geometric symmetry, periodic boundary conditions is specified with the exception of grid points on the tail. On the wing surface, the noslip and no-penetration conditions are enforced and $\frac{\partial p}{\partial n}=0$. On the tail surface, the no-slip and no-penetration conditions for the relative velocity components are enforced (points on the tail surface are moving). The normal pressure gradien: is no longer equal to zero due to the acceleration of the grid points on the tail surface. This equation becomes $\frac{\partial_{p}}{\partial n}=-\rho \bar{a}_{t} \cdot \hat{n}$, where $\bar{a}_{t}$ is the acceleration of a point on the tail and $\dot{n}$ is the unit normal.

Initial conditions consist of conditions for the fluid flow and conditions for the aeroelastic ileflections of the tail. For the fluid flow, the initial conditions correspond to the freestream conditions with no-slip and no-penetration conditions on the wing and tail. For the aeroelastic deflections of the tail, the initial conditions for any point on the tail are that the displacement and veloc:ty are zero, $w(z, 0)=0, \frac{\partial w}{\partial t}(z, 0)=0, \theta(z, 0)=0$ and $\frac{\partial \theta}{\partial t}(z, 0)=0$.

\section{METHOD OF SOLUTION}

The first step is to solve for the fluid flow problem using the vortex-breakdown conditions and keeping the tail as a rigid beam. Navier-Stokes equations are solved using the implicit, flux-difference splitting finite-volume scheme. The grid speed $\frac{\partial \xi^{m}}{\partial t}$ is set equal to zero in this step. This step provides the flow field solution along with the pressure difference across the tail. The pressure difference is used to generate the normal force and twisting moment per unit length of the tail. Next, the aeroelastic equations are used to obtain the tail deflections, $w_{i, j, k}$ and $\theta_{i, j, k}$. The grid displacement equations are then used to compute the new grid coordinates. The metric coefficient of the coordinate Jacobian matrix are updated as well as the grid speed, $\frac{\partial \xi^{m}}{\partial t}$. This computational cycle is repeated every time step.

\section{COMPUTATIONAL APPLICATIONS}

\section{Delta Wing-Vertical Tail Configuration:}

The delta wing-swept back vertical tail configuration consists of a $65^{\circ}$ swept back, sharp-edged, cropped delta wing of aspect ratio 1.5 and cropping ratio (tip length/root-chord length) 0.15 , and a $53.5^{\circ}$ swept-back vertical tail of aspect ratio 1.4 , which is placed in the plane of geometric symmetry. The tail has a span of 0.222 and a root chord of $c_{t}=0.2527$ with taper ratio of 0.23 . The leading edge of the tail root is located at .06 downstream the wing trailing edge. The lower edge of the tail is along the wing axis and the tail s 
clamped at that edge. The freestream Mach number is 0.85 and the Reynolds number is $3.23 \mathrm{mil}$ lion. The wing angle of attack has been chosen as $20^{\circ}$ and $28^{\circ}$. An $\mathrm{O}-\mathrm{H}$ grid of $65 \times 43 \times 95$ grid points in the wrap-around, normal and axial directions, respectively, is used for the solution of the fluid-flow part of the problem. The grid lines in the wake region has been modified to accommodate the tail topology. Figure 1 shows a typical grid and a blow-up of the wing-tail configuration.

\section{Initial Conditions (Fluid-Flow Problem),} $\alpha=20^{\circ}$ :

Keeping the tail rigid, the unsteady, compressible, full Navier-Stokes equations are integrated time accurately using the implicit, flux-difference splitting scheme of Roe to a dimensionless time, $t=10$. Figure 2 shows a three-dimensional view and a top view for the wing-rigid tail configuration. The vortex breakdown of the leading-edge vortex core and the stagnation pressure distribution are shown in the figure. The cross flow beneath the primary vortex reaches supersonic speeds and a ray shock develops beneath the primary vortex. The leading-edge vortex core passes through another transverse shock known as a terminating shock at $x=0.83$ which causes the vortex core to breakdown at $x=0.85$.

Figure 3 shows the static pressure contours on the wing surface and symmetry plane. A substantial supersonic pocket which is bounded by the terminating shock and the ray shocks (shocks beneath the primary vortex cores) is observed on the wing plane. Figure 4 shows the Mach contours and streamlines on a vertical ray plane (ray D) which passes through the vortex breakdown. The streamlines conclusively show a two-bubble cell vortex breakdown. The Mach contours show that the front surface of the vortex breakdown bubbles is enclosed by a hemispherical shape-like shock surface. Figure 5 shows the static-pressure variation along ray lines from the wing vertex. These curves show the spanwise locations of several points on the foot-print line of the terminating shock. The terminating shock is clearly seen to run in the spanwise direction from the plane of symmetry to the wing leading edge.

The solution at the present time step is taken as the initial conditions for the next case of the aeroelastic tail response.

\section{Uncoupled Bending-Torsion Tail}

Response, $\alpha=20^{\circ}$ :

The tail is treated as a swept back beam with thickness $d=0.005$. The tail material dimensionless modulii of elasticity and rigidity, $E$ and $\mathrm{G}$ are $1.8 \times 10^{5}$ and $0.692 \times 10^{5}$, respectively. The mass per unit length of the tail varies linearly from the tail root, $m_{r}=0.033$, to the tail tip, $m_{t}=0.0076$ and the mass-moment of inertia per unit length varies linearly from the tail root, $I_{\theta r}=1.75 \times 10^{-4}$, to the tail tip, $I_{\theta t}=2.1 \times 10^{-6}$. For the coupled bending-torsion case, the elastic axis is assumed to exist upstream the inertia axis with a distance of $x_{\theta}=-0.02$. For the uncoupled bending-torsion case, $x_{\theta}=0.0$.

Figures 6-8 show the results of the uncoupled bending-torsion responses of the tail. Figure 6 shows four pairs of responses. The first pair is for the variation of the bending deflection, $w$, and torsional deflection, $\theta$, along the tail height $z$ every 2000 time step. The bending and torsion responses are mainly of the first-mode shape type. The second pair of responses show the variation of the normal force and twisting moment along the tail height $z$ every 2000 time steps. The third and fourth pairs show the bending deflection, normal force, torsional deflection and twisting moment variation at the tail tip and its midpoint versus the number of time steps (it $=20,000$ or $t=20$ starting from the initial condition). It is observed that the frequency of the normal force and the twisting moment are almost the same as that of the bending deflection and the torsional deflection, respectively. Figure 7 shows the combined response, $W_{\text {net }}$, of the bending and torsional deflections along the tail height every 2000 time steps. Figure 8 shows a three-dimensional view and a top view of the wing-deformed tail configuration at it $=20,000$. Comparing this figure with Fig. 2 (Initial condition with rigid tail), the terminating shock moves upstream to $x=0.5$ and becomes weaker and smeared. The vortex breakdown occurs immediately after the terminating shock. Another shock is observed downstream of the original terminating shock and is accompanied by another breakdown. The breakdown flow is slightly asymmetric. This conclusively shows the substantial upstream aerodynamic effects of the tail bending and torsional deflections. 
Initial Conditions (Fluid-Flow Problem), $\alpha=28^{\circ}$ :

Keeping the tail rigid, the angle of attack is increased to $28^{\circ}$. The other flow conditions are kept the same as those of $\alpha=20^{\circ}$. Figure 9 shows a three-dimensional view and a top view of the vortex breakdown of the leading-edge vortex cores and the stagnation pressure contours. The vortex breakdown flow moves upstream covering almost all of the wing planform. Figure 10 shows the Mach contours on a constant $K$ plane near the wing surface and on the plane of symmetry. The supersonic pocket on the upper wing surface expanded in the spanwise direction to cover all of the wing planform, and part of the transverse terminating shock moved downstream ahead of the vertical tail location. Figure 11 shows the variation of static pressures along ray planes originating from the wing planform vertex. It is observed that several transverse shocks exist; one near the wing vertex at $x / c=0.2$, a second one at $x / c=0.9$ and a third one ahead of the tail location at $x / c=1.06$.

\section{Uncoupled Bending-Torsion Tail}

Response, $\alpha=28^{\circ}$ :

Figures 12-15 show the results of this case. Figure 12 shows the same sequence of results as those of Fig. 6. Comparing the results of Fig. 12 with those of Fig. 6, it is observed that the bending and torsional deflections of Fig. 12 are 4-5 times as those of Fig. 6. Moreover, the frequencies of the bending and torsional deflections and loads of Fig. 12 are lower than those of Fig. 6. The aerodynamic damping of the case of Fig. 6 is higher than that of the case of Fig. 12. The net deflection of Fig. 13 is 4 times higher than that of Fig. 7. Figure 14 shows a three-dimensional view of the vortex breakdown of the leading-edge vortex cores and the stagnation pressure at it $=20,000$. It is observed that the leading critical points of the vortex breakdown near the wing vertex are asymmetric. Figure 15 shows the Mach contours on a constant $K$ plane near the wing surface and on the plane of symmetry. The Mach contours on the wing surface show strong asymmetry with one side having a subsonic flow and the other side having a supersonic flow. It is observed that a shock near the plane of symmetry and originating from the wing vertex exists.

\section{CONCLUDING REMARKS}

The tail buffet problem due to the unsteady aerodynamic loads induced by the vortex-breakdown flow of the wing leading-edge vortices has been simulated computationally and efficiently usirg a delta wing-swept back vertical tail configuration. The wing aspect ratio and flow conditions (transonic regime) have been carefully selected in or der to produce unsteady vortex-breakdown flow. 'The solution has demonstrated the development of the tail buffet due to the unsteady loads produced by the transonic vortex-breakdown flow. The problem is a multidisciplinary problem which requires three sets of equations to obtain its solution.

In the present paper, the CFD solver is the implicit, upwind, Roe flux-difference splitting scheme.

The focus of this paper is to study the buffet response in transonic flow at different ancles of attack. It is conclusively found that the ail oscillations have a substantial upstream effect on the vortex breakdown of the leading-edge voriex cores, although a supersonic pocket exists on the wing upper surface. By increasing the angle of attack from $20^{\circ}$ to $28^{\circ}$, the vortex breakdown flow becomes stronger and the corresponding unsteady normal forces and torsional moments on the tail become larger resulting into substantially higher deflections with lower frequencies. Unlke the results obtained in Ref. 13 for subsonic vortex breakdown flows and a delta wing-rectangular vertical tail configuration, the aerodynamic loads and the deflections in the present case never reached periodic response and their loads were one order of magnitude lower than those of Ref. 13. These results are in a qualitative agreement with the conclusion reached by Cole, Moss and Doggett of Ref. 6 ; That the buffet deflections become larger as the Mach number is decreased.

\section{ACKNOWLEDGMENT}

This research work is supported under Grants No. NAG-1-994 and NAG-1-648 by the NASA Langly Research Center. The authors would like to recognize the computational resources provided by the NAS facilities at Ames Research Center and the NASA Langley Research Center. 


\section{REFERENCES}

1. Sellers, W. L. III, Meyers, J. F. and Hepner, T. E., "LDV Survey Over a Fighter Model at Moderate to High Angle of Attack," SAE Paper 88-1448, 1988.

2. Erickson, G. E., Hall, R. M., Banks, D. W., Del Frate, J. H., Shreiner, J. A., Hanley, R. J. and Pulley, C. T., "Experimental Investigation of the F/A-18 Vortex Flows at Subsonic Through Transonic Speeds," AIAA 89$2222,1989$.

3. Wentz, W. H., "Vortex-Fin Interaction on a Fighter Aircraft," AIAA 87-2474, AIAA Fifth Applied Aerodynamics Conference, Monterey, CA August 1987.

4. Lee, B. and Brown, D., "Wind Tunnel Studies of F/A-18 Tail Buffet," AIAA 90-1432, 1990.

5. Rao, D. M., Puram, C. K. and shah, G. H., "Vortex Control for Tail Buffet Alleviation on a twin-Tail Fighter Configuration," SAE Paper No. 89-2221, 1989.

6. Cole, S. R., Moss, S. W. and Dogget, R. V., Jr., "Some Buffet Response Characteristics of a Twin-Vertical-Tail Configuration," NASA TM-102749, October 1990.

7. Washburn, A. E., Jenkins, L. N. and Ferman, M. A., "Experimental Investigation of Vortex-Fin Interaction," ALAA 93-0050, AIAA 31st ASM, Reno, NV, January 1993.

8. Bean, D. E. and Lee, B. H. K., "Correlation of Wind Tunnel and Flight Test Data for F/A-18 Vertical Tail Buffet," AIAA 941800-CP, 1994

9. Kandil, O. A., Kandil, H. A. and Massey, S. J., "Simulation of Tail Buffet Using Delta Wing-Vertical Tail Configuration," AIAA 93-3688-CP, AIAA Atmospheric Flight Mechanics Conference, Monterery, CA August 1993, pp. 566-577.

10. Kandil,O. A. and Flanagan, M. W., "Vertical Tail Buffet in Vortex Breakdown Flows," 5th International Symposium on Computational Fluid Dynamics, Sendai-Japan, August 1993.

11. Flanagan, M. W., "Simulation of Vertical Tail Buffet in Internal Vortex Breakdown Flows," M.S. Thesis, Aerospace Engineering Department, Old Dominion University, Norfolk, VA, December 1993.

12. Kandil,O. A., Massey, S. J., and Kandil, H. A., "Computations of Vortex-Breakdown Induced Tail Buffet Undergoing Bending and Torsional Vibrations," AIAA 94-1428CP, AIAA/ASME/ASCE/ASC Structural, Structural Dynamics and Material Conference, SC April 1994, pp. 977-993.

13. Kandil, O. A., Massey, S. J. and Sheta, E. F., "Structural Dynamics/CFD Interaction for Computation of Vertical Tail Buffet," International Forum on Aeroelasticity and Structural Dynamics, Royal Aeronautical Society, Manchester, U.K., June 26-28, 1995.

14. Schuster, D., Vadyak, J. and Atta, E., "Static Aeroelastic Analysis of Fighter Aircraft Using a Three-Dimensional NavierStokes Algorithm," AlAA 90-0435, January 1990.

15. Kandil, O. A., Chuang, H. A. and Salman, A. A., "Unsteady Flow Computation of Oscillating Flexible Wings," AIAA 90-0937-CP, April 1990, pp. 1370-1381.

16. Kandil, O. A. and Salman, A. A., "Unsteady Vortex-Dominated Flow Around Wings with Oscillating Leading-Edge Flaps," ALAA 910435, January 1991.

17. Straganac, T. W., "A Numerical Model of Unsteady, Subsonic Aeroelastic Behavior," NASA Technical Memorandum 100487, December 1987.

18. Straganac, T. W., Mook, D. T. and Mitchum, M. W., "The Numerical Simulation of Subsonic Flutter," AIAA 87-1428, June 1987. 

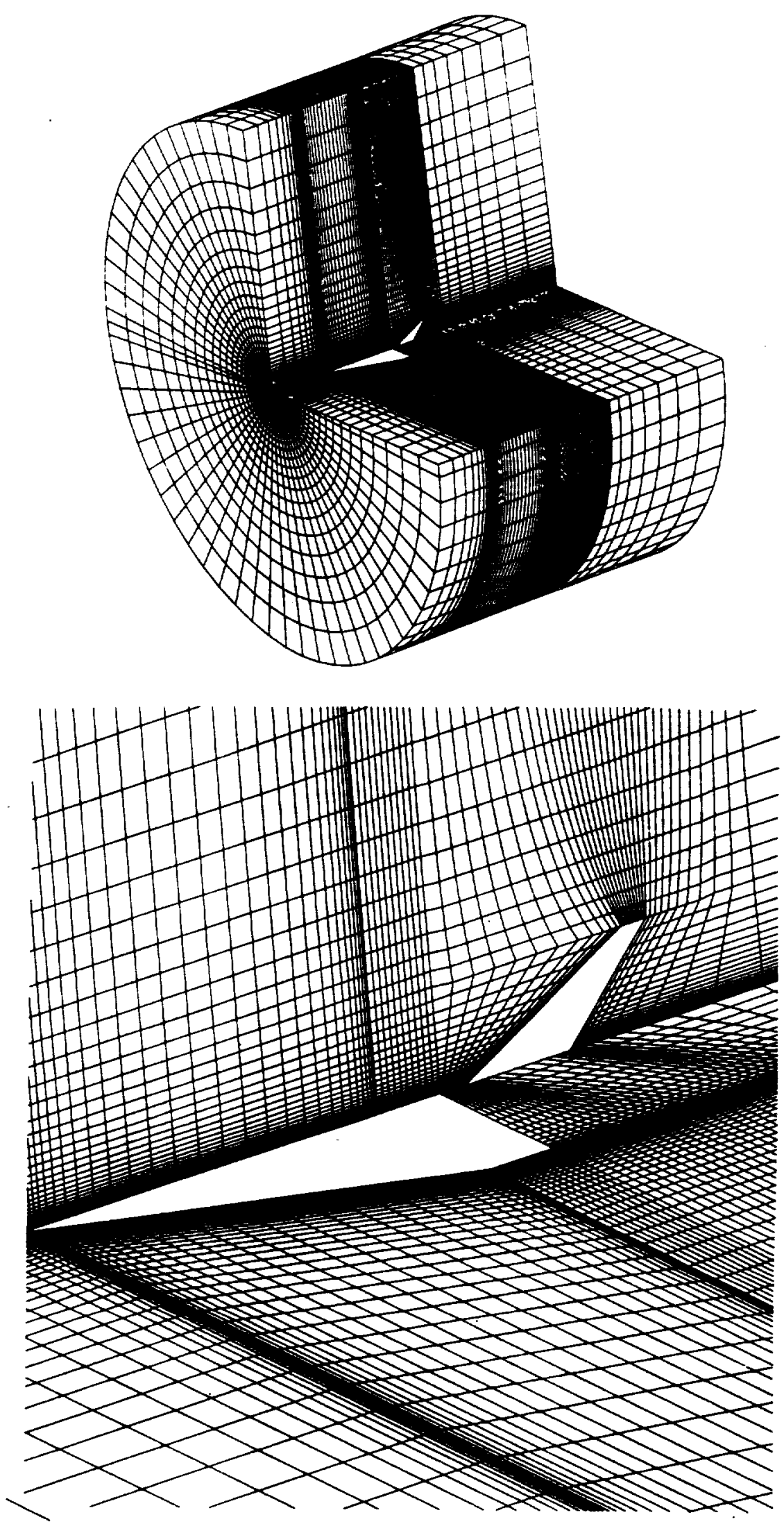

Fig. 1 An O-H grid of $65 \times 43 \times 95$ grid points in the wrap-around, normal and axial directions and a blow-up of the wing-tail configuration. 

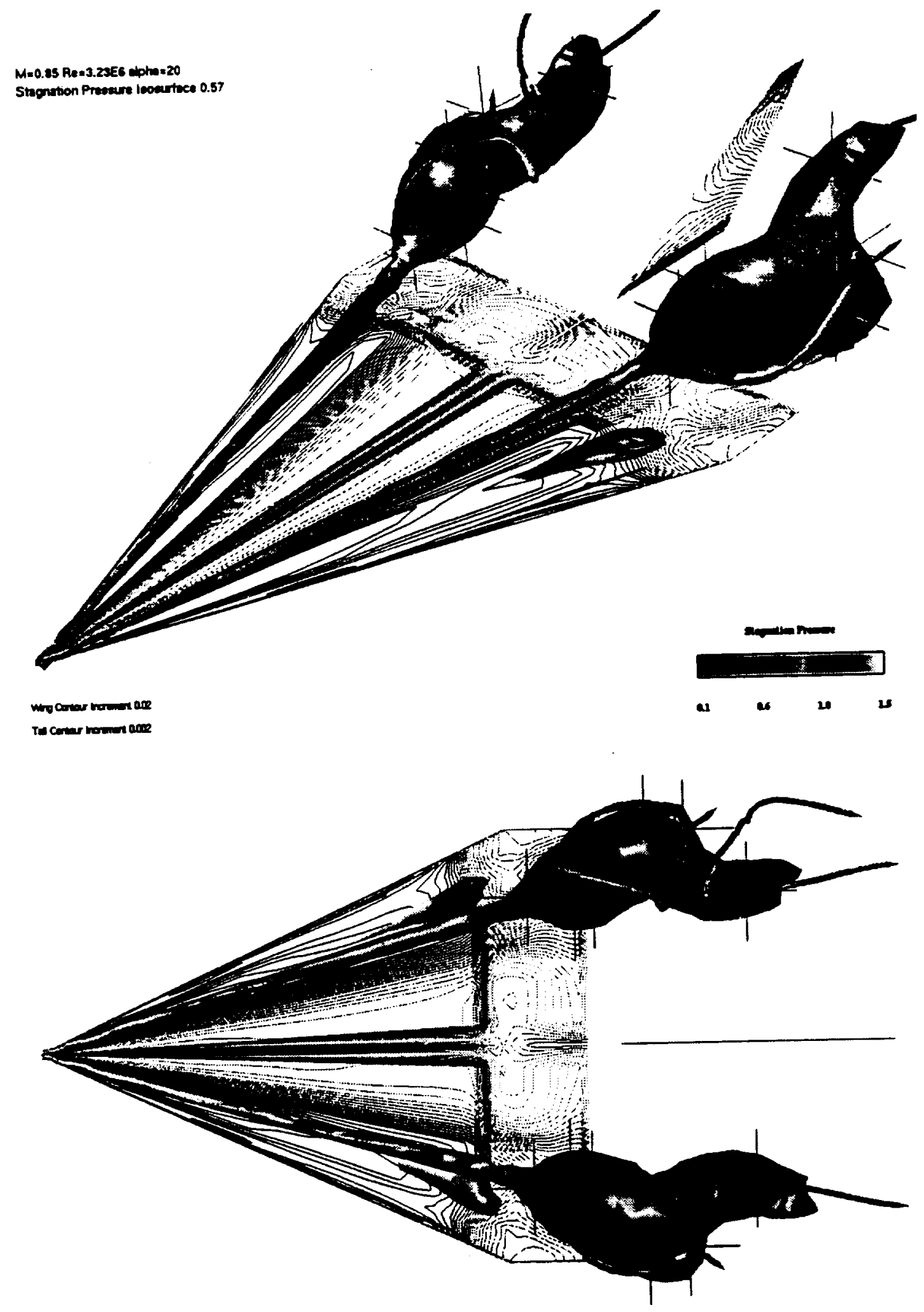

Fig. 2 Three-dimensional view and a top view of the wing-tail configuration for the initial conditions, $\alpha=20^{\circ}, \Delta t=0.001$, it $=10,000$. 


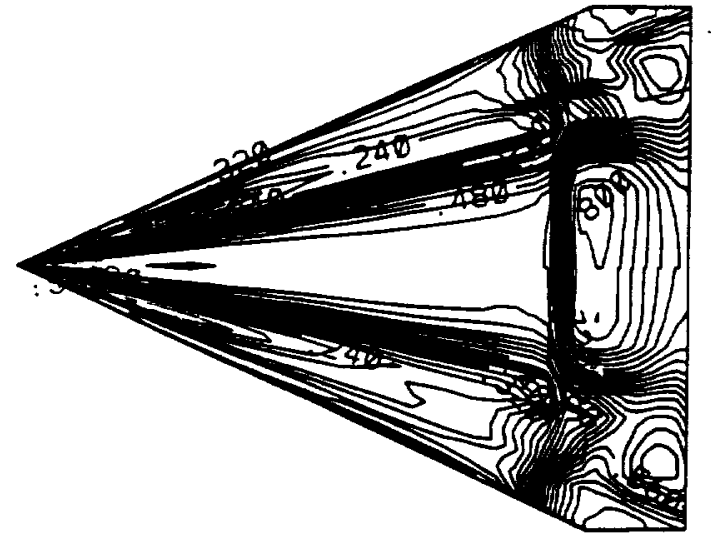

PRESSURE CONTOURS ON THE WING SURFACE

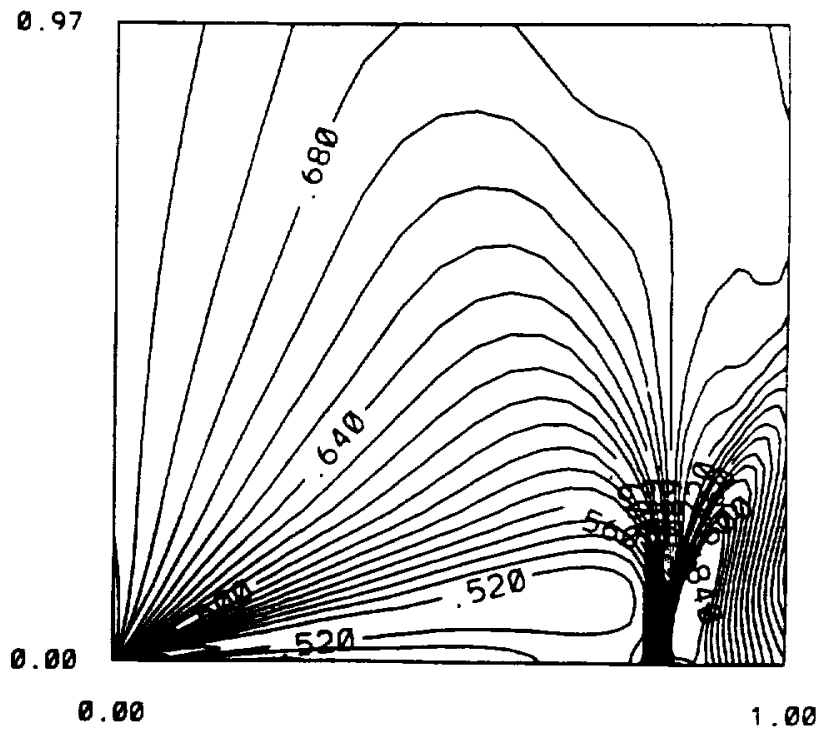

PRESS. CONTOURS ON THE PLANE OF SYMMTRY

Fig. 3 Pressure contours on the wing surface and plane of symmetry for the initial conditions, $\alpha=20^{\circ}, \Delta t=0.001$, it $=10,000$.

\subsection{9 \\ 0.00}

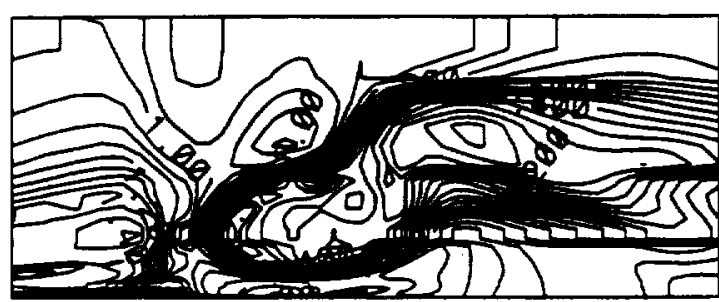

0. 59

TOTAL YACH NUMBER CONTOURS

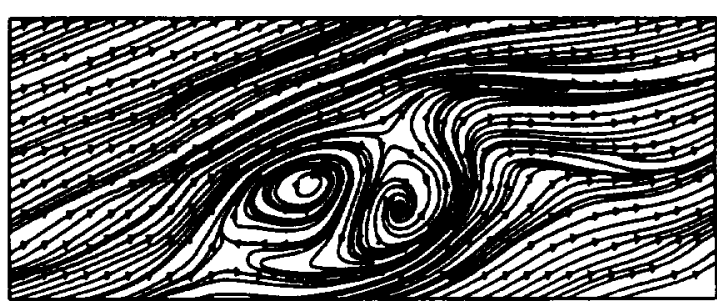

STREAMININS

Fig. 4 Total Mach contours and streamlines on a ray plane passing through the vortex-breakdown, $\alpha=20^{\circ}, \Delta t=0.001$, it $=10,000$.

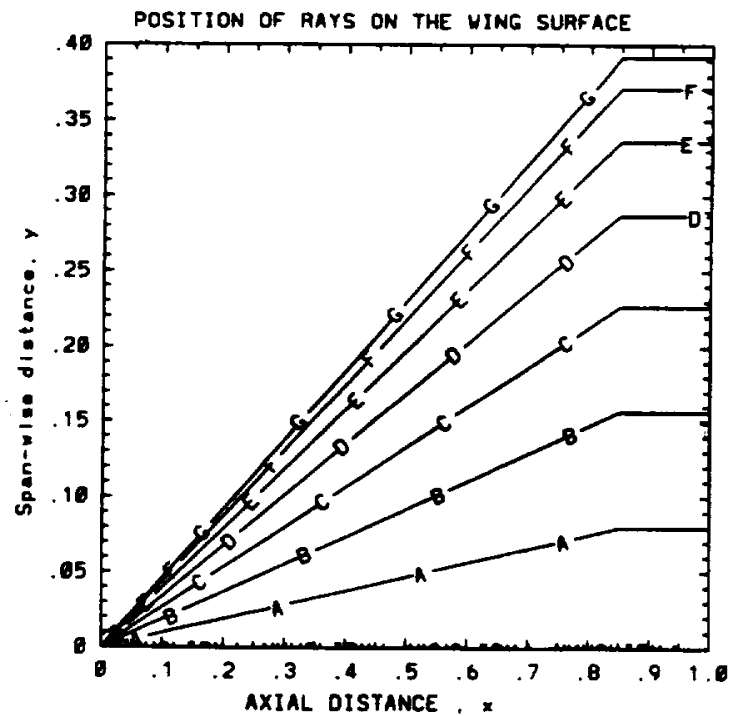

DELTA WING Moo=0.85 P.03.230.000

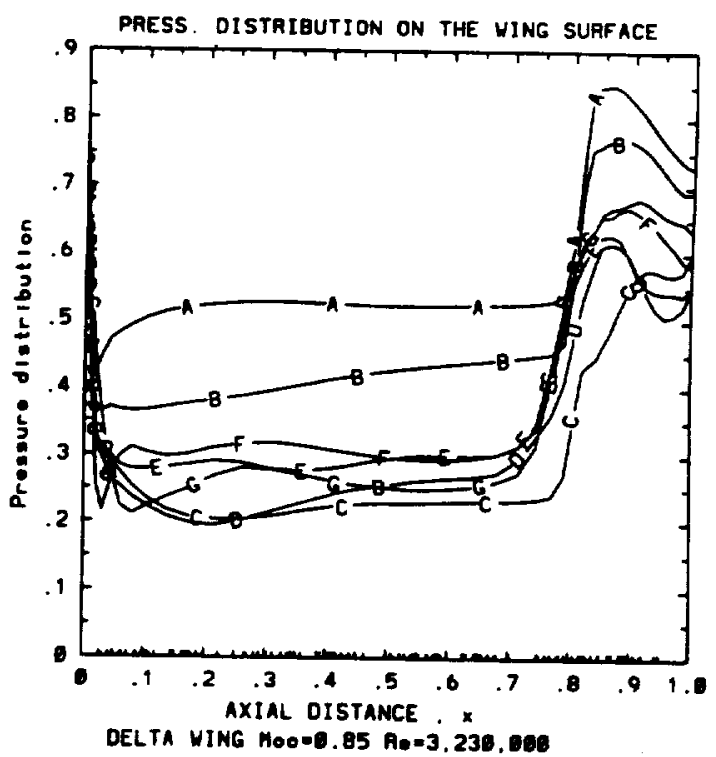

DELTA VING Hoo-0.85 A. $=3,230,000$

Fig. 5 Ray planes on the wing planform and surface pressure variation along these planes, $\alpha=20^{\circ}, \Delta t=0.001$, it $=10,000$. 
Bending Distribution History

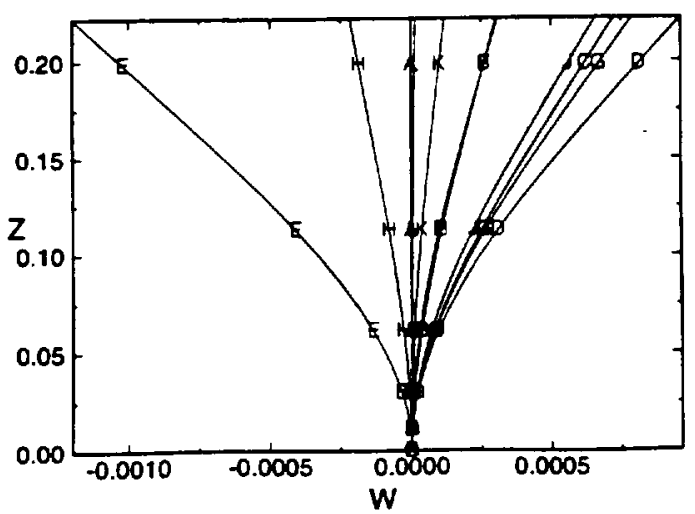

Force Distribution History

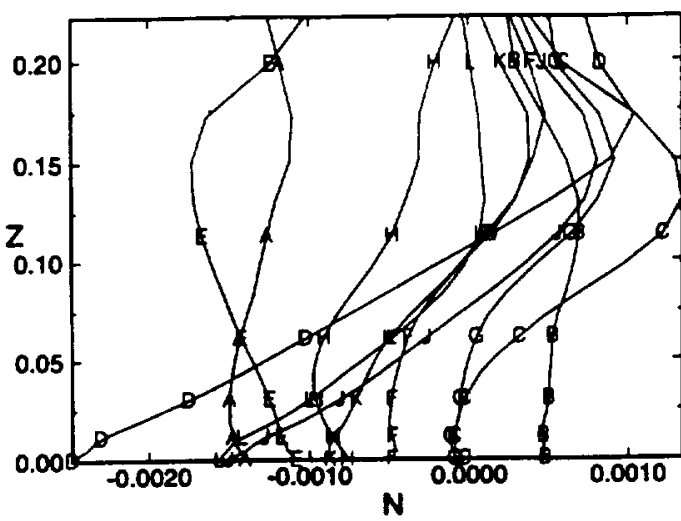

Tip Bending Displacement \& Force vs Time



Midpoint Bending Displacement \& Force vs Time

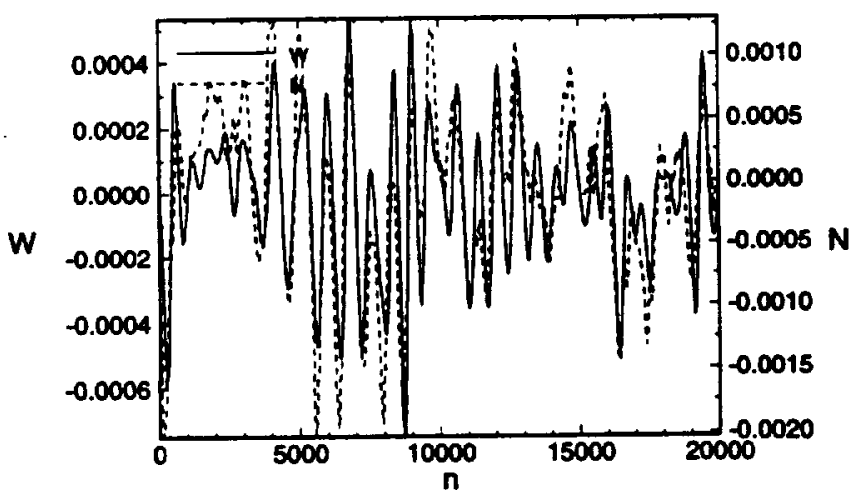

Rotation Distribution History

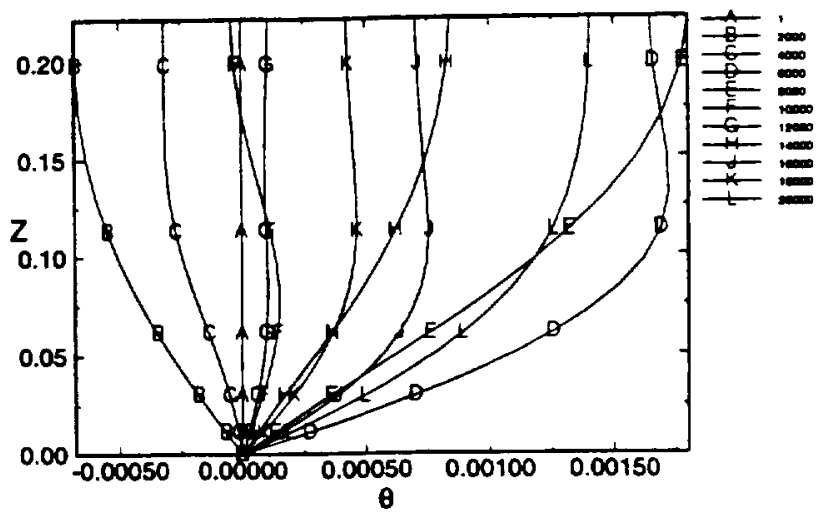

Moment Distribution History

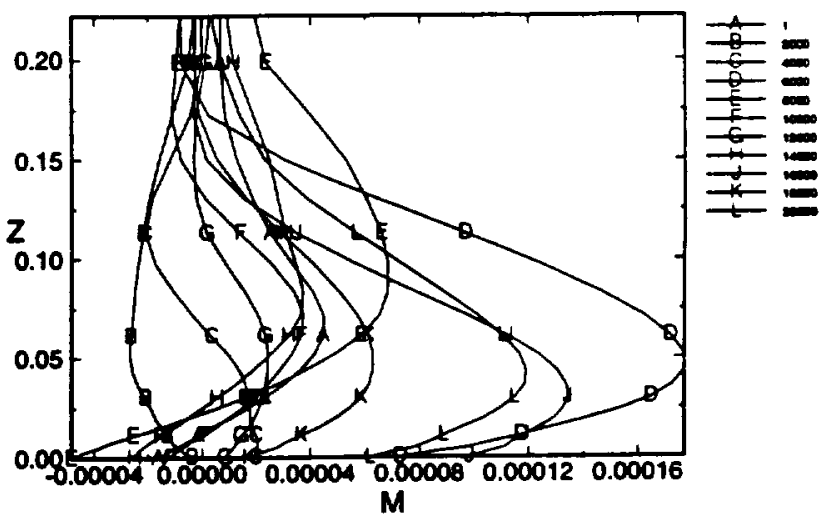

Tip Rotation \& Moment vs Time

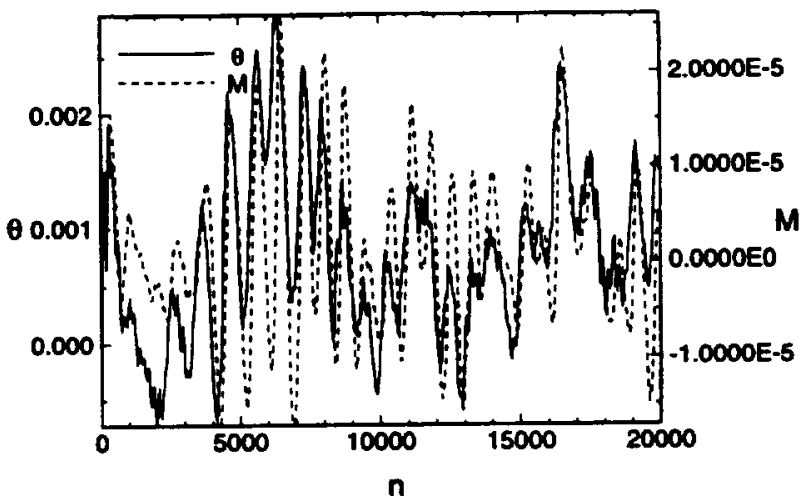

Midpoint Rotation \& Moment vs Time

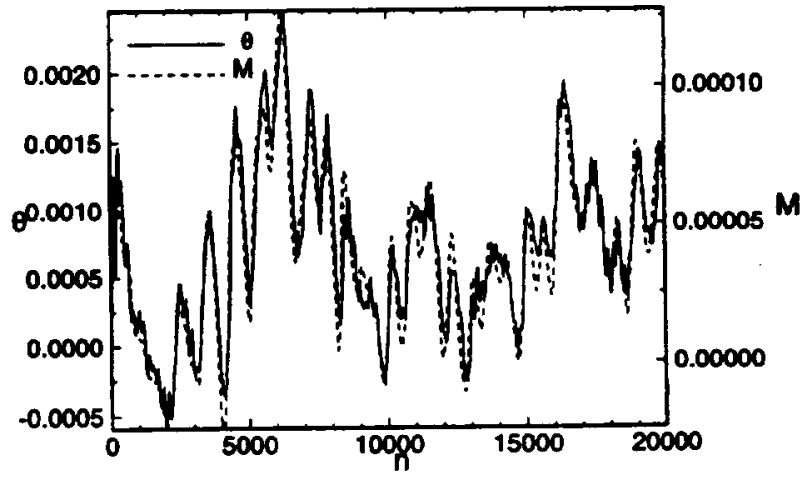

Fig. 6 Deflection and load responses for an uncoupled bending-torsion case, $\alpha=20^{\circ}, \Delta t=0.001, i t=10,000-30,000$. 


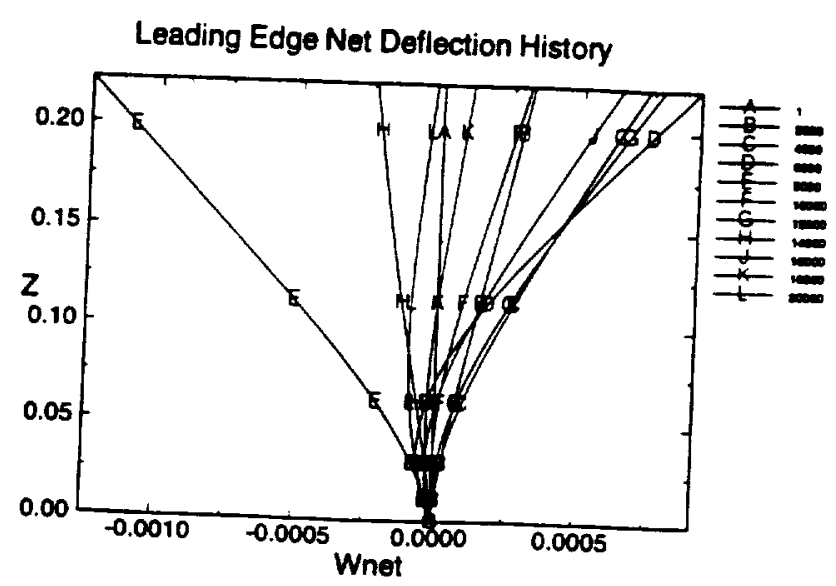

Fig. 7 Net deflection of the tail leading edge for the uncoupled bending-torsion case, $\alpha=20^{\circ}, \Delta t=0.001$, it $=10,000-30,000$.

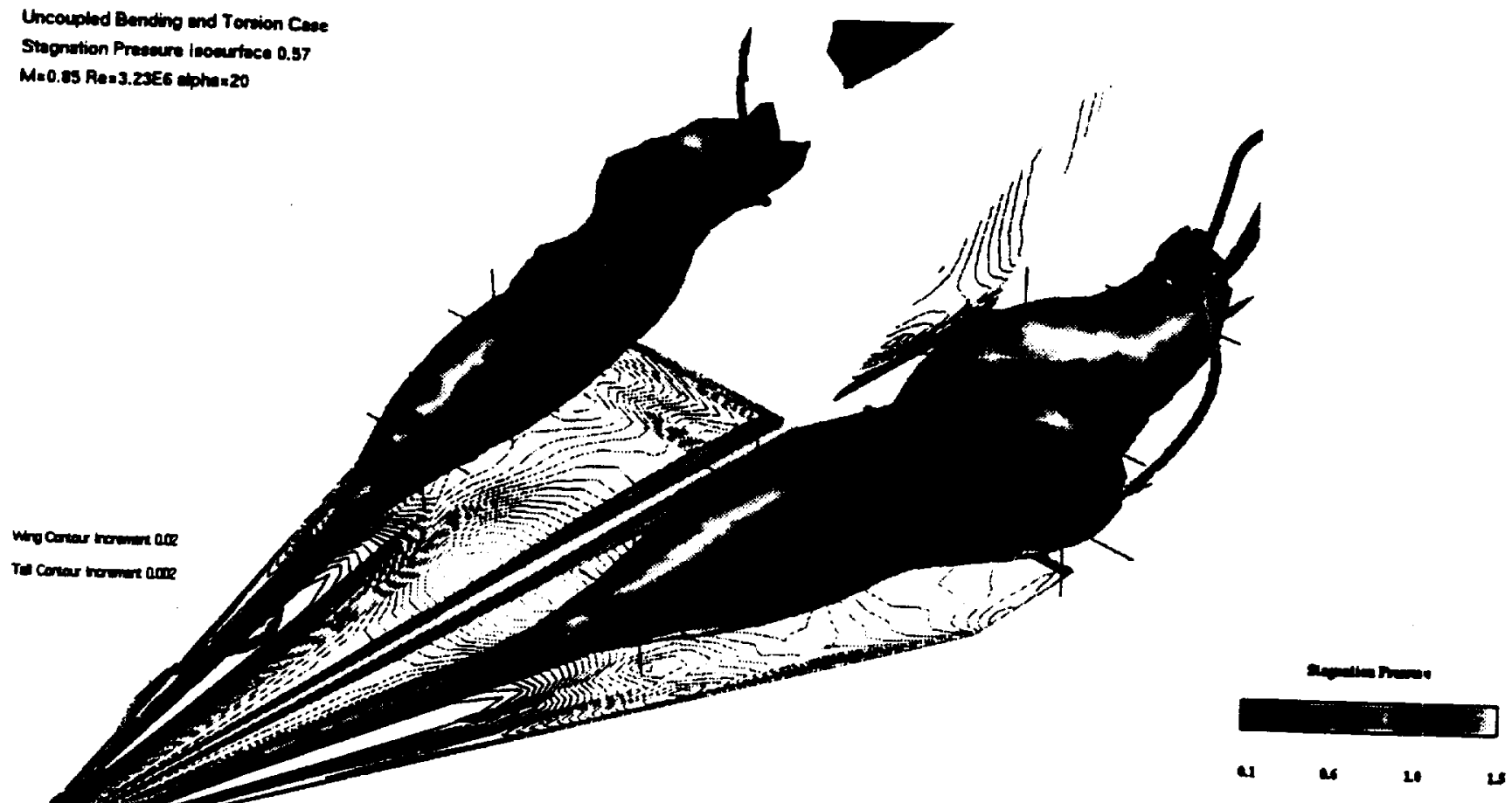

Fig. 8 Three-dimensional view and a top view of the wing-tail configuration for the uncoupled bending-torsion case, $\alpha=20^{\circ}, \Delta t=0.001$, it $=20,000$. 




Mrocentar hourer tols

162

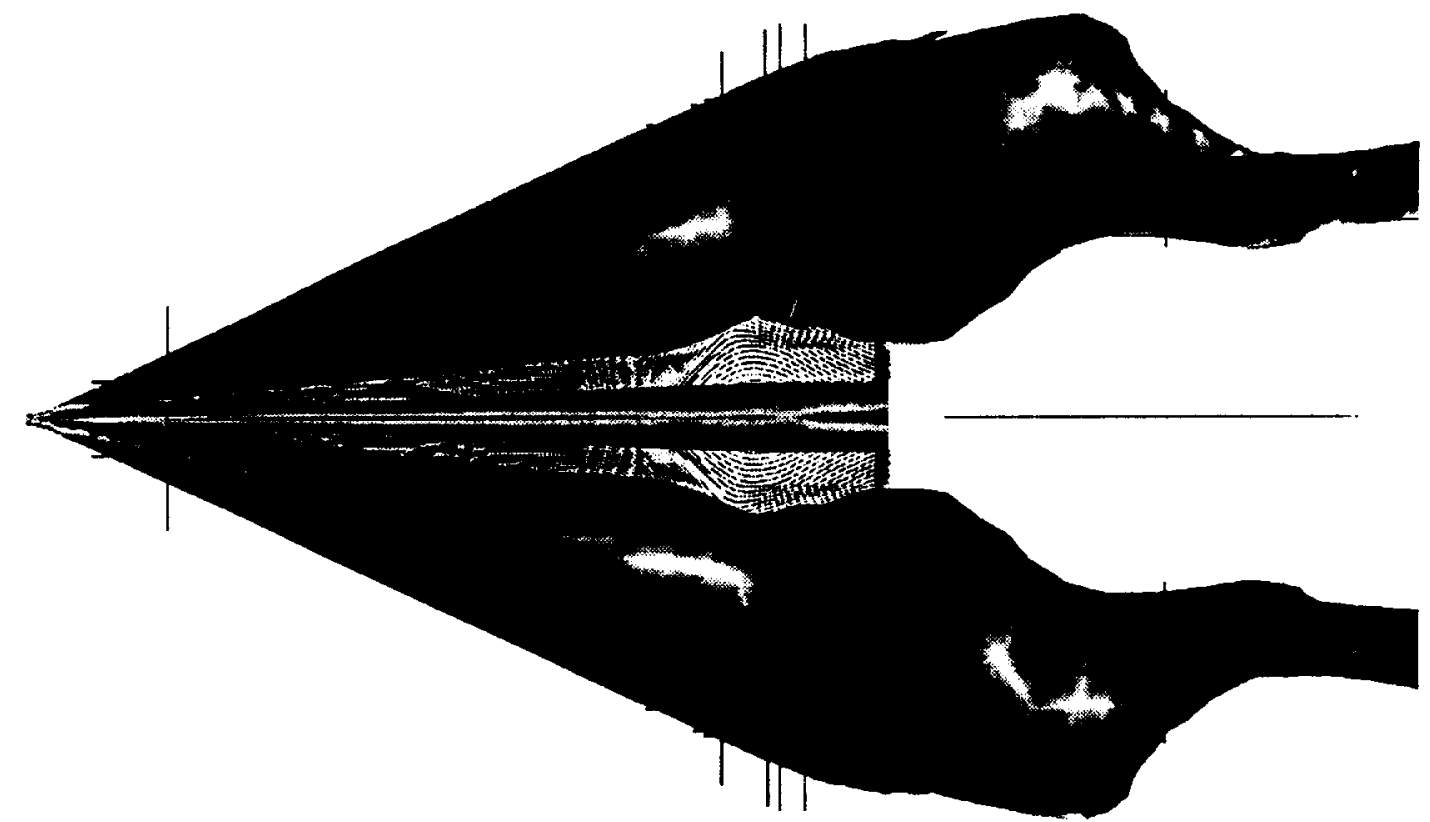

Fig. 9 Three-dimensional view and a top view of the wing-tail configuration for the initial conditions, $\alpha=28^{\circ}, \Delta t=0.001$, it $=10,000$. 


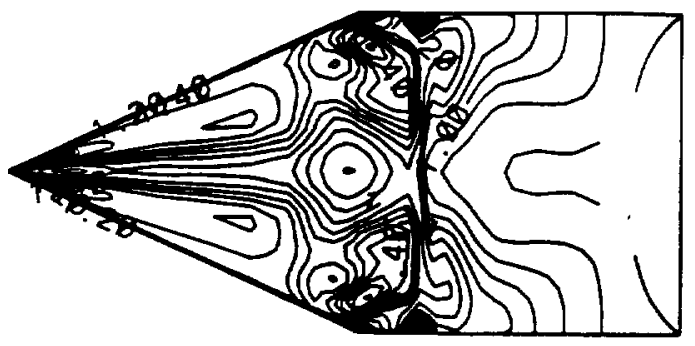

MACH CONTOURS ON A CONSTANT K PLANE

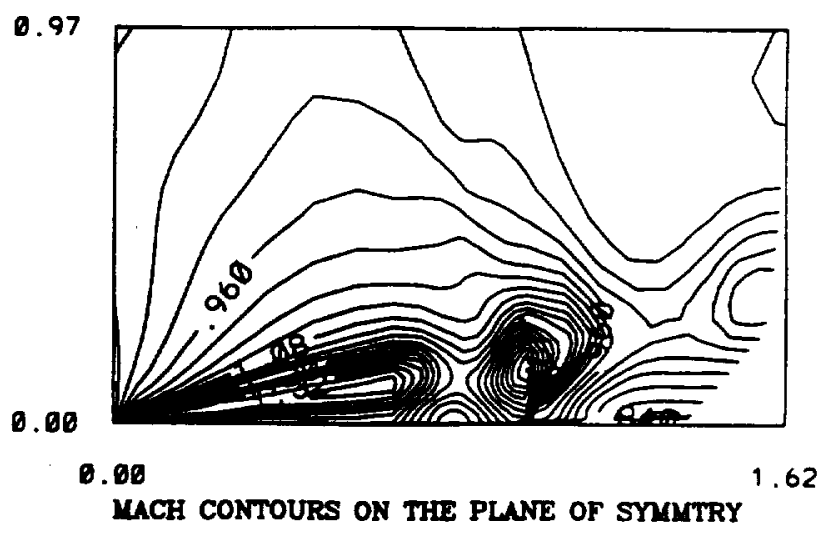

Fig. 10 Mach contours on a constant $K$ plane near the wing surface and on the plane of symmetry, $\alpha=28^{\circ}, \Delta t=0.001$, it $=10,000$.
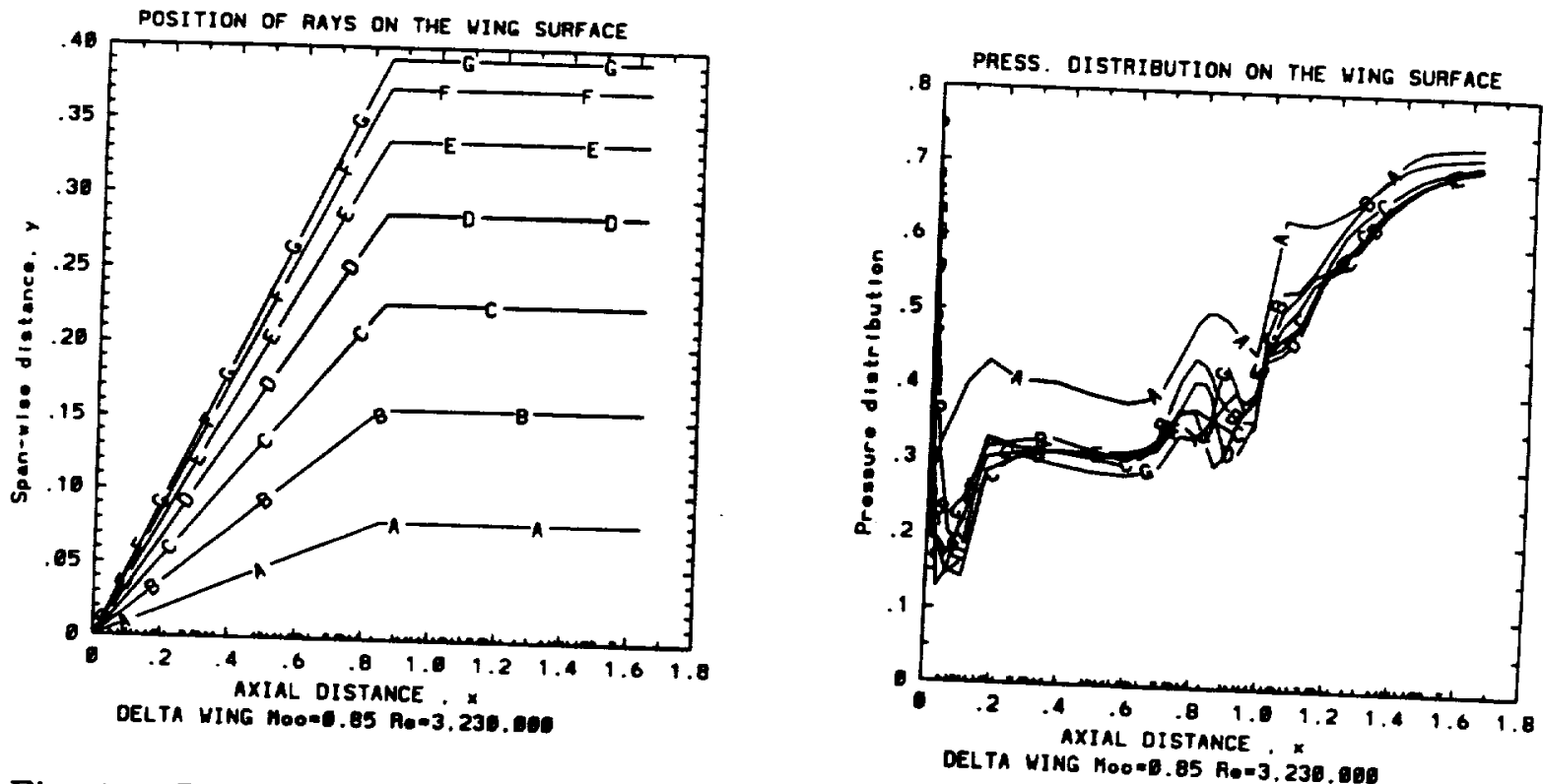

Fig. 11 Ray planes on the wing planform and surface pressure variation along these planes, $\alpha=28^{\circ}, \Delta t=0.001$, it $=10,000$. 
Bending Distribution History

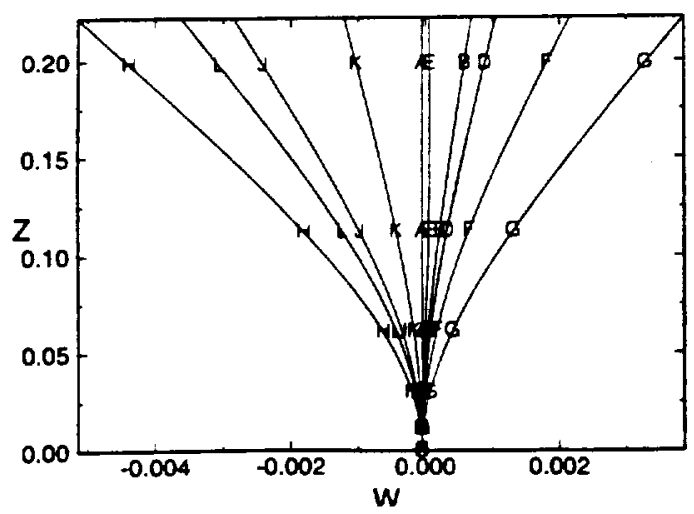

Force Distribution History

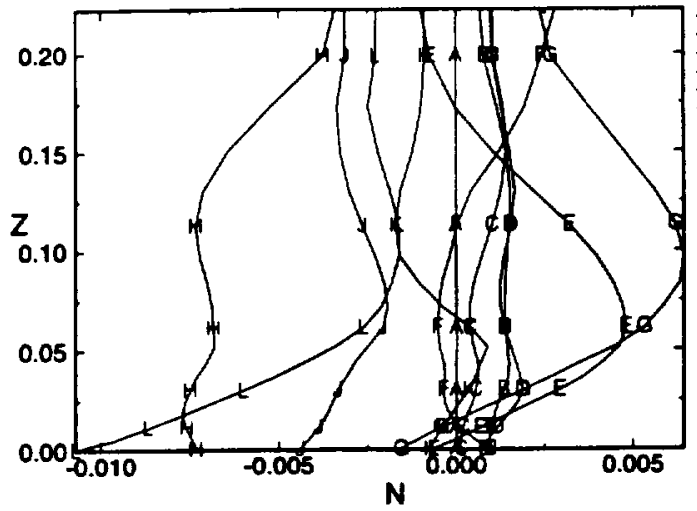

Tip Bending Displacement \& Force vs Time

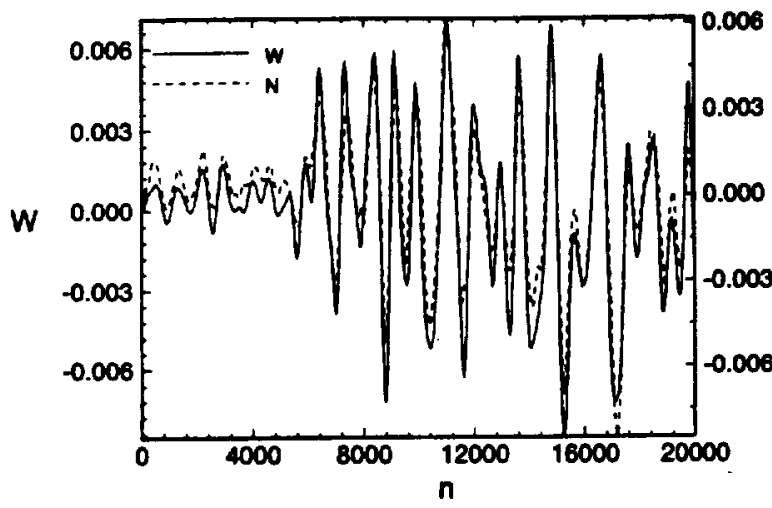

Midpoint Bending Displacement \& Force vs Time

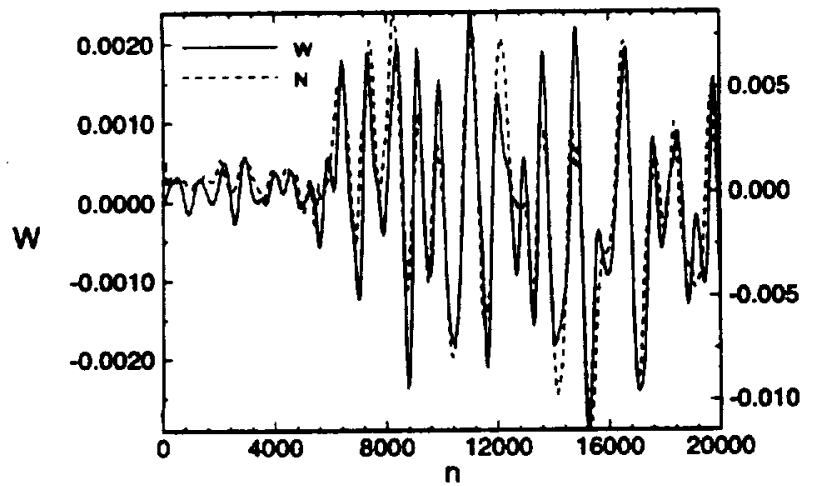

Rotation Distribution History

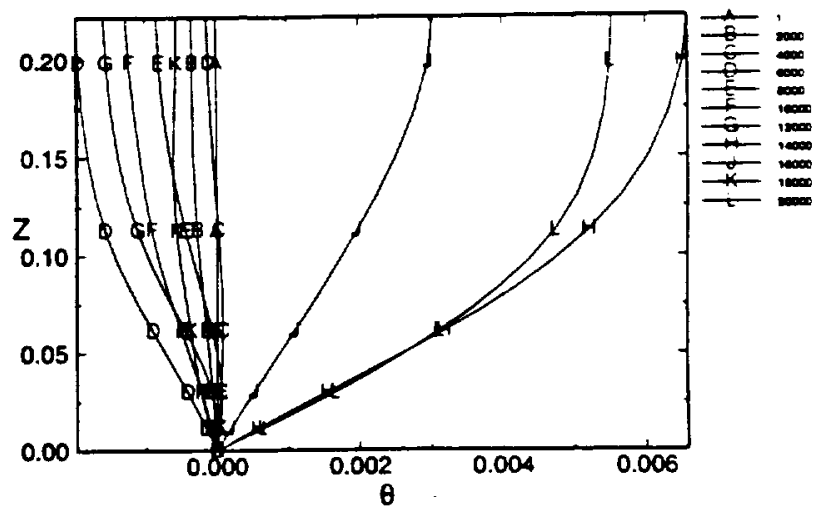

Moment Distribution History

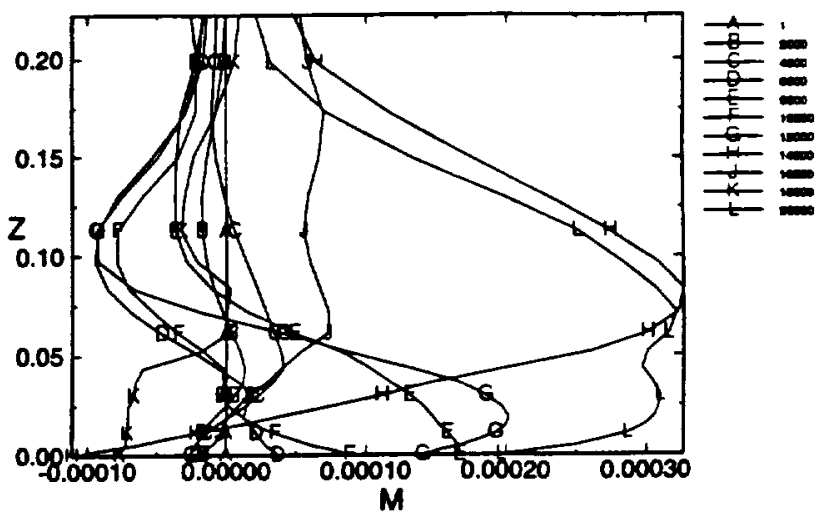

Tip Rotation \& Moment vs Time

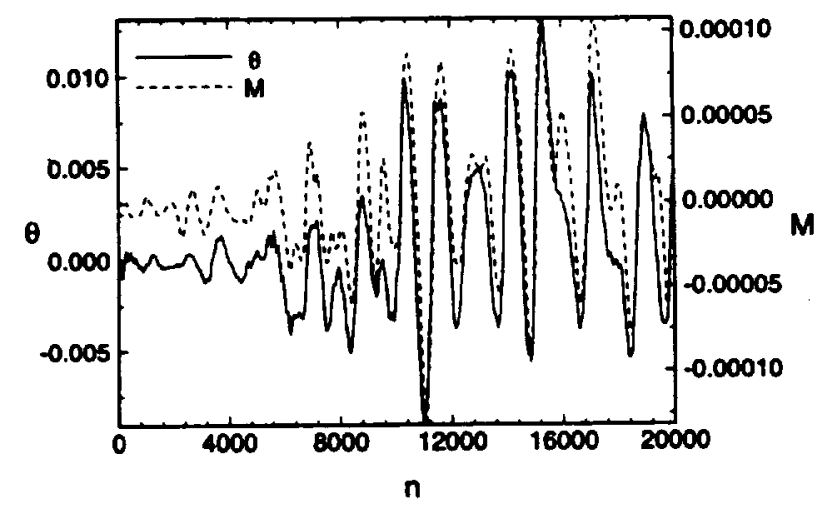

Midpoint Rotation \& Moment vs Time



Fig. 12 Deflection and load responses for an uncoupled bending-torsion case, $\alpha=28^{\circ} . \Delta t=0.001$, it $=10,000-30,000$. 


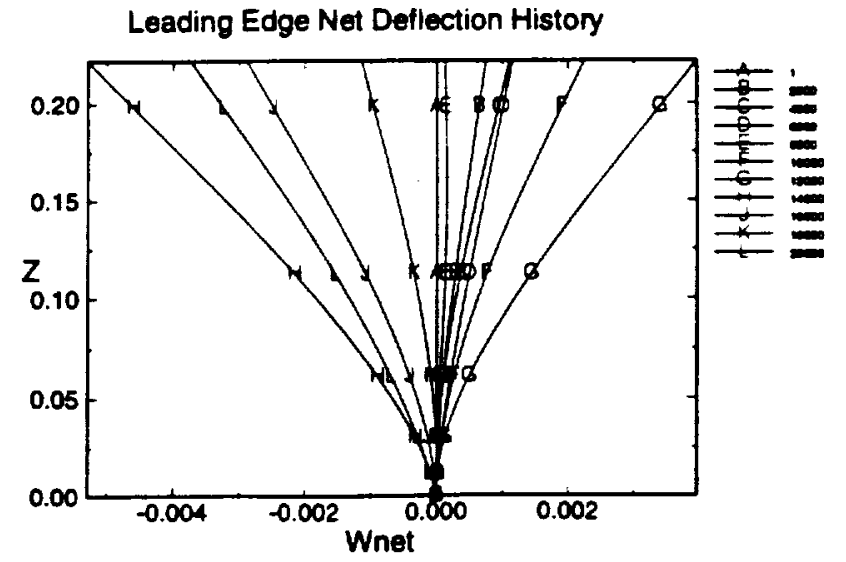

Fig. 13 Net deflection of the tail leading edge for the uncoupled bending-torsion case, $\alpha=28^{\circ}, \Delta t=0.001$, it $=10,000-30,000$.

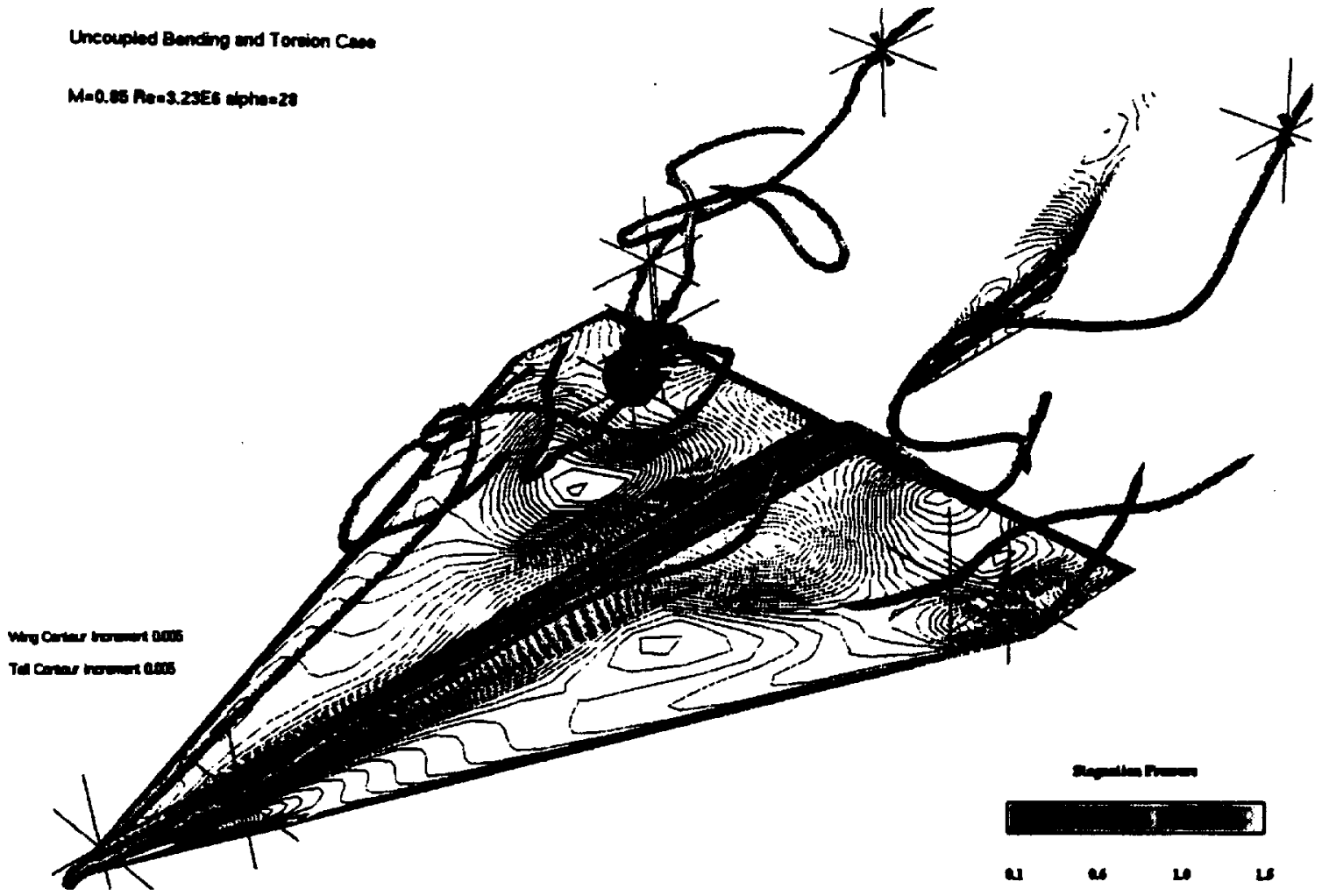

Fig. 14 Three-dimensional view and a top view of the wing-tail configuration for the uncoupled bending-torsion case, $\alpha=28^{\circ}, \Delta t=0.001$, it $=20,000$.

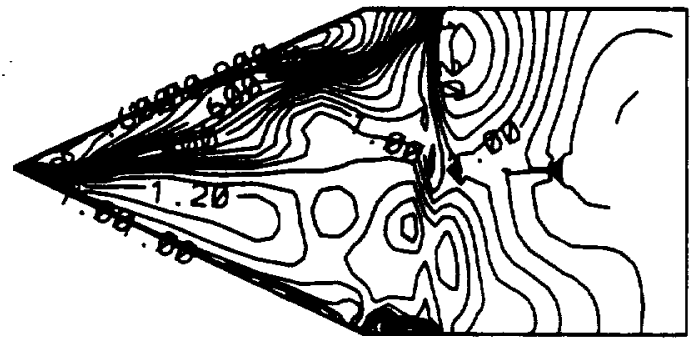

MUCH CONTOURS ON A CONSTANT K PLANE



Fig. 15 Mach contours on a constant $\mathrm{K}$ plane near the wing surface and on the plane of symmetry, $\alpha=28^{\circ}, \Delta t=0.001$, it $=20,000$. 